Portland State University

PDXScholar

\title{
Motivational processes involved in academic help seeking and help avoidance
}

Gwen Catherine Marchand

Portland State University

Follow this and additional works at: https://pdxscholar.library.pdx.edu/open_access_etds

Part of the Education Commons, and the Psychology Commons

Let us know how access to this document benefits you.

\section{Recommended Citation}

Marchand, Gwen Catherine, "Motivational processes involved in academic help seeking and help avoidance" (2004). Dissertations and Theses. Paper 3685.

https://doi.org/10.15760/etd.5569

This Thesis is brought to you for free and open access. It has been accepted for inclusion in Dissertations and Theses by an authorized administrator of PDXScholar. Please contact us if we can make this document more accessible: pdxscholar@pdx.edu. 
The abstract and thesis of Gwen Catherine Marchand for the Master of Science in Psychology were presented April 26, 2004, and accepted by the thesis committee and the department.

COMMITTEE APPROVALS:

Ellen Skinner, Chair

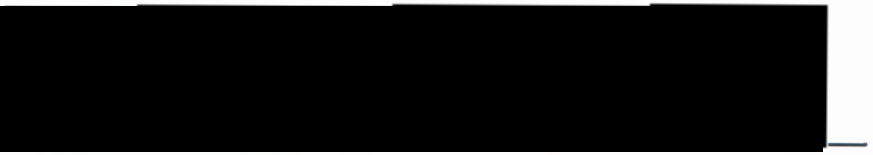

Thomas Kindermann
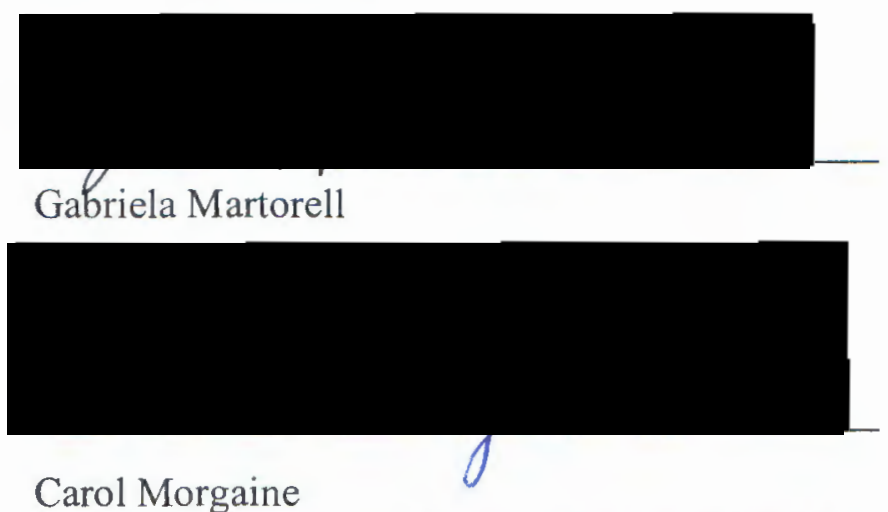

Representative of the Office of Graduate Studies

DEPARTMENT APPROVAL:

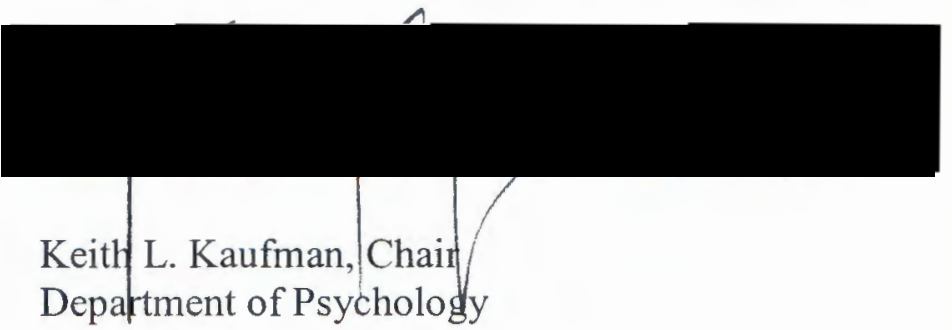




\section{ABSTRACT}

An abstract of the thesis of Gwen Catherine Marchand for the Master of Science in Psychology presented April 26, 2004.

Title: Motivational Processes Involved in Academic Help Seeking and Help Avoidance.

During middle childhood, help seeking and avoidance are two ways children deal with academic problems. For this study, the dominant view of help seeking as a strategy of self-regulated learning was elaborated to consider it a way of coping framed within the Self-System Model of Motivational Development. This framework allows for the consideration of (1) the opposite of help seeking (help avoidance) as a motivated way of coping, (2) the central role of teachers, and (3) the operation of multiple self-system processes in shaping students' coping behaviors.

Self-report, teacher-report, and school record data from $7653^{\text {rd }}$ through $6^{\text {th }}$ grade students and their teachers were analyzed to determine the structure of help seeking and avoidance, the antecedents and consequences of these ways of coping, and developmental differences that may account for age-related changes in coping. Data were available from two time points, the fall and spring of one academic year, allowing for concurrent and change over time analyses. 
Structural Equation Modeling demonstrated that help seeking and concealment are related, but different ways of coping with academic problems. Students' help seeking was positively correlated with concurrent assessments of their engagement whereas concealment was correlated with disaffection. Moreover, consistent with causal hypotheses, help seeking predicted increases in behavioral engagement over the course of the school year, while concealment predicted increases in disaffection.

In terms of predictors of coping, relatedness showed unique effects on coping over and above those of perceived competence and autonomy. In addition, teacher support predicted increases in help seeking, and reciprocally, student coping predicted changes in teacher support over the course of a school year. The results of mediational models indicated that teacher support may influence coping through its effects on children's self-system processes. Finally, no age differences were found in the links between coping and self-system processes or teacher support.

The implications of considering concealment as a motivated way of coping and the importance of social relationships and a sense of relatedness in academic coping are discussed. Recommendations for future research are given that focus on avoidance, diverse populations, specific developmental processes, additional social partners, and times of transition. 


\title{
MOTIVATIONAL PROCESSES INVOLVED IN \\ ACADEMIC HELP SEEKING AND HELP AVOIDANCE
}

by

GWEN CATHERINE MARCHAND

A thesis submitted in partial fulfillment of the requirements for the degree of

\author{
MASTER OF SCIENCE \\ in \\ PSYCHOLOGY
}

Portland State University

2004 


\section{ACKNOWLEDGEMENTS}

I would like to thank Drs. Thomas Kindermann, Gabriela Martorell, and Carol Morgaine for all of their help with this project. Additionally, I would like to express my gratitude to Dr. Ellen Skinner for being such a patient and dedicated mentor. Her passion for understanding the development of children's academic motivation and coping through research has been a source of inspiration for me. I am grateful for the knowledge she has shared with me and her insight with regards to this project and my future research.

In terms of this research project, I would like to acknowledge that it was supported by the W. T. Grant Foundation, from Research Grant No. HD19914 from the National Institute of Child Health and Human Development, and from Training Grant No. 527594 from the National Institutes of Mental Health. I would also like to express my gratitude to the Motivation Research Group, especially James Connell, Edward Deci, Thomas Kindermann, Richard Ryan, Ellen Skinner, and James Wellborn, without whom information for the current project would not be available. Likewise, I would like to thank the Brockport School District, and its superintendent, principals, teachers, students, and parents for their generous participation. 


\section{TABLE OF CONTENTS}

SECTION

$\underline{\text { PAGE }}$

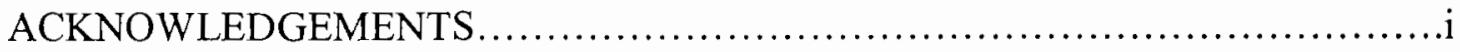

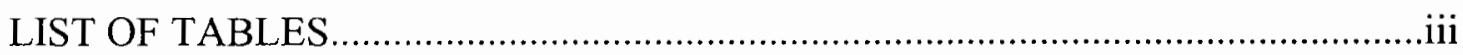

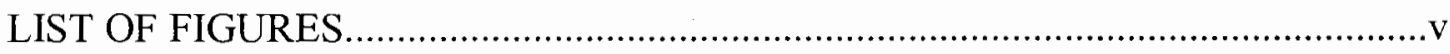

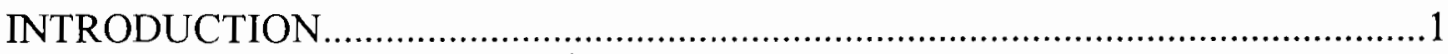

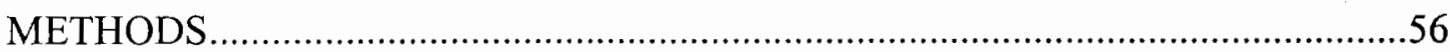

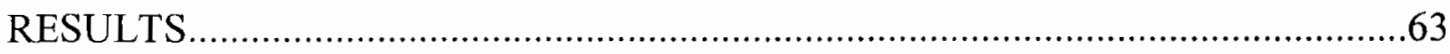

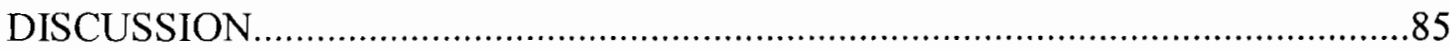

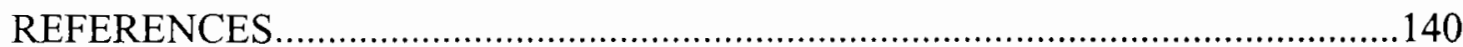

APPENDICES

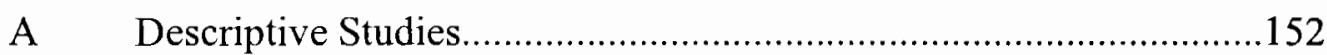

B Individual Differences, Help Avoidance, and Social

Context Studies................................................................... 155

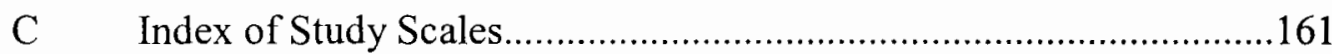




\section{LIST OF TABLES}

TABLE

PAGE

Table 1. Definitions of Help Seeking.

Table 2. Properties of Measurement Scales, Descriptive Statistics, and Stabilities.

Table 3. Single Factor Models for Help Seeking and Concealment in Fall and Spring.

Table 4. Comparison of Measurement Models for One Bipolar and Two Unipolar Help Seeking Factors.

Table 5. The Two-Factor Model of Help Seeking.

Table 6. Intercorrelations among Ways of Coping, Achievement, and Engagement during Fall and Spring.

Table 7. Ways of Coping as Predictors of Changes in Total Student Engagement from Fall to Spring

Table 8. Ways of Coping as Predictors of Changes in Behavioral and Emotional Engagement from Fall to Spring.

Table 9. Intercorrelations among Self-System Processes, Ways of Coping, and Achievement

Table 10. Self-System Predictors of Changes in Coping from Fall to Spring...124

Table 11. Unique Effects of Relatedness in Predicting Help Seeking. 125

Table 12. Unique Effects of Relatedness in Predicting Concealment.

Table 13. Intercorrelations among Teacher Support, Ways of Coping, and Achievement.

Table 14. Total Teacher Support as a Predictor of Changes in Coping from Fall to Spring

Table 15. Results for Mediational Models of Help Seeking. 
Table 16. Results for Mediational Models of Concealment

Table 17. Ways of Coping as Predictors of Changes in

Teacher Support from Fall to Spring.

Table 18. Ways of Coping Predicting Changes in Individual

Teacher Support Variables from Fall to Spring.

Table 19. Internal Consistency Reliabilites for Each Scale in Fall and Spring by Grade.

Table 20. Descriptive Statistics for Each Grade.

Table 21. Analysis of Variance Within and Between Grades for

Ways of Coping, Self-System Processes, and Teacher Support

Table 22. Zero-Order Correlations of Self-Systems and Teacher Support with Help Seeking.

Table 23. Zero-Order Correlations of Self-Systems and Teacher Support with Concealment. 


\section{LIST OF FIGURES}

FIGURE

PAGE

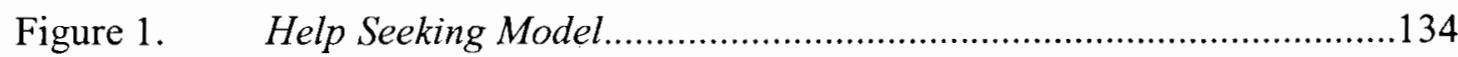

Figure 2. Self-System Model of Motivational Development ..............................135

Figure 3. Interaction between Relatedness and Teacher Support to

Predict Help Seeking.

Figure 4. Mean Scores on Coping, Sel-System Processes, and Teacher Support by Grade....

Figure 5. Correlations among the Self-System Processes and

Teacher Support with Help Seeking by Grade....

Figure 6. Correlations among the Self-System Processes and Teacher Support with Concealment by Grade. 
Help Seeking 1

Motivational Processes Involved in Academic Help Seeking and Help Avoidance

\section{INTRODUCTION}

At some point in most students' academic careers they will have the experience that they "don't know the answer" and that the only way to solve their problem is to enlist some sort of help. However, although some students might decide to approach a teacher or peer with a question, others may not ask for any help or even give an indication of their troubles. In a time when classroom size is increasing without a corresponding change in resources, it appears likely that how students deal with academic problems might differentially influence their future academic trajectories.

It seems like common sense to assume that if a student is in a situation where some assistance is needed and a ready source of help is available, then asking for that help is a logical step. Indeed, students who seek help with academic troubles appear to reap the benefits of such help. Students who are effective help seekers tend to demonstrate high achievement, have better understanding of concepts than their peers, and strong motivation (Karabenick, 1998; Nelson-Le Gall, Gumerman, \& Scott-Jones, 1983; Newman, 1994).

In American classrooms, teachers often utter phrases such as "if you have a question, please ask" and "no question is a stupid question." Yet, despite the normative view that asking questions is a good idea, it has been documented that in 
academic settings students rarely enact questioning behavior. Some estimates place the incidence of student-originated questioning as low as two information-seeking questions per hour (Dillon, 1988). Recently, the research community has begun to engage in some questioning themselves. Some of the most pressing issues pertain to the following questions: What are the factors that support or interfere with students' help seeking? Why don't children ask for help when aid would benefit them in a learning situation?

The study of children's academic help seeking emerged from help seeking research on adults. Early research on socialization and personality, social support, and epidemiology considered help seeking behavior a sign of immaturity and dependence (Nadler, 1997; Nelson-Le Gall, 1981). When viewed within the framework of Western individualistic culture, persons seeking help were considered unfit or ill prepared to effectively negotiate life's challenges. This viewpoint posited that well-functioning adults (and by extension, children) should be able to solve problems independently; over-utilization of social partners in times of trouble would lead to eventual helplessness. Further work in these areas suggested that help from anonymous sources was preferred over help from those with whom close interpersonal relationships existed.

Couched in these values, help seeking would be an activity that should be avoided (for reviews see Nelson-Le Gall, 1981; Nadler, 1997). However, these conceptualizations did not translate well to children's help seeking behavior. How could help seeking, which appeared to be a natural and necessary part of childhood 
survival, be something to be avoided (Sears, 1972)? In 1981, Sharon Nelson-Le Gall published a seminal work that reconceptualized help seeking as a positive, instrumental skill for children. This represented the beginning of current research on children's help seeking.

\section{Current Conceptualizations of Help Seeking}

During the past two decades there has been an increasingly focused attempt to understand more about children's help seeking behaviors. To date, this work has been guided primarily by a perspective in which help seeking is seen as a strategy of selfregulated learning that enables students to effectively negotiate barriers to their academic progress. As a field of study, self-regulation in academic learning is concerned with how students take control of their own learning process. "Selfregulated learning refers to self-generated thoughts, feelings, and actions, that are planned and systematically adapted as needed to affect one's learning and motivation"' (Schunk \& Ertmer, 2000, p. 631). Pintrich and Zusho (2002) suggest that it is through the development of metacognitive processes that students are able to monitor and control their cognitions, motivations, and behaviors to attain a goal. Theories of selfregulated learning heavily emphasize internal cognitive processes. For example, one cognitive learning strategy would be the use of rehearsal to remember words on a memory task.

Conceptualizing help seeking in self-regulatory terms has had an impact on how help seeking antecedents are identified and studied. It has also influenced the design of interventions engineered to increase the frequency of help seeking and the 
proficiency with which children utilize this strategy. As will be seen in the literature review, the empirical work on help seeking has focused almost exclusively on the cognitive processes of self-regulation. Relatively little is known about social factors that may shape help seeking.

Help seeking model. The most widely used model of the help seeking process includes characteristics of the help seeker, the helper, the task, the strategy, and the setting (Nelson-Le Gall, Gumerman, \& Scott-Jones, 1983; Newman, 1994). The model is depicted in Figure 1 (Ryan \& Pintrich, 1998). Students first become aware that help is needed by monitoring their comprehension or performance on a task. Once students recognize that help would be useful, they weigh the costs and benefits of seeking help and make a decision to seek help or not. At this point a decision is also made about whom to go to for help. Students may consider helper characteristics, such as availability and competence, when making this decision. In deciding to seek help, the student must also decide the type of help to seek. They might ask themselves: Should I ask for a hint or would an explanation be a better approach? The next step is to actually implement the strategy and ask the question. The final step of the model pertains to what the child does with the information they receive. For help seeking to be adaptive, the student must reinvest the information gained into future problem solving. These steps do not necessarily have to proceed in the order described above, but they all are included in the process.

Definitions of help seeking. Help seeking has been defined numerous ways since the early 1980's, but all conceptualizations of children's help seeking hold 
several commonalities (see Table 1 for different definitions). In general, help seeking is an activity that involves one or more social partners and arises following the recognition that one either cannot or does not want to solve a problem alone. Help seeking is considered an adaptive learning strategy that contributes to the development of self-regulated learning when it involves using (a) cognitive competencies such as knowing when assistance is necessary; (b) social competencies such as knowing who is the best person to approach for help; and (c) motivational resources such as goals and attitudes (Newman, 2002). Adaptive help seeking, also termed autonomous help seeking and instrumental help seeking, is associated with behaviors that contribute to independent mastery of a subject or task.

Other types of help seeking have been identified that are not considered adaptive. Executive, dependent, excessive and avoidant-covert help seeking behaviors are strategies that do not optimize learning. Students using these types of help seeking tend to ask for help when it is unnecessary and ask their social partners for answers rather than hints. They also tend to focus more on performance than learning. These types of help seeking differ from adaptive help seeking in that they do not appear to contribute to the development of self-regulatory learning skills.

For the most part, there appears to be general agreement regarding the characteristics of help seeking deemed desirable. However, as Newman (2002) recently noted, the practical utility of the construct of "adaptive help seeking," as identified by current measurement approaches, may be limited. He claims that researchers have used certain features of help seeking observed in experimental 
settings to operationalize adaptiveness, but these same features may be difficult to observe in classrooms. Therefore, Newman contends, "A major challenge is devising valid measures of adaptive help seeking-ones that capture different degrees of "adaptiveness," are observable in the classroom, and are appropriate at different grade levels" (p. 302). This cautionary note implies that the features of "adaptiveness" may manifest differently in naturalistic classroom settings as opposed to experimental or more controlled settings. Hence, researchers should use caution when generalizing findings.

A final definitional issue relates to not seeking help. Most help seeking literature refers to instances when a student needs help but does not ask for it as "avoidance of help seeking" (Ryan \& Pintrich, 1997). Within the expanding body of literature on help seeking, there exists a notable absence of research on the possible antithesis of help seeking. From the current help seeking research, it is not possible to clearly ascertain whether not seeking help is associated with unique predictors or if it is merely the polar opposite of seeking help.

Developmental orientation to help seeking. From the earliest theoretical formulations regarding children and help seeking, the role of development in seeking assistance has been emphasized (Nelson-Le Gall, 1981, 1983). Help seeking may not only manifest differently depending on age, but the functions of help seeking may change as well. In fact, prior to the accumulation of much empirical work, theorists maintained the claim that "Research shows that children do differ developmentally in the tendency to seek help and in the ability to use the help available in formal learning 
situations" (Nelson-Le Gall, 1985, p. 69). Current research in the area almost always includes a developmental component, most commonly by assessing a cross-section of school-aged children. The current questions in help seeking research from a developmental perspective, then, are not so concerned with whether children differ developmentally in help seeking behavior, but with how they differ.

\section{Literature Review}

\section{Methodologies used to study Help Seeking}

Three dominant methodologies have been employed to examine the questioning process as well as to explore the multiple intrapsychic predictors and contextual factors associated with help seeking. The most common methodology involves controlled task completion experiments. In this method, a student is usually removed from his/her classroom and placed in a one-on-one setting with the experimenter. In some studies children are interviewed about their self-perceptions or goal orientation prior to being given a task to solve. During the task completion, children are given some variation of a task, such as a puzzle problem, and told to solve it. Depending on the goals of the study, the procedure may differ, so that sometimes children are given practice problems and other times they are tested over a series of days. Students may or may not be encouraged to ask for help. Some studies provide question "menus" to prompt question asking (Newman \& Schwager, 1995). Children are usually evaluated for the frequency and type of help seeking during these task completion experiments. The salience of academic goals is manipulated in several 
studies. This is done when the experimenter reads a script that emphasizes either learning goals or performance goals prior to the child's problem solving.

A second format utilizes self-report questionnaires in which children indicate past help seeking behaviors or intentions to seek help. A final, but rare, methodology involves naturalistic classroom observation. These studies also tend to include a selfreport component, perhaps because one limitation of observational studies is that they only capture external behaviors, or instances when help is sought, and offer little information about times when help is not sought or about the motivational processes underlying help seeking behavior. Despite interest in developmental differences in help seeking, there are only few published accounts of longitudinal studies of help seeking.

\section{Correlates of Help Seeking}

Although research about children's help seeking has been conducted for over twenty years, the set of constructs that have been considered as correlates of help seeking is surprisingly small. The primary correlates of help seeking include: goal orientation, perceived competence or performance, attitudes or beliefs toward help seeking, actual performance or achievement, and helper characteristics. For the most part, these correlates can be thought of as antecedents to help seeking, or factors that tend to promote or inhibit help seeking. However, some correlates, such as performance, are considered as both antecedents and consequences of help seeking. For example, students with strong initial performance may be more likely to exhibit adaptive help seeking behaviors and this effective use of help seeking may result in 


\section{Help Seeking 9}

higher performance. Descriptions of variables commonly included in studies of help seeking are provided in the following sections.

Goal Orientation. The most robust set of research findings in the help seeking literature involves the motivational or goal orientation of students (Newman, 1994). Goal orientation, considered one component of achievement motivation, refers to students' reasons for engaging in academic activities (Newman, 1990). Goal orientation is usually described in a bipolar manner, using terms such as intrinsic versus extrinsic orientation, task versus ego involved, learning versus performance orientation, and mastery versus ability focused (Ames \& Archer, 1988)

Generally, students with an intrinsic orientation provide reasons for engagement that are directly related to the task itself. These students may identify their motivation to engage in an activity because the task is fun, interesting, or it provides a learning opportunity. Harter and Connell (1984) identified three dimensions of intrinsic motivation: (1) preference for challenge (2) curiosity or inquisitiveness and (3) independent mastery or motivation to figure something out on one's own. In contrast, students exhibiting an extrinsic orientation provide reasons for engagement that have little to do with the task itself and are more focused on how task performance relates to personal presentation of the self. For example, these students might report being motivated to use the task as a way to demonstrate their ability, please the teacher, or get a good grade.

Researchers and educators concur that a task-involved orientation is generally preferable to an ego-involved orientation. Children with a task-involved goal 
orientation prefer academic challenges and demonstrate academic goals that focus on learning. These students tend to exhibit more long-term engagement and tend to take responsibility for their academic actions (Jennings, 1991). On the other hand, students with an ego-involved orientation are motivated to engage in less challenging tasks to ensure success. This strategy serves to protect their self-conceptions and appease the teacher (Harter \& Connell, 1984).

It has been proposed that motivational factors influence the development of self-regulation through "changing goal structures and improving self-regulatory processing" (Pintrich \& Zusho, 2000, p. 267). There is the suggestion that students with an intrinsic orientation might be better self-regulated learners due to their propensity toward self-monitoring for understanding (Newman, 1994). If this is the case, then researchers might expect students who demonstrate a preference for learning over performance to display more adaptive patterns of help seeking. These students should be better at knowing when they need help, asking task appropriate questions, and reinvesting the received help to help their future performance.

Classroom Goal Orientation. Thus far, the term goal orientation has been used to refer to a student's personal motivational characteristics. This term has also been used to describe features of the classroom context. The contextual orientation or classroom goal orientation is the emphasis on either learning or performance as communicated by the teacher, classroom structure, and task focus. If the classroom context supports learning, then teachers tend to de-emphasize the importance of expediting a task or getting a good grade and instead tend to encourage concept and 
task mastery. In classrooms that emphasize performance, students are encouraged to complete tasks quickly, social comparison is amplified, and independent exploration is discouraged. Although there is little empirical work examining classroom goals, help seeking researchers believe that the messages given to students by the classroom structure influence whether students feel like help seeking is supported.

It is expected that in classrooms where learning goals are salient, help seeking will be supported because it is not viewed as a sign of low ability but rather as an avenue to higher levels of understanding. If performance is emphasized, student help seeking may be inhibited by classroom messages that asking for help or the inability to solve a problem alone is a sign of low ability.

Perceived competence/performancelachievement. Perceived competence can refer to students' perceptions of either their academic and social abilities. Perceived cognitive competence refers to children's feelings regarding their capacity to understand and complete their schoolwork. Perceived social competence refers to perceptions of skills and abilities for social interaction (Ryan \& Pintrich, 1997). Feelings and assertions of competence are often used as global measures of students' perceptions of their general abilities (Pintrich \& Schunk, 1996). Perceptions of competence, performance, and achievement are frequently used interchangeably in empirical help seeking research to discuss children's perceptions of whether or not they effectively completed or could complete a task. Theoretically, perceptions of competence should be related to the decision to seek help, as well as, to the types of help that are sought. 
There are two main hypotheses regarding how perceptions of competence influence the decision to ask for help. These hypotheses contend that students' perceptions of competence and self-esteem act as filtering mechanisms in the decision process (Butler \& Neuman, 1995). The vulnerability hypothesis suggests that students with low perceived competence may decide not to ask for help because by admitting that help is needed, their inadequacy is confirmed (Newman \& Goldin, 1990). The consistency hypothesis posits that students with high perceptions of their abilities might decide not to ask for help because engaging in help indicates that their competence is in danger and this presents views that are inconsistent with favorable perceptions of the self (Nadler, 1983). In both scenarios, help seeking is retarded by the admission of failure, as manifested through help seeking. Research has tended to support the vulnerability hypothesis (Karabenick \& Knapp, 1991) in that students with low self-perceptions not only seek help less frequently than those with favorable selfperceptions, but they also have a stronger perception of help seeking as threatening.

Once the decision to ask for help is made, students' perceptions of competence should also influence the frequency and kind of help that is asked for. Students with high perceived competence should show a lower frequency of help seeking, but when help is asked for it should be in a manner that will aid the student in solving a problem independently (hints or explanations). Students who do not feel competent may ask for help more frequently, but the help they ask for might demonstrate a dependency on the teacher for solving the problem (e.g. by asking for the answer); (Harter \& Connell, 1984). 
Actual competence/performance/achievement. Many studies utilize objective measures of children's abilities or achievement, such as grades or standardized test scores, to predict who is most likely to ask for help. These measures of achievement, competence and/or performance are sometimes used as proxies for ability or skill level (Butler, 1998). This construct may be both an antecedent and consequence of help seeking. Students who demonstrate high achievement levels might be more likely to know when they need help and be more effective as getting the needed help. If the outcome of help seeking is successful, then these students are more likely to increase their understanding, utilize the gained information in future tasks, and as a result, maintain or increase performance.

Attitudes and beliefs about help seeking. Attitudes toward help seeking, also referred to as perceptions of help seeking, are children's sense of the costs and benefits of employing help seeking strategies in an academic situation (Newman, 1994). These attitudes have been hypothesized to figure prominently in the decision of whether or not to seek help from a social partner (Newman, 1991). Children who perceive help seeking as beneficial and useful should be less hesitant to engage in help seeking behaviors. In contrast, students who perceive help seeking as a threat to their selfesteem or as an action that might expose their vulnerabilities should be more likely to avoid asking for help from teachers and peers.

Helper characteristics. Some studies have focused on the helper, identifying characteristics of the social partner that may inhibit or facilitate help seeking, such as the helper's competence, status, motivations for helping, personality traits, and 
willingness to provide help (Nelson-Le Gall \& Gumerman, 1984; van der Meij, 1988). In general, if a potential target appears competent, non-threatening (or nonjudgmental), and willing to help (versus unapproachable, threatening, or unable to provide effective help due to incompetence), then students should be likely to approach this person for help.

\section{Empirical findings}

The following review is organized according to the aim or goal the study. The earliest studies tend to focus on descriptions of help seeking and the processes associated with it. A second group deals primarily with determining how students who engage in a variety of help seeking behaviors differ from each other. These studies attempted to identify correlates, such as perceived competence, that may be associated with different help seeking behaviors. Third, studies that ask questions explicitly about help avoidance are reviewed. Finally, the few studies that have attempted to tease out contextual effects from personal effects are discussed. It should be noted that the studies in this field tend to build upon previous findings in incremental ways. There has been a gradual progression from simple descriptions of the phenomenon to sophisticated analyses regarding causation. Efforts were made to include studies that focus primarily on children in middle childhood, therefore most participants ranged from $3^{\text {rd }}$ to $6^{\text {th }}$ grade.

\section{Descriptive Studies}

The earliest help seeking studies were particularly concerned with identifying who students go to for help, what constitutes help seeking, if there are identifiable 
"types" of help seeking, and the frequency of help seeking in a variety of situations. Appendix A provides each study's sample characteristics, procedure, measures, and outcomes. These studies effectively outlined the behavioral manifestation of the internal decision processes relating to the help seeking model.

These studies were valuable in helping to establish help seeking as a viable research area, providing educators and academics with some tantalizing findings. First, there are some age-related differences in the ways children seek help. Preschool and first grade students tend to ask questions that are not necessarily related to the task, but are more related to getting teacher or peer attention (Good, Slavings, Harel, \& Emerson, 1987). Older students, particularly those in $5^{\text {th }}$ grade or above, tend to ask for task-related help (Good et al., 1987; Nelson-Le Gall, 1987). When all kinds of help seeking are included, there do not seem to be any age-related differences in the overall frequency of help seeking (Nelson-Le Gall \& Glor-Scheib, 1985). However, during elementary school, the questioning appears to be evenly distributed among pupils, but as they age, the majority of the questioning is done by few students (Good et al., 1987). Some studies also indicate that $5^{\text {th }}$ and $6^{\text {th }}$ grade students are better at asking questions that will get them the help they need (Nelson-Le Gall \& Glor-Scheib, 1985). Additionally, there may be a grade by ability interaction that impacts help seeking. It appears that low ability children in preschool and elementary school years tend to ask more questions than their higher-ability counterparts. This pattern seems to undergo a reversal as students age, whereas older low ability or low achieving students tend to ask fewer questions (Good et al., 1987). 
These studies helped identify some of the social processes of classroom help seeking. It appears that whom students report as the most desired helper differs from whom they actually ask for help. In studies with $1^{\text {st }}$ through $5^{\text {th }}$ grade students, although children report that they prefer to ask teachers for academic help, in actual classrooms students tend to get help from peers more often (Nelson-Le Gall \& GlorScheib, 1985, 1986; Nelson-Le Gall \& Gumerman, 1984). Younger children tend to target helpers based on the helper's personality characteristics, such as "niceness," whereas older children tend to target helpers they believe are competent. Additionally, the success of students in getting help may have something to do with social status, so that students whom are more accepted by their peers tend to be less likely to be rejected when they ask a question.

Individual differences in help seeking

The next set of studies examined intrapsychic processes that may predict individual differences in the kinds of help seeking behaviors children engage in during times of academic difficulty. The research reports in this section are in rough chronological order and grouped according to programs of research. Appendix B includes the sampling characteristics, procedures, and measures for the remainder of the reviewed studies.

Nelson-Le Gall. Sharon Nelson-Le Gall is not only responsible for the theoretical backbone of the study of help seeking in children, she and her colleagues conducted an early series of important empirical works that analyzed individual differences in help seeking. A 1989 study (Nelson-Le Gall, DeCooke, \& Jones) with 
$3^{\text {rd }}$ and $5^{\text {th }}$ graders elaborated on previous descriptive findings by introducing a measure of perceived competence. The procedure of the 1987 Nelson-Le Gall study was extended by incorporating a response-contingent reward system in an effort to get children to really evaluate their responses prior to asking for help. The researchers hoped that this reward system would cut down on instances of unnecessary or inappropriate help seeking. "Help seeking behavior from a child whose goals can be obtained readily and economically without the mediation of others" is considered unnecessary (Nelson-Le Gall, 1987, p. 54). Analysis of covariance indicated that the lower students' perceptions of competence, the more help they sought. Developmental differences in frequency of help seeking were found, in which older students asked for help more than younger students (also in Nelson-Le Gall \& Jones, 1990). Girls were also inclined to seek help more frequently than boys, regardless of age.

Nelson-Le Gall, Kratzer, Jones, and DeCooke (1990) conducted two studies designed to determine if $3^{\text {rd }}$ and $5^{\text {th }}$ grade students sought help based on their subjective impressions of competence, tapped through a 7-point scale of confidence ratings that they had answered verbal problem questions correctly. Children were provided opportunities for help in two ways: (1) through a confederate child's answers and hints for answers that were left at the scene, or (2) through the experimenter who provided hints or answers upon request. Help could be given following the child's initial answer and prior to the child turning in his/her final answer. Results indicated that confidence ratings were significantly related to different help seeking responses. Children who were more confident in their answers tended to either not request help or 
request hints. However, the effect of perceived competence was qualified by an age interaction, in which older students sought help more frequently for items they perceived themselves to have answered incorrectly, while younger students sought help with equal frequency for items perceived as correct or incorrect. Finally, the researchers found that subjective assessments of need were not more powerful in predicting help seeking than actual answers.

Within the same report, a second study was designed using the same method but added a reward contingency aspect to reduce help seeking requests to those only necessary to help solve the problem. Perhaps due to this increased evaluation, children's self-perceptions of performance predicted help seeking frequency above and beyond actual performance. The overall rates of help seeking declined but similar skill differences were found in this study. Many of the age related findings were not present. The only grade difference found that was consistent with the first study was a stronger preference for hints in $5^{\text {th }}$ graders than $3^{\text {rd }}$ graders. This study fine-tuned the first by demonstrating that when students, especially younger children, are motivated to really evaluate their work (by the response-contingent reward), they may become more aware of a need for help and able to discriminate when to ask for it.

In another 1990 publication, Nelson-Le Gall sought to identify individual differences among $4^{\text {th }}$ and $6^{\text {th }}$ grade females, who tend to be viewed as more dependent and inclined to ask for help in the learning process (Fischer \& Torney, 1976). Girls were divided into high and low mastery-oriented groups. Following an observation of the girls while completing tasks, their bids for help were divided into three categories 
(1) explicit or statements for help, (2) task statement or a characterization of the task, or (3) self-statement or a self-evaluation. A mastery orientation by bid type interaction was found and simple effects tests demonstrated that participants in the low mastery orientation group made fewer explicit bids for help than other types of help.

Additionally, girls in the high mastery group made more explicit statements for help and fewer self-statements than the low mastery girls. The researcher also assessed attitudes toward help seeking by measuring the girls' reactions to help after they had persisted in the tasks following a ten-minute work period. $85 \%$ of the girls were willing to accept help. In response to specific questions assessing their attitudes, the girls generally reported feeling unfavorably about failing to ask for needed help, being rejected after a bid for help, and being offered unnecessary help. High mastery girls had the most negative attitudes about not asking for help when it was needed. The main contributions of this study are the findings that girls high in mastery tend to use more task directed than self-directed ways of seeking help and that not seeking help when it is needed is frowned upon in high mastery groups. No grade-related differences were found.

Nelson-Le Gall and Jones (1990) conducted a study regarding black children's use of help seeking as an achievement strategy. They examined the effects of motivational orientation, academic achievement, grade, sex and self-perceptions of competence on help seeking. The $3^{\text {rd }}$ and $5^{\text {th }}$ graders were divided into four motivational orientation groups based on their scores on Harter's (1981) scale: low independent mastery (IM)/low curiosity interest (CI), low IM/high CI, high IM/low 
CI, and high IM/high CI. The results demonstrated that self-perceptions accounted for more variance in frequency of help seeking than actual item correctness. Interesting findings related to motivational orientation indicated that children high in independent mastery tended to ask for more hints than answers, but children with a low orientation toward independent mastery did not ask for help as often as high IM children.

Newman. Another influential program of research, both theoretically and empirically, has been developed by Richard Newman. Newman's work has been particularly important in identifying the mechanisms of influence in the help seeking process. Newman and his colleagues conducted a series of studies with elementary and middle school children, in which they examined help seeking behavior in a mathematics context. Math was chosen as the context because it is generally considered one of the most difficult school subjects, often requiring extra help from social partners (Newman \& Schwager, 1995). The correlates of interest in these studies were age (grade), goal orientation, perceived competence, and achievement.

Newman (1990) investigated the effects of perceived competence and motivational orientation on attitudes toward help seeking and intentions to seek help and modeled these relationships for each grade-level $\left(3^{\text {rd }}, 5^{\text {th }}, 7^{\text {th }}\right)$. Based on structural equation modeling, he found that for $3^{\text {rd }}$ and $5^{\text {th }}$ graders, the factors that directly effected intentions to seek help were preference for challenge, teacher dependence, and positive attitudes. In younger students, there was not a significant relationship between negative attitudes toward seeking help and intentions to seek help. In contrast, the model for $7^{\text {th }}$ grade students demonstrated that attitudes were the key 
factors in determining children's intentions to seek help. For older students, neither motivational orientation nor perceived competence had direct effects on attitudes or intentions to seek help, although perceived competence did have an indirect effect through negative attitudes. At all ages, children with higher perceived competence reported weaker feelings that there are costs associated with seeking help. However since negative attitudes do not predict help seeking in younger children, it appears that in these children, perceptions of competence do not significantly factor into the decision to ask for help. These results suggest that as children gain more experience in school, their attitudes become increasingly important in predicting help seeking. This data depicts a developmental shift from a model where motivations and positive attitudes increase the likelihood of help seeking, to a model where motivations no longer matter and negative attitudes begin to make a difference.

In testing over a three-day period, Newman and Schwager (1995) presented groups of low, middle, and high achieving students $\left(3^{\text {rd }}\right.$ and $6^{\text {th }}$ grade) with inductive reasoning problems and the children were allowed to generate questions or use a "question menu" to help them generate questions. On the third day, a learning or performance goal orientation was introduced by reading a script to the children prior to problem solving. Requests for help were coded into five categories, with the majority falling into the first two categories: requests for process related information (including big hints, little hints, and explanations), requests for confirmation of final answers, requests for the correct answer, nonspecific statements indicating lack of understanding, and non-task related questions. 
There were age, achievement, and goal effects in this study (Newman \& Schwager, 1995). Sixth graders asked for more hints than third graders. There was an interaction between age and goal condition, in which older children given performance goals showed more instances of maladaptive help seeking, such as asking for answers, and a focus on completing as many problems as possible. There were no differences in help seeking according to goal condition in younger students. In relation to achievement, low achievers made more process related requests than high achievers. Finally, as indicated by a goal by achievement interaction, low achieving students solved significantly fewer problems in the performance condition than the learning condition. Stepwise regression demonstrated that prior math achievement predicted performance but that an interaction between goal and process related questioning predicted performance over previous achievement. This means that when children ask more process related questions in a learning goal condition, they tend to have better performance, but this is not the case for students given performance goals. These findings demonstrate that the goal orientation affects the type and frequency of questioning engaged in by the students. When performance is emphasized, questioning is inhibited more than when learning is emphasized.

Other programs of research. Puustinen (1998) was interested in three specific self-regulatory processes: awareness of need for help, asking only necessary questions, and applying information gained through help to future tasks. The researcher evaluated the awareness of the need for help from $2^{\text {nd }}$ and $4^{\text {th }}$ grade students' selfevaluations only on problems where the students did not ask for help. In the awareness 
area, older and higher achieving students demonstrated a stronger relationship between their self-assessments and actual performance. In the area of asking only necessary questions, there was an age by achievement interaction. Low achieving fourth graders tended to ask more executive style help seeking questions, high achieving second graders asked some instrumental questions, and confirmation type questions were asked more by $2^{\text {nd }}$ grade high achievers than $4^{\text {th }}$ grade high achievers. The third aspect of self-regulation, reinvestment of help, was only related to achievement. High achievers tended not to ask for help after their first question and were able to successfully solve future problems independently. Overall, academic achievement had a stronger effect on the self-regulatory aspects of this study than did age. It appears that high skill children are better at assessing their own competence and thus recognizing when help might be beneficial. According to the author, only high achieving fourth graders scored well enough on all three categories to be considered "self-regulated learners".

Summary. This series of studies supports the hypotheses that students' beliefs and self-perceptions influence help seeking in the classroom. First, students who hold task-focused goals tend to ask for more help, primarily in the form of requests for hints, than those with performance goals. These students value being able to independently solve a problem, thus using help seeking strategies that will help them solve problems on their own and tending to apply the information gained to future tasks. In contrast, performance oriented students tend to ask for help that will provide the answer and not lead to independent problem solving. 
Another strong finding relates to attitudes and beliefs about help seeking. Negative attitudes toward help seeking are strongly related to deciding not to ask for help. Students who believe help seeking is beneficial are more likely to ask for help. The relationships between motivational factors, like goal orientation, and attitudes toward help seeking are not clear. Some studies suggest that motivational factors contribute to attitudes (Newman, 1990) while others do not support this idea (Ryan \& Pintrich, 1997). A developmental shift seems to occur so that negative attitudes play a stronger role in help seeking behavior for older than younger children.

Perceptions of competence are also related to help seeking, but the relationship is less clear. In some studies, perceived competence was directly related to help seeking. Students who have low perceived competence tend to ask for more help and those requests are usually for answers. Children with high-perceived competence tend to ask for hints and also tend to be better at assessing when they actually need help to solve problems. Yet, there is some indication that perceptions of competence might not directly influence help seeking, but are mediated by attitudes. However, one developmental pattern seems clear: Older children appear to be better self-evaluators of when they need help.

Generally, these findings demonstrate that students who are task-oriented, have high-perceived competence, and have positive attitudes toward help seeking, tend to seek help when it is needed. Performance orientation, low self-perceptions, and low ability are associated with negative perceptions of help seeking and more ineffective help seeking behaviors. Actual achievement also has a significant relationship with 
help seeking in that children who perform better in school tend to be more effective help seekers.

\section{Help Avoidance}

These works include both elements of description and predictive factors. What separates these studies from the previous are their focus on help avoidance, not simply as the absence of help seeking but as a potentially distinct contrast.

An oft cited and influential study explored constraints on questioning in the classroom or factors that might inhibit questioning (van der Meij, 1988). Answers by $3^{\text {rd }}$ and $5^{\text {th }}$ graders to open-ended questions regarding intentions not to seek help in either a seatwork or instruction situation were coded into twelve categories relating to help givers, help seekers, and the task/setting. In respect to help givers (most often peers) students reported most frequently that they would hesitate to ask for help if they had worries about the helper's competence. When speaking of teachers, students reported concerns about the helper's willingness to assist and a possible negative reaction. When thinking about their own characteristics, students often reported a concern with independence as a primary reason for not seeking help. Other inhibitions stemmed from classroom rules. Fifth grade students did report a concern with being the only one with a question. This study gives us a brief glimpse into personal and contextual characteristics that contribute to avoidant behavior.

In light of the increasingly complex findings regarding help seeking and goal orientation, Butler and Neuman (1995) designed a study to find out not only why children do ask for help but what the motivations are behind why they avoid asking for 
help. $2^{\text {nd }}$ and $6^{\text {th }}$ grade students were randomly assigned to either a task focused (learning) or ego focused (performance) goal condition and interviewed individually. Children were read the condition script and informed they could ask questions, and then set to their task. Upon task completion, the interviewer asked the children why they did or did not ask for help. Answers from these open-ended questions were coded into (a) reasons for not asking for help (independent mastery, help was not necessary, and mask incompetence) and (b) reasons for asking for help (promote mastery, task difficulty, in order to succeed, and effort avoidance). The analysis of responses given for why help was requested yielded no significant differences in explanations between the goal conditions. Older children gave more reasons related to task difficulty and younger children gave more reasons related to effort avoidance. Most children reported avoiding help due to strivings for independent mastery $(62 \%)$ or beliefs that they could succeed without help (32\%).

Yet when asked why they thought other children might avoid asking for help, $2^{\text {nd }}$ grade children in the task focused condition cited striving for independent mastery while those in the ego condition attributed lack of help seeking to masking incompetence. Interestingly enough, children who in the experiment did not frequently ask for help were likely to attribute help avoidance in others as masking incompetence in the ego condition but to independent mastery in the task condition. A curvilinear effect was found for initial performance and attributions of help avoidance so that students with high and low initial performance in the ego condition were more likely than average performers to explain help avoidance as a way to mask 
incompetence. A final finding speaks to the process of adaptive help seeking in that children who asked for help on problems they could not solve alone (compared to those who did not request help) were more likely to successfully solve future problems.

In a unique study, Butler (1998) attempted to determine the underlying structure of perceptions of help avoidance, identify orientations toward help avoidance through these perceptions, and relate these avoidance orientations to patterns of help seeking. The publication encompassed two studies with $5^{\text {th }}$ and $6^{\text {th }}$ graders. The first study utilized questionnaire data in which students were asked to rate why other students might avoid asking for help in the classroom. The data were analyzed and a three-factor structure of help avoidance was found. Reasons for help avoidance were (1) expedient or the perception that asking for help will not expedite task completion, (2) autonomous or the striving for independent mastery, or (3) ability-focused or help avoidance to mask incompetence. 3 (perceptions of help avoidance) $x 2$ (sex) $\times 3$ (perceptions of competence) MANOVA results indicated that students endorsed autonomous reasons for help avoidance more than ability or expedient reasons. In the only significant interaction, students with higher perceived competence tended to endorse ability-focused reasons for help avoidance most often. This indicates that perhaps students with high perceptions of competence are trying to protect those perceptions by avoiding situations that might reveal any incompetence.

A second study was designed to investigate the link between help avoidance orientations and help seeking behaviors and attitudes. First, researchers classified the 
kinds of requests as hints, directions, or all help requests. Analysis of variance demonstrated that children who held more autonomous and expedient orientations to help avoidance asked for more help than students with ability-focused orientations. Those with an autonomous help avoidance orientation asked for hints most often while those children with an expedient orientation asked for directions most often. Second, cheating was analyzed and the only significant effect was for boys in that cheating was most common in those with an ability-focused orientation. Third, researchers determined that in the task situations, students in the expedient orientation asked for help more quickly than other students. They spent less time trying independently. The next set of analyses looked at students' hint behavior and the effects on subsequent performance. Students with an autonomous help avoidance orientation, who requested hints frequently during the first three problems, solved more of the later problems independently. However, the number of problems solved independently did not increase for either the expedient or ability-focused students even when they asked for hints.

Researchers used their observations of help seeking behavior to group students into three help seeking styles: (1) autonomous or that which is initiated following independent attempts to solve problems, is expressed in hints, and results in improvements in solving future problems, (2) executive or that which is characterized by frequent but unnecessary help seeking, asking for answers, and a preference to have someone else solve the problem, or (3) avoidant-covert or help seeking subterfuge, like copying. Researchers found the following links between help seeking and help 
avoidance: autonomous help seekers tend to endorse autonomous reasons for avoidance, executive help seekers endorsed expedient reasons for help avoidance, and avoidant-covert help seekers endorsed ability-focused help avoidance. These results were qualified by a sex interaction in that girls who displayed autonomous or executive help seeking were more likely to endorse ability-focused reasons for help avoidance, but for boys ability-focused help avoidant orientation was associated with avoidant-covert styles of help seeking. Using the information gained about the reasons students ask or avoid asking for help and students' actual help seeking and help avoidant behavior, researchers suggested that perhaps there is a single underlying orientation to help seeking and help avoidance.

Ryan and Pintrich (1997) were interested in the relationships between perceived competence, achievement goals, attitudes toward help seeking, and help seeking/avoidance strategies. The participants were an equal number of $7^{\text {th }}$ and $8^{\text {th }}$ graders. After controlling for gender, grade, and achievement level, path analyses were conducted. First, achievement goal orientation had strong effects on both attitudes toward help seeking and help seeking behavior. Children who held task focused goals were likely to perceive help seeking as a beneficial strategy and unlikely to perceive help seeking as threatening in relation to teachers. Yet, students with extrinsic goals considered help seeking as a threatening activity in relation to teachers. The model indicated that students who were worried about demonstrating their ability in relation to others, or who had strong relative ability goals, considered help seeking negatively in regard to both peers and teachers. Task focused goals had a direct, positive 
relationships with adaptive help seeking. A similar relationship was also discovered between extrinsic goals and reported avoidance of help seeking. It appears then, that achievement goals have a substantial impact on both attitudes toward help seeking and self-reported intentions to seek help.

A second factor, perceived competence, was investigated by these authors (Ryan \& Pintrich, 1997) who suggested that because help seeking is a strategy that involves both social and cognitive engagement, then one's perceptions of their effectiveness with social partners might influence use of help seeking and thus influence academic outcomes. Path analyses demonstrated that although neither type of perceived competence affected help seeking behavior, both types of competence did directly contribute to students' negative attitudes toward help seeking from their peers. Cognitive competence was negatively related to reported avoidance of help seeking so that children with higher perceived cognitive competence were less likely to avoid seeking help. Cognitive competence was also found to interact with extrinsic goals to influence negative attitudes toward help seeking in relation to peers. This finding suggests that as students decrease in cognitive competence, performance goals increasingly predicted their perceptions of feeling threat from peers regarding help seeking.

Finally, Ryan and Pintrich (1997) found that attitudes linked the motivational variables of perceived competence and goal orientation to help seeking behavior. These motivational variables directly influenced attitudes toward help seeking. Using hierarchical multiple regression, researchers found that attitudes fully or partially 
mediate the relationship between all motivational predictors (except social competence) and help avoidance. For help seeking, only the effects of task-focused goals were partially mediated by perceived benefits. The other motivational variables were not significantly related to help seeking when controlling for attitudes. This research demonstrates that although motivational factors are important contributors to help seeking and help avoidant activity, attitudes may be the primary mechanism controlling help seeking behavior.

Summary. Based on these findings, researchers may conclude that students likely to avoid help seeking are those who demonstrate either very low or very high levels of perceived and actual competence. Help avoidance is also related to goals, in that when learning goals are salient for children, they are less likely to avoid help seeking and also attribute help avoidance to strivings for independent mastery. When performance goals are salient, children tend to believe that help avoidance is related to masking incompetence. The studies reviewed in this section suggest that decisions to avoid help seeking are sensitive to individuals' attitudes toward help seeking. However, at this point, the unique relationships between personal motivational factors, attitudes toward help seeking, and help avoidant behavior are not yet clear. Nor does this research fully describe the construct of help avoidance.

\section{Social Context}

Social context is an explicit part of the help seeking model depicted in Figure 1. Although some of the previous studies hinted at the influence of context on help seeking, for instance by reading a goal script, few have focused directly on personal 
and contextual factors. The following studies investigated unique effects of the social context on help seeking or help avoidance and identified interactions between the student and his/her context that may have particularly powerful effects on help seeking.

One study is relevant to both help avoidance and social context issues. Ryan, Gheen \& Midgley (1998) were concerned with how classroom structure and interactions might encourage $6^{\text {th }}$ grade students, even those with low academic selfefficacy, to seek help when it is needed. This innovative research provides one of the few accounts of social climate and the role of the teacher. Hierarchical Linear Modeling (HLM) was used to separate the effects of student-level characteristics and classroom-level characteristics. The results indicate that approximately $20 \%$ of the variance in reported help seeking was due to classroom effects. The betweenclassroom analyses showed that teachers' reports of their instruction style did not explain help avoidance. However, students' reports of a task-focused structure were predictive of lower help avoidance, while reports of relative-ability goal structure were associated with increases in levels of help avoidance. Even with these added classroom-level variables, student self-efficacy and gender predicted help avoidance. Students with lower self-efficacy and males were more likely to avoid help. Although teachers' reports of their social-emotional role did not affect average levels of reported help avoidance, they did modify the relationship between self-efficacy and help avoidance. In classrooms where teachers identified highly with a nurturing role, perceptions of self-efficacy did not matter as much in relation to who sought help. 
Overall, it appears that even when students feel unable to complete their schoolwork successfully, if the teacher demonstrates a concern for the social and emotional well being of the students, the negative effects of poor self-efficacy on help seeking may be ameliorated.

Newman (1998a) conducted a study to analyze how contextual goals might moderate the normally detrimental effects of personal performance goals on help seeking. Students $\left(4^{\text {th }}\right.$ and $5^{\text {th }}$ grade $)$ were tested over three days in a similar method to the 1995 study but with the addition of a questionnaire designed to identify personal motivational orientation. Using regression and path analyses, researchers found that when both personal and contextual goals were performance oriented, help seeking was inhibited. However, students with moderate to strong performance goals asked for more help in the learning than performance contextual goal condition. Therefore, an important finding of this study is that when the context is supportive and encourages learning, the negative relationship between personal performance goals and help seeking is weakened. This finding has implications for actual outcomes, because after comparing performance trends over the three days, researchers found that help seeking was a significant predictor of improved performance.

A recent article evaluated types of avoidance strategies and the effects of classroom environment on their utilization. With a sample of $6^{\text {th }}$ graders, Turner et al. (2002) used surveys and observations to identify the effect of perceived classroom goal structure on the use of avoidance strategies and how teachers' discourse patterns might affect these perceptions. The researchers identified three avoidance strategies: 
self-handicapping or withdrawal of effort, avoidance of help seeking, and avoidance of novelty. Hierarchical linear modeling (HLM) was used to examine students nested in classrooms, in order to differentiate between student and classroom effects.

Classrooms were classified as either mastery or performance orientated by aggregating student reports of perceived classroom goal structure. The full HLM models with this classroom-level predictor explained $23 \%$ of the between-class variance in selfhandicapping, $20 \%$ of the between-class variance in help avoidance, and $9 \%$ of the between-class variance for novelty avoidance, when the effects of student gender, ethnicity and math grades were held constant. Classrooms with a greater emphasis on mastery resulted in a lower level of avoidance strategies, but perceptions of performance goal structure did not significantly predict avoidance.

Observations were conducted to identify features of the classroom (teacher discourse) that might be considered supportive or non-supportive. These classroom characteristics were used to create profiles of classroom structure and were compared to students' perceptions and avoidance patterns. Student reports characterized two classrooms as high mastery/low avoidance and the teachers' instructional discourse in these classrooms emphasized understanding. About one fifth of the discourse in these classrooms was motivational in nature with instances of encouragement for interest in math and collaborative learning. The low mastery/high avoidance classrooms were characterized by both nonscaffolding instructional discourse and an expectation for students to prove their answers. Moreover, the instances of motivational discourse were very low in these classrooms and at times teachers relied on the use of sarcasm 
and disrespect to convey their impatience. These results suggest that students' avoidance behaviors may vary between classrooms and that this variance may be related to the messages teachers send to students through their interactions with students. Less help avoidance was found in classroom environments where teachers emphasize that questions and mistakes are a part of the natural learning process.

\section{Conclusions from Review}

\section{Help seeking}

Help seeking is an adaptive response for students when faced with academic challenges and difficulties. However, descriptive research suggests that only certain types of help seeking are beneficial to scholastic outcomes. Help seeking in the form of hints is better and more effective for future problem solving than help seeking in the form of requests for answers. Additionally, when students are successful in their help seeking attempts, the empirical work shows a clear link to positive self-perceptions and beliefs. The benefits extend beyond intrapsychic processes to actual performance and academic achievement. When help seeking interactions result in a higher or more advanced level of comprehension, many students are able to reinvest the information they gain to more effectively and independently solve future problems.

\section{Self-system predictors}

Research has identified specific self-system processes that predict the decision to seek help and the kind of help sought. One process identified as important to help seeking is goal orientation. Students who think of classroom tasks as an enjoyable learning opportunity appear to recognize help seeking as a tool useful for solving 
problems and mastering schoolwork. In contrast, students who tend to associate tasks with performance and demonstrating ability ask for help in such a way that dependence on their social partners, particularly teachers, for taking care of their problems is encouraged.

A second set of self-system processes associated with help seeking are students' perceptions of their own competence, or self-efficacy. Students who feel effective in their learning attempts are more likely to recognize when help is needed and ask for appropriate help. Those students who feel less confident in their competence tend to shy away from situations, such as help seeking, that they think might expose their incompetence. These students, whose thoughts and behaviors center around the desire to mask incompetence, are most at risk for implementing avoidant behavior. They may fall into protective patterns of action that prevent them from ever getting the help they need, thus further increasing perceptions of incompetence when they fail, over and over again, at problem solving.

\section{Context}

Although research directly examining the roles of social partners and social contexts on help seeking is rare, the review does offer some hints and clues that these factors influence help seeking. Children appear to be quite sophisticated in distinguishing particular characteristics of potential targets that might make them good helpers. Students choose helpers if they appear competent, willing to help, and approachable. The research regarding perceptions of threat from teachers and classmates indicate that students' actions are largely based on their feelings about 
exposing personal shortcoming and fear of rejection. Although it has not been directly examined, this suggests that social partners and the relationships that exist in the classroom might underlie how these feelings of threat arise.

Due to the limited availability of publications examining both contextual and personal effects, only a small number of possible contextual influences have been identified. At a classroom level, the primary focus has been on classroom goal structure. The research reveals that teachers' communication styles and the values they highlight can influence children's help seeking. Classrooms in which performance goals are stressed tend to be inhibitive of help seeking. However, as Newman (1998a) and Ryan et al. (1998) highlighted, supportive messages presented in academic situations may serve to ameliorate or lessen the help-inhibitory effects of negative self-perceptions and personal ego-focused goal orientation. Classrooms that support students in their learning goals and emotions tend to be more facilitative for adaptive help seeking.

\section{Development Matters}

Finally, the research reinforces the theoretical contention that development matters. Children in kindergarten and first grade tend to ask many questions that are not necessarily task focused. Then there seems to be a shift from asking non-task related to task-related questions. Older students appear to be more efficient or "better" at help seeking, however, this increase may be somewhat dependent on ability level and perceived competence. One consistent finding shows that students do gain metacognitive abilities as they age. Advances in the ability to monitor one's own 
levels of understanding result in more adaptive patterns of help seeking for some high ability students. Unfortunately, as many students progress through middle and high school, help seeking behaviors become all but extinct. The developmental processes and patterns of help seeking are not yet entirely clear. This may be due to the prevalence of cross-sectional, as opposed to longitudinal, designs that focus on age differences in help seeking.

\section{Critique of Current Research}

Despite advances in work on children's academic help seeking, this review of the research suggests several areas for critique and elaboration. There are three critiques that can be made of virtually all the current empirical literature. These critiques center around the cognitive orientation that has thus limited the study of help seeking, the lack of research on social factors, and the limited advances that have been made in understanding how development impacts and is impacted by help seeking.

\section{The Cognitive Focus}

The literature review demonstrates that help seeking researchers have discovered a great deal about some of the personal factors related to academic support seeking. Because empirical work has been guided by a self-regulation paradigm, researchers have asked questions designed to discover how children's cognitive processes about their knowledge state impacts the implementation of a help seeking strategy. This focus is obvious in models of help seeking. The focal point is the student and his/her competencies and decision processes. The variables that facilitate or constrain help seeking are primarily related to intrapsychic cognitions. Although 
other variables, such as classroom climate, are explicit in models of help seeking, they have received little empirical attention.

Conceptualizations about the opposite of help seeking are also inherently limited by labeling help seeking a cognitive strategy. Within the current framework, there exists the assumption that students who do not ask for help either lack ability or skill in seeking help. These students are considered immature or metacognitively deficient. When something is a "strategy" it is either intentionally implemented or it is not via a decision-making process (Newman, 1991). Simply speaking, once a student knows how to effectively seek help, he should always do so. Yet, research shows that is not the case and that many students fail to ask for help, even when they are aware of its benefits. This suggests that perhaps there are other frameworks that might be useful for conceptualizing help seeking and help avoidance.

\section{Social-relational Factors}

Researchers recognize that help seeking is an inherently social activity, yet few empirical investigations have focused on the social-relational factors involved in help seeking. In 1991, Newman recognized this as a limitation when he said that, "most research on children's help seeking has focused on personal characteristics of the child while very little has examined the role of the school context" (p. 171). To date, only contextual factors that may impact a child's cognitive processes or decisionmaking have been considered. For example, classroom climate and goal structure are proposed to have a mechanism of influence through the student's development of and manifestation of personal goal orientation. 
Help Seeking 40

Yet, it is likely that the relationships forged in the classroom have a primary impact on help seeking or help avoidant behavior. Attachment perspectives highlight the importance of forming close relationships in how children deal with challenges and difficulties. Research suggests that the internal working models of relationships that infants form with their primary caregivers may guide the formation of future interpersonal relationships and behavior patterns within these relationships (Kesner, 2000). One recent study demonstrates that during middle childhood, students with a secure model of relationships tend to be better adjusted at school and more able to deal with the multiple demands associated with it than children with less secure relationships (Granot and Mayseless, 2001). These secure models allow children to know that when they are in trouble, they can respond to threats by seeking help from a social partner.

The perceptions of emotional support and feelings of belonging that come with relationships may also have an influence on how comfortable or accepted students feel when asking questions. These feelings of belonging may differ widely depending on the student's individual relationship with the teacher and the feelings of security within the class group structure (Smith, Murphy, \& Coats, 1999). Students who tend to form anxious or avoidant attachments with their social partner or group may feel isolated or uncomfortable and unable to go to others for help. Those who feel like they belong may stay engaged in school (Lynch and Cicchetti, 1997) and be more likely to expose incompetencies through questioning. 
Help Seeking 41

These aspects of attachment, the ability to form secure relationships and experience a feeling of belonging, imply that the quality of the relationship between students and teachers is important to potential help seekers. Recent research suggests that aspects of emotional support in the classroom, that may foster security, are important in the decision to seek help (Ryan et al., 1998). Attachment theory lends credence to the idea that social-relational factors should be important in classroom help seeking.

There may also be additional self-system processes and predictors that are related to help seeking. The search for help seeking correlates has focused almost exclusively on those related to cognition. Variables associated with student motivation and emotions in the classroom have been virtually ignored. To enhance understanding about help seeking and help avoidance, it is vital to consider social-relational, motivational, and affective personal resources that act as mechanisms of influence on the help seeking process.

Finally, there is no mention of reciprocal effects of academic help seeking. Both the student and their social partner are involved in help seeking interactions. The result of these help seeking instances likely has an impact on how the two players approach future interactions. For example, it is entirely possible that over time, if a student repeatedly asks questions designed to get the teacher's attention, but are not task-related, the teacher may eventually ignore the student's bids for help. The current research has not explored how the student and his social partner reciprocally influence each other through help seeking interactions. This is likely due to the major limitation 
of most studies in that they measure help seeking at only a single time point. Additionally, since the context has been minimized in favor of cognitive factors, there has not been any reason for researchers to ask questions about how the context changes over time in response to help seeking interactions.

\title{
Developmental Limitations
}

Current research describing developmental processes associated with help seeking is not complete. There is virtually no empirical investigation of change over time in the processes involved in help seeking. Investigators have done a fine job describing age-related differences in help seeking behavior, but there has been little progress in explaining causal mechanisms or the developmental processes associated with age differences in help seeking. There are obviously differences in the kinds and frequency of questions asked between $3^{\text {rd }}$ grade students and $6^{\text {th }}$ grade students. But research designed to test why these variations occur is scant. Additional work is needed to uncover how developmental changes in motivational and cognitive resources influence help seeking.

\author{
The Present Study \\ Elaboration of Research on Help Seeking and Avoidance
}

Purpose of the Present Study

The purpose of this study is to extend current conceptualizations of help seeking as a strategy of self-regulated learning to one with a broader and more social orientation. Specifically, a self-system model of children's motivational development is used as an organizing principle to suggest that help seeking can be considered a way 
of coping with academic difficulties. Considering help seeking as a strategy of selfregulation suggests that it always follows a conscious, decision-making process. In contrast, by thinking about help seeking as part of a child's repertoire of responses to stress, the search for antecedents and consequences of help seeking can be extended to consider how such a response comes to be incorporated, developed, and utilized within an individual's coping repertoire.

This view expands the current conceptualization in several ways. First, the possibility that avoidance may be more than simply not seeking help may be explored. In the present study the opposite of help seeking is considered a motivated way of coping. Under stress, people may be motivated to intentionally conceal their need for help. Moreover, motivational personal resources are considered that may influence how a child responds to academic stress. Finally, this framework holds that social resources and relationships are key in shaping help seeking behavior. By providing a coping orientation to help seeking, we are able to look beyond cognitive competencies associated with self-regulation to the role of relationships in this highly social activity. The Self-System Model of Motivational Development

For the purpose of elaborating the cognitive orientation to help seeking, help seeking is framed within Skinner \& Wellborn's (1994) coping model (See Figure 2) based on the self-system model of motivational development. The self-system model of motivational development posits that fundamental needs are the basis for the development of individual's self-system processes. Self-system processes are defined as, "a set of appraisal processes whereby the individual evaluates his or her status 
within particular contexts with respect to three fundamental needs: competence, autonomy, and relatedness" (Connell \& Wellborn, 1991, p. 51). This motivational model contends that these processes are constructed through interactions between the person and his/her social contexts. When their needs are met, children should respond to stress in more positive and flexible ways because they have a deeper reservoir of personal and social resources to draw upon.

In this model, coping is defined as "action regulation under stress" (Skinner, 1999). Coping is considered a process that involves the regulation of emotion, behavior, and motivational orientation during psychological distress, not just cognition. Moreover, because coping is part of a process that involves a dynamic interaction with the context and self that affects the appraisal process, students may have a variety of possible responses to a challenge, not just one. Help seeking is just one way children utilize their resources to cope with a challenge.

Help Avoidance Reconceptualized

Within the coping framework help avoidance or concealment does not merely reflect the absence of help seeking. Instead, help avoidance is a motivated, legitimate response to academic threats and challenges. There is evidence to suggest that help avoidance might serve an adaptive purpose for a student in a situation perceived as threatening (Turner et al., 2002). Indeed, there may be instances in a child's academic career where it is more beneficial for their self-system development to conceal that help is needed rather than ask for it. This suggests that it is important to explore if help avoidance is a distinct construct from help seeking. The motivations underlying help 
avoidance have not been fully explored, nor have the range of personal and contextual antecedents and outcomes associated with it. Help avoidance could have unique relationships with the self-system processes, engagement, and achievement that are different than those associated with help seeking.

\section{Additional Self-system Predictors}

Thus far the help seeking literature has concentrated on two specific selfsystem processes: autonomy, operationalized as goal orientation, and competence. The motivational model suggests that a third self-system process, relatedness, may be instrumental in how children cope with academic problems. Newman (1998b, 2000, 2002) has provided theoretical support for the relevance of these three self-systems to help seeking.

Work in the attachment area suggests that relationships impact student adjustment. It has been theorized that the roots of the relatedness self-system lie in an individual's attachment experiences (Newman, 2000). Relatedness is the sense of belonging or connectedness that one has toward social partners and contexts (Furrer \& Skinner, 2003). In a recent publication, Furrer \& Skinner demonstrated that relatedness is an important academic self-system process. The feelings of acceptance children experience in their school environment have a direct impact on tangible scholastic outcomes. Yet, surprisingly, this self-system has been overlooked in the help seeking literature. Because help seeking is a social activity, it would stand to reason that self-system processes reflective of social relationships, such as relatedness, might have an impact on whether or not children feel they can ask for help. 


\section{Motivational Outcomes}

Theoretical and empirical work suggests that an important outcome of the help seeking process may be children's engagement versus disaffection. Engagement refers to "active, goal-directed, flexible, constructive, persistent, focused interactions with the social and physical environments" (Furrer \& Skinner, 2003, p. 2). In educational research, high levels of engagement have been linked to strong achievement and motivation (Skinner \& Belmont, 1993). Definitions of adaptive help seeking indicate that children who are successful in their help seeking attempts should be able to reinvest the information they gained into future academic activities and become more effective at asking for help. This would suggest that help seeking is a way for students to remain active participants in the school environment. Descriptive studies show that as children move through the school system, those who are low achievers also tend to withdraw any help seeking efforts, thus likely becoming less engaged in school activities. Research also suggests that students who think of school work as fun and interesting tend to have more positive attitudes about help seeking and tend to ask for help when it is needed. This indicates that there may be a relationship between being motivationally engaged in school and help seeking. The examination of this link to help seeking might offer some important insight into the motivational function of help seeking as it effects the quality of students' involvement in learning activities.

\section{Contextual Supports}

In the self-system model of motivational development, contextual supports play a vital role in the development of self-system processes. There are three ways in 
which teachers provide support to fulfill the basic psychological needs of their students. The need for autonomy is supported when teachers allow students some freedom to determine their own behavior. This is referred to as autonomy support as opposed to coercion. This kind of contextual support has been investigated to some extent in the help seeking literature through classroom goal orientation (Newman, 1998b). Teachers provide support for competence through their provisions of structure in the classroom. In classrooms where teachers clearly communicate their expectations and provide appropriate rules and monitoring, students gain information about how to be effective in achieving their goals. Turner et al. (2002) found that in classrooms where teachers provided explicit communication about their expectations for students, help avoidance was low. The final way in which teachers provide contextual support is through involvement. Involvement refers to the relationship quality between the student and teacher. Low involvement is akin to rejection. This is the way through which teachers provide support for students' feelings of relatedness. Recent research about teachers' perceptions of their role in providing emotional support in the classroom suggests that this might be a central way which the context affects student help seeking (Ryan et al., 1998). The combined effects of these contextual supports need to be examined to understand their influences on help seeking. In particular, this paper will provide some much needed information about the role of classroom relationships and the effects of teacher involvement on help seeking.

The reciprocal effects between help seeking and contextual support are also of interest. Although there has been little empirical investigation of the effects of student 
help seeking on teacher thoughts and behaviors, research in related areas shows that children's coping and school behaviors have an effect on the responses of their social partners. For example, children's ways of coping predict changes in the support parents provide over the school year (Skinner \& Edge, 1998). Likewise, in the classroom, teachers' support changes over time as a function of their perceptions of student motivation and engagement (Skinner \& Belmont, 1993).

This research suggests that teachers likely pay attention to how children negotiate challenges in the classroom and their responses, both immediate and over time, are shaped by students' actions. In general, it can be expected that positive child behaviors elicit reciprocal supportive responses from teachers. Therefore, when students respond to challenges by seeking help, teachers may respond with increased involvement. When students conceal that help is needed, teachers may respond by withdrawing their support.

\section{More on Development}

This conceptualization can be used as a framework to expand research about developmental differences in the self-system and social processes that support or inhibit help seeking. One possible contributing factor to why children respond to challenges differently might be age differences in relevant self-system processes. Through childhood, as children form relationships and interact with an increasingly complex set of environmental stimuli, the fulfillment of the self-system evolves as well. For example, attachment perspectives suggest that relatedness might be a particularly important self-system for younger children (Connell, 1990). Research on 
perceived control suggests that competence is a salient developmental motive during middle childhood (Skinner, Zimmer-Gembeck, \& Connell, 1998). As children develop into adolescents, the need for autonomy becomes more pressing (Ryan \& Lynch, 1989; Connell, 1990). As a result different self-systems might be more central predictors of help seeking and concealment at different ages.

A second factor that could account for variation in coping is related to age differences in the role that teachers play in student help seeking. There are several alternative viewpoints as to how teachers' roles change as students progress through school. One possibility is that there is no change, that is, teachers are equally important in predicting children's help seeking across the elementary and middle school years. Alternatively, it is possible that teacher support is more important to children's use of help seeking for younger students. Perhaps, for teenagers, the dominant role of the teacher may be competent instructor. However, recent research suggests that, surprisingly, teacher provision of emotional support and involvement to students is more strongly related to student outcomes during the middle school years as opposed to grade school years (Skinner et al., 1998). At this time, there is not enough research in this area to make definitive predictions about age differences in the role teachers play in shaping children's help seeking and concealment.

\section{Research Questions}

By framing help seeking in the self-system model of motivational development, it is possible to formulate specific research questions and hypotheses that bear on each of the areas suggested for elaboration. 


\section{What is the structure of help seeking and help avoidance?}

The first aim of this study is to examine help avoidance as motivated way of coping, potentially associated with unique antecedents and outcomes. In this study, help avoidance is conceptualized as active concealment of the need for help. The first hypothesis then is that help seeking and concealment are not bipolar opposites, but two distinct forms of coping.

The issue of whether help seeking and avoidance can best be represented as a single bipolar construct or as two separate ways of coping is an important one, with implications for conceptualization, measurement, and research questions. In terms of conceptualization, a single bipolar construct implies that there is only one possible alternative to seeking help, namely, help avoidance. This conceptualization prevents researchers from considering other responses that can occur when students do not seek help. For example, students can freeze, escape the situation, or emotionally withdraw when faced with challenges. Within a coping framework, all of these responses could be alternatives to help-seeking.

In terms of measurement, if help seeking is scored as single bipolar construct (by averaging scores on help-seeking items with reverse-coded scores from help avoidance items), then students who are low on help seeking must be high on avoidance and vice versa. However, if the constructs are actually distinct (or only correlated at a moderate level), then some students can be high on both help seeking and avoidance. These different profiles of responses could only be assessed by calculating separate scores for help seeking and help avoidance. 
Finally, in terms of research, if the construct is bipolar, then there would be no reason to evaluate the antecedents and outcomes of help seeking and help avoidance independently. However, if help seeking and avoidance actually have distinct antecedents and consequences, this pattern of findings would be obscured unless these two ways of coping are examined as separate constructs. Achieving conceptual clarity regarding the structure of help seeking and avoidance provides a strong basis for future conceptualizations, measurement efforts, and research studies in this field.

\section{What are the connections between coping, engagement, and achievement?}

The second set of hypotheses involves the connection between help seeking and concealment, on the one hand, and engagement and achievement, on the other. One reason help seeking is adaptive is that it allows students to continue to remain constructively engaged in academic activities when they run into difficulties.

Eventually, this should result in higher academic performance. Therefore, it is expected children who seek help will also show more engagement and higher levels of achievement, whereas children who report more concealment will also show more disaffection and perform more poorly in school. Moreover, in keeping with the expectation of causal influence, it is expected that help seeking and concealment will predict changes in engagement and disaffection over time.

\section{What are the self-system predictors of coping?}

Research has focused on children's perceptions of competence and their goal orientations (autonomy) as key self-system predictors of their help seeking. The next goal of this study is to examine whether other, more social self-system processes, such 
as relatedness, are also important predictors of coping. The motivational model contends that all three self-system processes should be instrumental in shaping coping behavior, both concurrently and over time.

Because of its social nature, the self-system process, relatedness, is of particular interest as a predictor of help seeking and concealment. We hypothesize that relatedness will make a unique contribution, above and beyond the strong effects of competence, to both types of coping. In addition, the effects of autonomy have figured prominently in predicting help seeking. We will also examine whether relatedness uniquely predicts coping beyond the effects of autonomy.

\section{What are the effects of teacher support on coping?}

An additional aim is to empirically examine the theoretical contention that a child's social context is related to his/her help seeking behaviors. The proposed coping perspective contends that social support is a vital contributor to coping (particularly help seeking and help avoidance) with academic problems. Teacher provisions of motivational support will serve as a measure of contextual support in this study. It is expected that when teachers provide autonomy support, structure, and involvement, children should employ more help seeking. The lack of these supports should predict concealment.

5. Is the relationship between teacher support and coping mediated by self-system processes?

An important component of the motivational model is that the self-systems develop through interactions of the individual with his/her context. However, the ways 
of coping that a child employs during troubled times are posited to stem directly from their well of personal motivational resources. In this way, teacher supportiveness is expected to influence coping through its role in the development of the self-systems. This mediated model will be tested.

6. How does coping effect teacher supportiveness?

Reciprocal effects, namely, that children's coping may exert an effect on teachers' provisions of support, will be explored in this study as well. It is expected that how students cope with problems will predict changes in how their teacher supports them. Specifically, students who cope by seeking help will elicit more motivational support from their teachers over the school year whereas children who conceal their problems should experience reductions in teacher support over the same time period.

7. Can teacher support compensate for low self-system processes in predicting students' help seeking and concealment?

The most recent research suggests that teacher support may ameliorate some of the effects of negative self-perceptions on help seeking (Newman, 1998; Turner et al. 2002). It is expected that students with low self-system processes may seek help more and use concealment less when teacher support is strong.

8. Are there age differences across middle childhood in the self-system and teacher support predictors of coping?

The final goal of this study is to further explore age-related differences in the predictors of children's help seeking. First, we will test whether or not differences 
exist between $3^{\text {rd }}, 4^{\text {th }}, 5^{\text {th }}$, and $6^{\text {th }}$ grade students in the effects of the self-system processes on ways of coping. It could be expected that the importance of the motivational self-system processes on particular ways of coping might change as children learn more about themselves and the schooling process. Previous research (Ryan \& Pintrich, 1997, Newman \& Schwager, 1995) suggests that help seeking in young children is motivated by a desire for attention and teacher dependence, while help seeking in older children is more closely related to task mastery and performance. As a result, we expect that for younger children (grades $3 \& 4$ ) relatedness will be most predictive of help seeking. Alternatively, for students in $5^{\text {th }}$ and $6^{\text {th }}$ grade, competence may be a stronger predictor of help seeking (Newman, 1990; Puustinen, 1998). Autonomy (goal orientation) appears to be important throughout the school years (Nelson-Le Gall, 1990; Ryan \& Pintrich, 1997). Therefore, we expect that autonomy will predict coping similarly at all ages.

Second, of further interest is whether differences exist between grades in the relationship between teacher supports and coping. It is expected that as children age, experiences and maturation will create some differences in the importance of how supportive the teacher is in coping behavior. There is not a wealth of literature in this area to help form expectations as to exactly what these differences will look like. These analyses will be of a more exploratory nature. It is possible that teacher support may be more important for younger students, for whom being liked by the teacher is a salient goal. Alternatively, teacher support may be more important for older children due to the general trend of loss of teacher support that occurs during middle school 
Help Seeking 55

years (Skinner et al., 1998). For older children, a support from the teacher could have a stronger effect on coping than for younger children. 


\section{METHOD}

\section{Participants}

Data from a four-year longitudinal study on children's motivation and coping in school was used for this study (for a complete description see Skinner et al., 1998). Participants were 1600 students in grades three through seven and 53 of their teachers. The students attended a public elementary school in a rural-suburban school district located in upstate New York. The student sample was predominantly Caucasian with only approximately $5 \%$ of the students identifying themselves as non-white. The sample was approximately equally divided by gender. The students' socioeconomic status ranged between working to middle class. Socioeconomic status was determined by parents' level of education and occupation.

A subset of these children (total $N=1004$ ), from year three of the study (measurement points 5 and 6), was available for the current study. Following an analysis of missing data patterns, the decision was made to exclude any students who were missing more than two complete student report scales $(n=169)$ or more than $50 \%$ of items within the teacher report scales $(n=239)$. Based on Schafer and Graham's (2002) recommendation, data for the remainder of the sample was imputed with SPSS 11.5 using maximum likelihood (ML) estimation with an estimation maximization (EM) algorithm. The final data set included 765 students ( 375 males and 390 females). The students were in grades three through six for the two time points used for these analyses. The grades were divided as follows: $1103^{\text {rd }}$ grade students, $2794^{\text {th }}$ graders, $925^{\text {th }}$ graders, and 284 sixth graders. 


\section{Procedure}

Trained interviewers administered self-report questionnaires to students in their classrooms in three 45-minute sessions. In each session, one interviewer read the questions aloud while students marked their answers on the questionnaire. A second interviewer was present to monitor question comprehension and answer questions. During these sessions, teachers were not present in the classroom. Instead, most teachers spent their time filling out their questionnaires during student assessment periods. Data were collected in October and May.

\section{Measures}

Students reported on their ways of coping with academic problems, selfsystems, and engagement vs. disaffection in the classroom. Student report of selfsystems included reports of relatedness to their teacher, perceptions of control in academics, and perceptions of autonomy in school. Teachers reported on the level of involvement, structure, and autonomy support they provided to each child. Students were assessed by the teacher that claimed to know him or her best. Grades, or school marks, were collected from student records for a portion of the participants.

Every scale utilized in this study, with the exception of those measuring autonomy and ways of coping, contained both positively and negatively worded items. Negatively worded items were reverse coded. Response options were provided on a 4point Likert scale for each item. The respondents indicated whether each item was for them: Not at all true (1), Not very true (2), Sort of true (3), or Very true (4). The items in each scale were averaged together to get a composite score on each scale; hence 
scale scores could range from 1 to 4 . Higher scores indicated stronger endorsement of the construct. See Appendix C for the complete questionnaire.

\section{Student Report Scales}

Ways of Coping

Multiple ways of academic coping were assessed, but only the scales pertaining to help seeking and isolation/concealment are used for this study. Help seeking consisted of five items tapping students' help seeking actions in relation to their teacher. Children reported their help seeking in response to the following academic challenge: "When I have trouble with a subject in school." Example response items from the help seeking scale are: ... "I ask for some help with understanding the material" and "I ask the teacher to explain what I didn't understand." The isolation/concealment scale consisted of nine items, tapping the withdrawal and hiding tactics of students in the classroom. The academic challenge was: "When something bad happens to me in school (like not doing well on a test or not being able to answer an important question)." Example responses from the isolation/concealment scale are: “...I don’t let anyone know about it" and "I don’t want to talk to anyone about it."

\section{Self-system measures}

Relatedness to teachers. Students completed four self-report items regarding their sense of belonging or connectedness to teachers. For each item, the stem was as follows: "When I'm with my teacher." These items tapped students' feelings of emotional security when with their teacher. Example responses are: "I feel accepted" 
and "I feel ignored" (reverse coded). Cronbach's alpha for this scale when used with a sample of $3^{\text {rd }}$ through $6^{\text {th }}$ graders $(\mathrm{N}=641)$ equaled .79 (Furrer $\&$ Skinner, 2003).

Perceived control (competence). Students' expectancies about the extent to which they can achieve success and avoid school failure were assessed using the sixitem Control Beliefs subscale of the Student Perceptions of Control Questionnaire (SPOCQ: Skinner, Chapman, \& Baltes, 1988; Skinner, Wellborn \& Connell, 1990). This measure captured generalized beliefs about student competencies in the school domain. Example items include: "I can get good grades in school" and "I can't do well in school, even if I want to" (reverse coded). This scale has yielded consistent reliability estimates in use with grade school students $(\alpha=.66$, averaged across time and grades 3-7, Skinner et al., 1998; $\alpha=.63$, grades 3-6, Furrer \& Skinner, 2003).

Autonomy. The measure of academic autonomy was composed of 17 items that tap whether children engage in activities because they feel coerced or because they desire understanding and enjoy the task. The measure consists of four subscales: (1) external self-regulation which refers to doing work because of rules or fear of punishment ("Why do I do my homework? Because I'll get in trouble if I don't"); (2) introjected self-regulation which refers to doing work because one "should" and to avoid negative emotions ("Why do I try to do well in school? Because I'll feel really bad about myself if I don't do well"); (3) identified self-regulation which refers to reasons for working related to desire for understanding and learning ("Why do I work on my classwork? Because I think classwork is important for my learning"); and (4) intrinsic self-regulation which refers to doing work because it is enjoyable ("Why do I 
work on my classwork? Because it's fun"). The four subscales have been averaged in previous literature to form a summary score called the Relative Autonomy Index (RAI). The internal consistencies of the subscales of the RAI range from $.61-.85, M \alpha$ $=.75$ when used with $3^{\text {rd }}-5^{\text {th }}$ graders (Patrick, Skinner, \& Connell, 1993). Ryan and Connell (1989) tested the following three subscales with children ranging from $4^{\text {th }}-12^{\text {th }}$ grade: external (average $\alpha=.63$ ), introjected (average $\alpha=.77$ ), and identified (average $\alpha=.81$ ).

Engagement versus Disaffection

Responding to 25 items, each student reported on his/her own behavioral and emotional engagement in the classroom. Ten behavioral items assessed students' perceptions of their effort, attention, and persistence when initiating and executing learning activities. Item examples are: "The first time my teacher talks about a new topic, I listen very carefully" and "In class, I try to do just enough to get by" (reverse coded). Fifteen emotional engagement items tapped students' emotional involvement during academic activities. Item examples are: "When I'm working on my classwork, I feel involved" and "When I'm doing my work in class, I feel bored" (reverse coded). A composite scale of student engagement was created by averaging the emotional and behavioral engagement subscales. Skinner and Belmont (1993) used these scales with $3^{\text {rd }}, 4^{\text {th }}$, and $5^{\text {th }}$ graders and the measure of internal consistency for emotional engagement was .79 and behavioral engagement was .81 . In another study with $3^{\text {rd }}-6^{\text {th }}$ grade students, total engagement $\alpha=.89$, emotional engagement $\alpha=.86$, and behavioral engagement $\alpha=.75$ (Furrer $\&$ Skinner, 2003). 
Academic Performance

An aggregate measure of school performance was computed from students' grades. Letter grades were converted to numbers ranging from 1 (F or U-) to 12 (A or V). Scores were computed by averaging children's marks from classes focusing on math performance and verbal performance (reading, language, and/or spelling) (Skinner et al., 1998). The average achievement score for these student was 8.94 (between a B and a B-), with a standard deviation of 1.67.

\section{Teacher Report Scales}

\section{Teacher Context}

Teacher warmth vs. neglect. Teachers reported on the level of involvement they provided to each child. Fourteen items tapped warmth/affection, dedication of resources (time, attention, etc.), knowledge about the student and his needs (attunement), and dependability. Example items from each area are: "This student is easy to like," "I spend a lot of time with this student," "I know a lot about what goes on for this student," and "This student can count on me to be there for him/her." The measures of reliability in previous use of this measure are $\alpha=.83$ (11 items, grades 35; Skinner \& Belmont, 1993).

Teacher structure vs. chaos. 5 items measured the kind and amount of structure versus chaos provided in the classroom, including contingency (consistency and predictability of responses) and expectancy (clarity). Example items are: "I find it hard to be consistent with this student" (reverse coded), and "I try to be clear with this student about what I expect of him/her in class". Studies that have used a version of 
this scale report internal consistency measures of $\alpha=.70$ (8 items, grades 3-5; Skinner \& Belmont, 1993).

Teacher autonomy support vs. coercion. Autonomy support provided by the teacher was measured using a 12-item scale tapping teacher control, provision of choice, relevance (use of learning), and respect. Example items are: "When it comes to assignments, I'm always having to tell this student what to do" (reverse coded), "I try to give this student a lot of choices about classroom assignments," "I explain to this student why we learn certain things in school," and "I let this student make a lot of his/her own decisions regarding schoolwork." Previously reported reliability measures are $\alpha=.90$ (13 items, grades 3-5; Skinner \& Belmont, 1993). The three scales of teacher context can be aggregated to form a Teacher Supportive vs. Unsupportive Context scale. 


\section{RESULTS}

\section{Descriptive Information}

Measurement properties and descriptive statistics. All analyses were conducted using SPSS 11.5 with the exception of the structural equation modeling. Table 2 presents the internal consistency reliabilities (Cronbach's alphas), means, standard deviations, and range statistics for all student and teacher report scales.

All but two of the assessments showed adequate $(\geq .70)$ internal consistency reliabilities for both measurement points. Student report of competence and teacher report of structure displayed low internal consistencies in the fall (.63 and .63 , respectively), but improved by spring (.70 and .71$)$.

An examination of the means indicated that the distributions of all scales except concealment and autonomy were slightly negatively skewed. Mean scale scores tended toward the upper half of the score range. However, the skewness statistics did not exceed the acceptable level of 1.0, thus no transformations were necessary. All variables fell below 2.5 in kurtosis analyses. This information suggests that the students tended to positively endorse the scales.

As can be seen, on average, students reported high levels of help seeking and were less likely to report concealing when help is needed. Also, students perceived themselves to be highly competent, as well as behaviorally and emotionally engaged in classroom activities. Students reported that on average they felt a strong sense of belonging in class. Autonomy had the lowest mean of the self-system processes, perhaps reflecting the typical classroom environment, which affords students little 
power and few choices. Teachers perceived themselves to be strongly supportive in all areas, particularly in providing structure for students. The means for all scales exhibited little change from fall to spring, indicating that the average self-perceptions of students and teachers remained consistent across the school year.

The standard deviations for all scales were moderate, ranging from .41 to .77 . This suggests that the variability in scale scores between students is somewhat restricted, thus limiting the possibility of finding significant effects. However, for all scales, the entire range of scores fell between \pm 1 standard deviation of the mean. An examination of the minimum and maximum scores did suggest that on most scales, at least some students had reached the ceiling of the scale scores. The lowest possible scale score of 1.00 was only reported for two scales in the fall and three in the spring.

Stabilities. Table 2 also provides correlations of each scale from fall to spring. All scales exhibited a high level of stability over time (average $r=.67$ ). As a result, there may not be enough variance in scores to predict change over time. This finding, in conjunction with ceiling effects, implies that it may be particularly difficult to find significant effects for positive changes, because some students who already report high levels of a variable in the fall do not have the option of reporting an increase in the spring.

Intra-construct correlations. For those constructs that are made up of subscales (the self-system processes, engagement, and teacher supports), correlations were calculated among the subscales as an indication of the degree of interdependence that exists among the subscales. Table 9 shows the correlations among the self-system 
processes both in fall and spring. The self-system processes were only moderately inter-correlated, indicating that they should not be aggregated. The correlation between behavioral and emotional engagement was .64 in the fall and .71 in the spring. This indicates that the two scales may be measuring similar aspects of engagement and can be aggregated for a more parsimonious measure. However, the correlation is not so high as to suggest the scales are measuring the same thing. Therefore, they may be disaggregated for use in exploratory analyses. Similarly, the correlations between the teacher support variables (Table 13) indicated that the scales may be aggregated into a single teacher support variable. Again, the teacher support variable may be separated into its component subscales (involvement, structure, and autonomy support) if more differentiated information about teacher support is needed.

The remainder of the analyses are organized around the eight research questions.

\section{What is the Siructure of Help Seeking and Help Avoidance?}

To test the hypothesis that help seeking and avoidance are distinct ways of coping, first the zero-order correlations between help seeking and concealment were examined. The correlation in the fall was $r=-.32(p<.01)$ and was $r=-.38(p<.01)$ in the spring. The moderate strength and negative sign of the correlations signify that while there is the predicted negative relationship between the two ways of coping, they are not polar opposites.

To further explore the underlying structure of these two potentially unique ways of coping, structural equation modeling was performed using AMOS. The 
sample was split into derivation $(N=414)$ and replication $(N=351)$ samples in case some items need to be deleted. As recommended by Maruyama (1998), a ratio of at least 10 participants per item was maintained.

Testing unidimensionality of the item sets. As a first step, the unidimensionality of the item sets for each way of coping were assessed separately. Table 3 presents the factor loadings and model fit of the unidimensional item sets for help seeking and concealment in fall and spring using the derivation sample. Both of the item sets tested showed a good fit with the single factor models of help seeking and concealment. An examination of the internal consistency analyses (Cronbach's alpha) also showed that no items were particularly weak for either factor. The decision was made to keep all of the original 5 help seeking items and the original 9 concealment items.

Examining the fit of the one bipolar versus two unipolar factors. The next set of analyses tested and compared the models of one bipolar factor versus two unipolar factors. The Chi-square tests for both models were significant. This significance can be attributed to a large sample size and a corresponding increase in the ability to detect small differences. Therefore other indices were examined to assess model fit. Modelsample discrepancy measures reflect the difference between the observed covariances and predicted covariances. CMIN/DF $\left(\chi^{2} / \mathrm{DF}\right)$ ratio should be less than 3 to 1 . The Goodness of Fit Index (GFI), a measure of the discrepancy between predicted and observed covariances, should be greater than .85 . Because we are comparing models, we also look at the Adjusted Goodness of Fit Index (AGFI), which adjusts the GFI for 
degrees of freedom. A desirable value for this index should be greater than .90 . The RMSEA (the square root of the averaged squared amount by which the sample correlations differ from their estimates under the model) is actually based on population discrepancies and tests noncentrality. Values should be less than .05 . Comparisons to baseline model indices are computed relative to the independence or null model, which assumes that there are no relationships between the measured variables. The Normed Fit Index (NFI- based on the ratio of hypothesized model fit to the null model fit) and the Relative Fit Index (RFI - NFI corrected for degrees of freedom) should have values greater than .90 . Recent research by $\mathrm{Hu}$ and Bentler (1995) suggests that the Incremental Fit Index (IFI - similar to NFI) be reported as well because it has been shown to be relatively unaffected by sample size.

Chi-square statistics and the goodness-of-fit indices for the one and two factor models are reported in Table 4. As can be seen, the two factor model fits the data better than the one factor model. The CMIN/DF value for the two factor model was nearly half of the value of the single factor model. The GFI, AGFI, NFI, RFI, and IFI were higher for the two factor model and approached or exceeded the recommended levels of .90. The value for the RMSEA was smaller for the two-factor model, although it was slightly higher than the recommended level of .05 . This pattern of results held for the replication sample as well.

The factor loadings indicated the strength of the relationship between each measured variable and its corresponding latent variable. The loadings for the two factor model in both the fall and spring are reported in Table 5. Loadings for help 
seeking ranged from .44 to .72 (average across both time points $=.61$ ) and loadings for concealment ranged from .49 to .73 (average across both time points $=.62$ ).

Loadings of .5 or greater are considered satisfactory. Squared multiple correlations (SMC) ranged from .20 to .47 in the fall and .33 to .54 in the spring. These values reflect the proportion of variance in each measured variable accounted for each latent variable. The factor inter-correlation between help seeking and concealment was -.45 in the spring, offering additional support for two unipolar constructs as opposed to one bipolar construct.

These results indicated that the data were a better fit to the two factor model than the one factor model. However, some of the fit indices for the two factor model fell short of recommended levels, indicating that the two factor model could be improved in some way. Overall, when considering the zero-order correlations, measures of internal consistency, and the results from the structural equation modeling, there is no evidence that a single factor model of help seeking is appropriate. Rather, help seeking and concealment appear to be two distinct ways of coping.

2. What are the connections between coping, engagement, and achievement?

Achievement. The zero-order correlations between overall achievement and each way of coping, separately for fall and spring are reported in Table 6. Neither way of coping was significantly related to achievement in the fall. However, the correlation between help seeking and achievement in the spring, although moderate, was significant. The correlation between achievement and concealment in the spring did 
not reach significance. These results indicate that the relationship between coping and achievement was not particularly powerful.

Engagement. The second set of analyses examined the effects of coping on student engagement. As expected, help seeking was strongly and positively associated with student engagement at both measurement points (Table 6). Likewise, concealment had a strong, negative relationship with engagement in both fall and spring. This suggests that students who ask for more help are also likely to be more highly engaged in school and those who tend to hide that they need help also feel and act less engaged in the classroom.

The coping model contends that the proximal outcomes of coping are engagement and disaffection. To test whether help seeking and concealment in the fall predict changes in engagement in the spring, hierarchical regressions were conducted controlling for the effects of fall engagement. The regression results are reported in Table 7.

In the regression using help seeking as a predictor, the first step of the model was significant $\left[\mathrm{R}^{2}=.548, \mathrm{~F}(1,763)=926.30, p<.001\right]$, indicating that fall engagement accounted for nearly $55 \%$ of the variance in spring engagement. This finding reflected the high degree of stability exhibited between engagement at the two time points. When help seeking was added as a predictor, it did not significantly contribute to the variance explained in engagement in the spring.

The second regression included concealment as a predictor in the second step. The change in $\mathrm{R}^{2}$ was significant when concealment was added to the model. After 
controlling for the effects of fall engagement, students' concealment predicted engagement in the spring. This indicated that despite the high degree of stability in engagement across the school year, children who were more likely to use concealment as a way of coping when school started, became less likely to remain engaged in the classroom over the school year.

Additional analyses: Separating the components of engagement. Since help seeking did not predict changes in overall engagement across the school year, the two components of engagement, behavioral and emotional engagement, were disaggregated and tested separately with each way of coping. It was expected that perhaps help seeking may function differently with actions and feelings. The regression results are presented in Table 8 and indicate that help seeking did predict behavioral engagement in the spring after controlling for fall behavioral engagement, but help seeking did not predict changes in emotional engagement. Concealment was a significant negative predictor of changes in behavioral and emotional engagement. The additional amount of variance explained in the spring for all of these regressions was small, yet it was surprising that significant effects were found at all because engagement did not tend to change much across the school year.

These results indicate that students who seek help more in the fall tend to be more behaviorally engaged in the spring. However, help seeking did not appear to have an effect on children's emotional engagement across time. Additionally, the more students concealed that help was needed, the more behaviorally and emotionally disaffected they were likely to be in the spring. 


\section{What are the self-system predictors of coping?}

Competence, autonomy, and relatedness. To determine how each self-system process is related to coping, the correlations between the three self-systems and each way of coping were examined at both time points. These correlations can be found in Table 9. All three self-systems were moderately related to help seeking (range $r=.29$ to .50 , average .38 ). The more students reported seeking help, the more related, competent, and autonomous they were. The relationship between the self-systems and concealment were of moderate strength and negative. This indicates that students who were more likely to conceal their help were also likely to report lower feelings of belonging, competence, and autonomy. The self-systems, particularly competence, had a slightly stronger relationship with concealment than with help seeking.

To determine if the self-system processes predicted changes in coping over time, two sets of three heirarchical regressions were performed. The results are reported in Table 10. The first step of the three help seeking models were the same and demonstrated that help seeking in the fall contributed significantly to help seeking in the spring $\left[\mathrm{R}^{2}=.316, \mathrm{~F}(1,763)=352.23, p<.001\right]$. The bivariate correlation between help seeking at the two time points was .56, accounting for almost $32 \%$ of the variance.

The second step of each of the three models entered a self-system variable. Relatedness, competence, and autonomy were each significant predictors of increases in children's help seeking from fall to spring. These results are consistent with the notion that students' perceptions of their levels of belonging, competence, and 
autonomy early in the school year has an effect on their help seeking behavior in the spring. Those students who feel more related, competent, and autonomous are likely to increase their help seeking over the school year.

The first step of the three concealment models tested whether concealment in the fall predicted concealment in the spring. This step of the regression was significant. The bivariate relationship between fall and spring concealment was .66, accounting for $44 \%$ of the variance in spring concealment $\left[\mathrm{R}^{2}=.44, \mathrm{~F}(1,763)=\right.$ $600.19, p<.001]$

When relatedness was entered as a predictor in the second step predictor, $\mathrm{R}^{2}$ Change was not significant. This indicated that feelings of relatedness did not predict changes over time in students' avoidance behavior. A significant Beta was found for competence and for autonomy, demonstrating that at least a portion of the variance in concealment in the spring could be explained by how competent and autonomous children perceived themselves to be in the beginning of the year.

Unique effects of relatedness. The previous analyses showed that all three selfsystem processes separately predicted changes in coping. However, the question remained whether relatedness would emerge as a significant unique predictor. The next set of analyses were designed to examine whether relatedness predicted coping over and above the effects of competence and autonomy, respectively.

Hierarchical multiple regressions were performed separately to predict help seeking and concealment in the fall and spring. Table 11 shows that both competence and relatedness had significant Betas in the fall and the spring. Nevertheless, 
relatedness also uniquely predicted help seeking over the effects of competence in these concurrent analyses. The effects of relatedness were especially strong in the spring, predicting an additional $14.6 \%$ of the variance in help seeking. In separate analyses, relatedness also accounted for a significant amount of the variance in help seeking at both time points after controlling for the effects of autonomy. Once again, the unique effects of relatedness were stronger in the spring, accounting for over $16 \%$ of the variance in help seeking. These results suggest that, as expected, competence and autonomy are important in predicting help seeking, but feelings of belongingness have unique and strong influences in children's help seeking behavior.

A similar set of analyses were conducted to concurrently examine the unique effects of relatedness on concealment. Table 12 displays the results of these analyses for fall and spring. Relatedness had a significant negative Beta in the fall and spring after controlling for the negative effects of competence. Perceptions of belonging also uniquely negatively predicted concealment after controlling for the negative effects of autonomy and these effects were particularly strong in the spring. Over and above the influences of competence and autonomy, the less children felt like they belonged, the more they used concealment as a way of coping.

\section{What are the effects of teacher support on coping?}

The correlations between teacher supportiveness and each way of coping were calculated in both the fall and spring (see Table 13). Teacher support was significantly, but not strongly related to help seeking at both measurement points. The relationship between teacher support and concealment in the fall and spring was in the 
expected negative direction, but was also fairly weak. It should be noted that these are correlations between teacher report measures of teacher support and student report measures of coping, and since they share no common method variance, the correlations were not expected to be as strong.

To examine change over time, separate multiple regressions were used for each way of coping to examine whether teacher support in the fall predicted coping in the spring, after controlling for coping in the fall (see Table 14). The first step of the help seeking model was significant $\left[\mathrm{R}^{2}=.316, \mathrm{~F}(1,763)=352.23, p<.001\right]$, demonstrating that help seeking in the fall explained $32 \%$ of the variance in help seeking in the spring. When teacher support was added during step two, a significant Beta was obtained. This indicates that when teachers reported being more supportive in the beginning of the school year, students increased in their help seeking across time. In terms of concealment, scores in the fall did predict significant variance in spring concealment $\left[R^{2}=.44, F(1,763)=600.19, p<.001\right]$. However, teacher support was not a significant predictor of changes in concealment.

Additional analyses: Disaggregating teacher support. Because teacher support as an aggregate variable did not predict changes in concealment, the three types of teacher support were analyzed individually as predictors of concealment. Neither teacher report of involvement nor teacher report of structure accounted for significant variance in changes in concealment across the school year. However, low autonomy support in the fall predicted increases in concealment over time $\left[\Delta \mathrm{R}^{2}=.004, \mathrm{~F}(1,762)\right.$ $=5.76, p<.05]$. 
5. Is the relationship between teacher support and coping mediated by self-system processes?

The previous concurrent analyses established that self-system processes are important to coping and that teacher support is important to coping. The next set of analyses tested a mediational model, which in line with the self-system model of motivational development, predicted that the relationship between teacher support and coping works through the development of self-systems. The four-step procedure outlined by Baron and Kenny (1986) was used to examine each self-system process as a mediator between teacher support and each way of coping ( 6 mediated models). The process of establishing that a mediator existed followed the following protocol: (1) a significant relationship existed between teacher support and the way of coping; (2) a significant relationship existed between teacher support and the self-system processes; (3) the self-systems predicted coping; and (4) the link between teacher support and coping was significantly reduced following the addition of the self-system.

Previous analyses demonstrated that all three self-system processes were significant predictors of both ways of coping and that significant relationships existed between teacher support and coping. Simple linear regressions demonstrated that teacher support was a significant predictor of relatedness $[R=.24, F(1,763)=48.41$, $p<.001]$, competence $[\mathrm{R}=.33, \mathrm{~F}(1,763)=95.50, p<.001]$ and autonomy $[\mathrm{R}=.14$, $\mathrm{F}(1,763)=16.27, p<.001]$

In the test of the mediated models, in the first step of the hierarchical regression, teacher support was entered. As expected, teacher support was a significant 
predictor of help seeking and concealment. In the second step, each of the three selfsystems were added (separately for 6 models), testing whether the previously significant association between teacher support and the way of coping was significantly reduced or fell below the level of significance when the mediator variance was taken into account.

The results from the three models using help seeking as the criterion variable are presented in Table 15. These results indicated that the relationship of teacher support to students' help seeking was fully mediated by the students' perceptions of relatedness. Children's perceptions of competence also fully mediated the relationship between teacher support and help seeking. Teacher support remained significant when students' perceived autonomy was added into the model, yet the level of significance was reduced. To test if the decline in significance did demonstrate mediation, the Sobel test was calculated as outlined in Baron and Kenny (1986). This test calculates whether the indirect effect of an independent variable on the dependent variable through a mediator is significantly different than zero. The Sobel test indicated that autonomy support did act at least as a partial mediator in the relationship between teacher support and help seeking $(z=3.63, p<.001)$.

Table 16 presents the results from the three concealment models. Only competence rendered the relationship between teacher support and concealment insignificant. Sobel tests were conducted for the effects of relatedness and autonomy, both of which significantly reduced the relationship between teacher support and concealment. The Sobel tests indicated that the effects of teacher support on students' 
concealment were partially mediated by relatedness $(z=-6.05, p<.001)$ and by autonomy $(z=-3.89, p<.001)$.

In summary, all of the models demonstrated full or partial mediation of the relationship between teacher support and students' coping by students' selfperceptions. This suggests that one way that teacher support matters to students' help seeking or concealment is by influencing students' perceptions of their belonging, competence, and autonomy.

\section{Does coping affect teacher support?}

This next set of analyses were designed to test potential reciprocal effects of coping on teacher supportiveness. It was established that a concurrent relationship between teacher support and coping existed. Also, teacher supportiveness predicted changes in help seeking over the school year, while teacher autonomy support predicted changes in concealment. What is not yet known is whether coping contributes to changes in teacher support over time. This was tested with multiple regressions that examined whether each way of coping predicted teacher support in the spring after controlling for teacher supportiveness in the fall.

The results for the reciprocal analyses are presented in Table 17. The first step of the sequential model demonstrated that teacher support in the fall explained nearly $63 \%$ of the variance in teacher support in the spring $[\mathrm{R}=.795, \mathrm{~F}(1,763)=1309.29$, $p<.001]$. Nevertheless, even after controlling for fall levels of teacher supportiveness, help seeking accounted for significant variance in spring teacher support. When students seek help more at the beginning of the school year, teachers are more likely to 
become more supportive over time. Concealment was also a significant predictor of change in teacher support over the school year. This indicates that when students use concealment as a way of coping with problems within the first few weeks of school, teachers are likely to decrease in the support they provide as the school year progresses.

Additional analyses: Disaggregating the teacher support variables. In keeping with the proposed analyses plan, the aggregated teacher support variable was separated into its component parts: involvement, structure, and autonomy support. It was hypothesized that because help seeking and concealment appear to be distinct ways of coping, they might have different effects on the individual types of teacher support. The regression results for this set of analyses is presented in Table 18. The pattern of standardized regression coefficients $(\beta)$ demonstrated that help seeking most strongly predicted changes in involvement. Help seeking also predicted increases in teacher levels of autonomy support, but help seeking was not a significant predictor of changes in teacher provision of structure. A slightly different pattern emerged for concealment. Concealment was a significant predictor of decreases in involvement, structure, and autonomy support. Again, teacher report of structure appeared to be least affected by coping.

In conclusion, the two types of coping did appear to have relationships with the various kinds of teacher support. Help seeking clearly mattered the most in boosting levels of teacher involvement. The more students ask for help, the more likely teachers are to increase their involvement over the school year. Concealment influenced all 
aspects of teacher support, yet the impact appeared strongest on teacher involvement and autonomy support. When students conceal their problems, teachers are more likely to respond by withdrawing their attention and becoming more coercive.

\section{Can teacher support compensate for low self-system processes in predicting students' help seeking and concealment?}

To test if teacher support acted as a moderator in the relationship between selfsystem processes and coping, multiple regressions were conducted with each selfsystem process and teacher support predicting each way of coping at both measurement points. First, the independent variables were centered as recommended by Tabachnick and Fidell (2001). Then teacher support and the self-system predictor were entered into the model. In the second step, an interaction term that consisted of the cross product of teacher support and the self-system was added. A significant interaction would indicate that influence of self-systems on ways of coping depended on levels of teacher support.

Only one significant moderated relationship was found. Teacher support moderated the relationship between relatedness and help seeking at both time points. After the first step, which tested the main effects of teacher support and relatedness, approximately $17 \%$ of the variance in help seeking was explained $[R=.419, F(2,762)$ $=81.197, \mathrm{p}<.001]$. When the interaction between teacher support and relatedness was added, a significant Beta of .073 was found $(\mathrm{t}=2.20, p<.05)$. A graphical depiction of the relationship can be found in Figure 3. This figure demonstrated that students who were low in relatedness tended to endorse similar levels of help seeking, but as 
students increased in relatedness, those with higher teacher support tended to ask for help more. This effect was replicated in the spring $\left[R^{2}\right.$ Change $=.005, F_{\text {inc }}(3,761)$ $=4.93, p<.05]$ and the graphical depiction was nearly identical.

This graph indicates that teacher support was most influential for those students who felt most related to the teacher. Yet, teacher support could not compensate for feelings of low relatedness.

8. Are there age differences during middle childhood in the self-system and teacher support predictors of coping?

The final set of analyses was designed to examine whether self-system processes and teacher support were more salient for coping at different developmental levels. A new data set was constructed for this set of analyses. To make comparisons between grades, groups of roughly the same size were needed. The smallest group size $(\underline{n}=92)$ in the initial data set was found for $5^{\text {th }}$ graders. In order to maintain enough power to conduct statistical tests, 100 students from the remaining grades were randomly chosen from the larger data set. The remaining analyses were conducted with this data set $(\underline{\mathrm{N}}=392)$. Table 19 presents the measures of internal consistency reliabilities of each scale used for the following analyses by grade.

To address research question 8 and establish some norms for the different levels of middle childhood, an initial set of analyses examined the descriptive information about age differences. The mean levels for each grade on the three selfsystem predictors (autonomy, competence, and relatedness), the aggregate teacher support variable, and the two ways of coping were compared. Table 20 presents the 
descriptive statistics by grade. Figure 4 is a graphical depiction of the patterns of means across the school year within and between each group.

Generally, the means and standard deviations of the groups were consistent with patterns found in the larger data set. This held true for range statistics as well. There was a slightly larger range of scores, particularly in the areas of teacher support and concealment, for students in the higher grades. The lowest maximum score reported for autonomy (3.50) was found for $6^{\text {th }}$ graders.

Overall, no major differences within any of the major scales between grades was readily apparent. The highest mean levels of help seeking were found for $5^{\text {th }}$ graders, while the lowest levels were reported by $6^{\text {th }}$ graders. An opposite, but consistent, pattern was noted for concealment. Mean levels of autonomy were lower than mean levels of relatedness or competence, with the lowest levels exhibited in $6^{\text {th }}$ grade. For most scales, the fall scores for $3^{\text {rd }}$ through $5^{\text {th }}$ graders appeared to be fairly similar. However, there was a sharp divergence between scores from the end of $5^{\text {th }}$ to the beginning of $6^{\text {th }}$ grade. Sixth graders showed a marked decrease in most means. The increase in concealment was particularly large. It should be noted that for our sample, $6^{\text {th }}$ grade marked a transition from grade to middle school.

Analysis of variance (ANOVA) were conducted with each construct to determine if the means levels were statistically different between fall and spring. See Table 21 for a summary of the ANOVA results. There was a significant main effect for both help seeking and concealment. Bonferroni post hoc tests showed that between 
grades 5 and 6, there was a significant decrease in help seeking and a corresponding increase in concealment.

ANOVA also showed that teacher support appears to peak in $5^{\text {th }}$ grade and significant differences were found between $5^{\text {th }}$ grade levels of teacher support and all the other grades. There was an interaction for teacher support, which suggests that there is a sharper increase in teacher support over the school year for students in the $5^{\text {th }}$ and $6^{\text {th }}$ grade than for younger students.

The self-system processes showed various patterns in the ANOVAs. There were no significant between or within group effects for competence. Main effects were present for relatedness, and follow up analyses demonstrated that $5^{\text {th }}$ grade seems to be the high point for feelings of belongingness. $5^{\text {th }}$ grade levels of relatedness were significantly higher compared to all other grades. Finally, there were significant main effects and an interaction for grade by time for autonomy. $6^{\text {th }}$ grade appears to be a time of particularly low feelings of perceived autonomy. Sixth graders reported feeling significantly less autonomous compared to $3^{\text {rd }}, 4^{\text {th }}$, and $5^{\text {th }}$ grade students. The interaction indicates that the change across the school year depends on the students' grade level. $3^{\text {rd }}$ graders experience a cross year increase in perceived autonomy. There are decreases in cross year feelings of autonomy for students in $4^{\text {th }}$ through $6^{\text {th }}$ grade, with the sharpest decrease occurring during $5^{\text {th }}$ grade.

Next, the inter-construct correlations of the self-system predictors and teacher support variables with help seeking and concealment were computed for each age 
group. The correlations are presented in Tables 22 and 23. Graphical depictions of the age trends in these relationships are found in Figures 5 and 6.

In the next step of analyses, multiple regressions were conducted to determine whether the predictive value of the self-system processes and teacher support variables on help seeking and concealment differed depending on the age of the student.

Self-system processes. Analyses were done for both fall and spring time points for each self-system processes predicting each way of coping ( 6 models at each time). Using hierarchical multiple regression, the first step of each analysis included the selfsystem predictor and grade variable. An interaction term that consisted of the cross product of the self-system predictor and grade variable was entered into the second step of the model. A significant interaction effect would indicate that the relative salience of the self-system to a way of coping differed depending on students' grade level. No significant interactions were found to indicate that the effect of the selfsystem process on coping differed depending on grade.

Teacher support. A second, similar set of analyses was conducted to determine if grade differences existed in the effects of teacher support on coping. Analyses were done to predict each way of coping in both fall and spring. Hierarchical regression was again used, so that the first step included the teacher support variable and grade; the second step included the teacher support by grade interaction term. If a significant interaction were found, it would indicate that the importance of teacher support in predicting students' coping behavior differed depending on grade level. 
Once again, no significant interactions were found to support the proposition that grade acted as a moderator in the relationship between teacher support and coping.

Further analyses. The results of the above regressions indicated that the effects of the self-system processes and teacher support were homogenous across the grades. The visual examination of the correlations suggested that there might be differences in developmental trends between the grade school years and over the transition to middle school. Regressions were conducted by developmental phase (3-5 grades and 5-6 grades) for the same constructs. The results showed only isolated findings that were not replicated. For the grade school group, the effects of competence on help seeking did differ depending on grade in the spring time point $\left[\mathrm{R}^{2}\right.$ Change $\left.=.013, \mathrm{~F}_{\text {inc }}(3,288)=4.22, p<.05\right] .$. Competence appears to be a stronger predictor of help seeking in the $5^{\text {th }}$ grade than other grades. The only significant interaction during the transition to middle school was found for teacher support predicting concealment in the spring $\left[\mathrm{R}^{2}\right.$ Change $\left.=.025, \mathrm{~F}_{\text {inc }}(3,188)=5.33, p<.05\right]$. Teacher support appears to have more of an effect on concealment during $5^{\text {th }}$ grade than $6^{\text {th }}$ grade. 


\section{DISCUSSION}

\section{Summary of Findings}

This study sought to provide empirical support for a broader, more socially oriented conceptualization of help seeking. Help seeking and help avoidance were conceptualized as motivated ways of coping with unique antecedents and consequences. The primary goal of this study was to investigate the self-system and social antecedents, as well as the motivational outcomes of help seeking and avoidance. Moreover, developmental differences in the self-system processes and teacher supports that influence coping were examined.

\section{The Structure of Help Seeking and Help Avoidance}

The first goal of this study was to determine whether help seeking and help avoidance are distinct constructs rather than bipolar opposites. The evidence from the zero-order correlations and the structural equation modeling suggest that help seeking and avoidance (concealment) as measured in this study are unique ways of coping.

\section{Help Seeking Antecedents and Outcomes}

Help seeking is a positive way of coping with academic stress. Students who endorsed help seeking were overall also more engaged in classroom activities. Increases in behavioral engagement, a previously un-examined motivational outcome of help seeking, were predicted by help seeking. Another tangible scholastic outcome, achievement, was correlated with help seeking in the spring. These results suggest that when children ask for help, they are more likely to participate in class and their grades are positively affected. 
Another novel finding relates to reciprocity in classroom relationships. High teacher support was found to increase help seeking both concurrently and over time. Reciprocally, children who sought help at the beginning of the school year had teachers who increased their support over the school year. These findings indicate that not only does teacher support influence help seeking, but how children cope shapes teachers' reactions to them over the school year.

Not surprisingly, help seeking was precipitated by feelings of competence. Perceptions of autonomy, consistent with previous research relating to goal structure (Butler \& Neuman, 1995; Newman \& Schwager), were also associated with help seeking. This study extended previous research by demonstrating that feelings of competence and autonomy predicted increases in help seeking behavior over the course of a school year. Additionally, perceptions of belonging were directly analyzed with respect to help seeking behavior and these results clearly show that classroom relationships are very important in directing help seeking. Specifically, relatedness was strongly and uniquely associated with help seeking, even over the proven and powerful effects of competence and autonomy. These results provide empirical support for Newman's (2002) theoretical contention that all three self-systems are individually important in coping with problems by help seeking.

Another interesting finding is related to the directionality of these motivational processes. This study found that teacher support affects help seeking through its influence on the development of students' self-system processes. Therefore, as teachers offered support to students, students developed a greater reservoir of personal 
resources, which translated into more flexible and positive coping. In light of this finding, it was not surprising that very small and primarily non-significant effects were found for the subsequent proposed moderated relationships. The mediated models showed that teacher support had an indirect effect on help seeking, leaving little variance available for teacher support to act directly on help seeking. The only situation in which teacher support appears to directly influence help seeking is when students are already high in perceptions of relatedness: If teacher support is increased, students ask for help more.

Finally, an examination of the differences in means across grades did suggest that the period between fifth and sixth grades is a time of general decline in help seeking, the self-system processes, and teacher support. However, for the most part, the present study did not uncover any significant age differences in the effects of the self-system processes or teacher support on help seeking.

\section{Concealment Antecedents and Outcomes}

This study conceptualized one type of help avoidance as concealment of the need for help. Ryan, Stiller, and Lynch (1994) found evidence to suggest that when adolescents did not utilize any social partners when faced with emotional and school concerns, they coped less positively and had lower self-esteem, identity integration, and school engagement. The current findings are consistent with Ryan et al.'s results. When children conceal that they are in trouble, it is generally bad news. Correlations suggest that the more children conceal, the lower their grades are in the spring. Also, concealment was found to be related to disaffection. When examining change over 
Help Seeking 88

time, in contrast to the results for help seeking, concealment in the fall predicted increases in behavioral and emotional disaffection over the school year. Concealment appears to lead to greater withdrawal on the part of the students and has sobering consequences on tangible achievement outcomes.

Further evidence for the multidimensionality of help seeking and concealment is found in the effects of teacher support on concealment. Parallel to findings for help seeking, low levels of teacher support were associated with concurrent high levels of concealment. However, even though teacher support predicted changes in help seeking over time, it did not predict changes in concealment. The only component of teacher support associated with a significant change in concealment was that of autonomy support. Apparently, when teachers are more coercive, students respond by increasing their concealment of problems. Interestingly enough, student concealment was a strong predictor of changes in teacher support over the school year. Not only did higher levels of concealment result in overall decreases in teacher support, but each of the three support dimensions were negatively impacted by student concealment. These results suggest that teachers are quite sensitive to student help avoidance. Perhaps this avoidance is interpreted as not needing help or perhaps teachers find these students more difficult to get to know. This study was not able to examine teachers' reasons for withdrawing their support, but clearly concealment results in less teacher support.

All three self-system processes were significant predictors of concealment. Lower levels of perceptions of relatedness, competence, and autonomy were concurrently associated with higher levels of concealment for both time points. These 
results are consistent with previous research demonstrating that students low in selfefficacy are more likely to avoid seeking help (Ryan et al., 1998). In addition, relatedness again showed that it had unique importance, over the effects of the other two self-systems, to concealment. However, relatedness was not a significant predictor of changes in concealment, although low perceptions of competence and autonomy did predict increases in coping via concealment over the school year.

The results of the mediated models of concealment demonstrated that the mechanism of influence of teacher support on concealment was through the development of the self-system processes. The effect of low teacher support impacted students by diminishing or retarding the development of favorable self-perceptions. When students do not feel like they belong in the classroom, feel incompetent, or feel coerced, they tend to conceal more. It should be noted that the relationship between teacher support and concealment was only partially mediated by autonomy, suggesting that in the absence of other self-systems or additional predictors, teacher support is able to exert some measure of influence directly on students' concealment behaviors. However, the lack of evidence for teacher support as a moderator between the selfsystems (including autonomy) and concealment suggests that teacher support has little, if any, significant direct effect on concealment after taking students' self-perceptions into account.

Finally, no support was found for the hypothesis that teacher support and the self-system processes may differentially influence concealment depending on students' grade level. Mean level differences between fifth and sixth grade students 
suggest that students increase their concealment behavior after the transition to middle school, but the antecedents and consequences of concealment showed no corresponding age differences in predicting this way of coping.

\section{Strengths and Limitations of the Present Study}

There are four main areas that reflect both the strengths and limitations of the present study. One strength is found in the measurement of multiple dimensions of many constructs. Yet, the measurement properties of perceived competence, teacher report of structure, and autonomy demonstrate limitations of this study. The second area, measurement strategies, encompasses the strengths of multiple sources of measurement as well as limitations associated with methods used to gain information. Next, strengths and limitations relating to the assessment of development are discussed. Finally, there are limitations in this study pertaining to generalizability issues.

\section{Measurement Properties}

Strengths. The measurement of multiple dimensions of several key constructs provides clarity and depth to research in this field. This study assessed both help seeking and help avoidance. Until recently, the majority of help seeking research included a measure of help seeking only. By including both ways of coping, they can be compared on the basis of their relationships with predictors and they can also be evaluated with respect to each other.

While previous studies often included a measure of one self-system process, such as competence, this study measured multiple self-system processes. The 
measurement of relatedness, competence, and autonomy allowed for analyses of how the self-systems acted on coping both individually and in tandem. Additionally, the inclusion of a measure of teacher support is an improvement over typical research, which almost never includes contextual variables in the study of help seeking. This study went even further by measuring multiple dimensions of teacher support: involvement, structure, and autonomy support. Likewise, two dimensions of another previously unexamined motivational construct, engagement, were measured in the present study. The measurement of multiple dimensions of teacher support and engagement allowed for more targeted analyses to deconstruct seemingly homogenous findings at the aggregated level. In addition to these strengths, the study also had several limitations relating to measurement properties.

Perceived competence. Of all the student report measures, perceived competence had the lowest level of internal consistency. The overall alpha for the fall measurement point fell below what is normally considered acceptable. However, the alpha for this study is consistent with previous research that has successfully used this scale (Furrer \& Skinner, 2003; Skinner et al., 1998). Likewise, when examined by grade, the alphas for perceived competence were especially low for $3^{\text {rd }}$ and $4^{\text {th }}$ grade students. This suggests that the measure of perceived competence did not work as well with younger students. This possibility may offer some insight into why grade related differences were not found in this study. It should be noted that the measures of internal consistency reliability improved from fall to spring for all aforementioned instances, indicating a solidification of perceptions over the course of the year. 
Overall, perhaps a better measure of perceived competence would increase the power to find real differences among students if they are indeed there.

Teacher report of structure. There was some concern that the positively worded items of the teacher report of structure scale included ambiguous language that could be confusing for teachers. Psychometric analyses indicated that several of those items did not work well and were subsequently removed. The remainder of the items focused more heavily on actions teachers failed to do to provide support (teacher "chaos"). The final, 5-item, scale still displayed relatively low internal consistency reliability. To further explore how teacher provision of structure in the classroom may impact the development of self-system processes and subsequently coping, the development of a more psychometrically sound measure of teacher structure may be appropriate.

Autonomy. The measure of autonomy used in this study did not have problems with scale properties. However, autonomy was used as a proxy for goal orientation, and while the two constructs are conceptually similar, they are not interchangeable (Deci \& Ryan, 2000). To truly compare the findings of this study to those of previous research, a scale specifically designed to measure goal orientation, such as Harter's (1981) scale of Intrinsic versus Extrinsic Orientation in the Classroom (commonly used in help seeking research), would need to be implemented.

This study indicates that perceived autonomy is an important predictor of classroom coping. Further research may benefit from including both measures of autonomy and goal orientation. The perception of coercion or choice likely impacts 
whether or not children have an orientation toward schoolwork as fun and interesting or view it as a performance indicator. Educators and researchers may find it useful to understand the unique contributions or pathways of influence of perceived autonomy and goal orientation in children's coping.

\section{Measurement Strategies}

In the present study, three sources of data were available: student report, teacher report, and school records (grades). When variables used in analyses come from a single source via self-report (i.e. students), the correlations may reflect an inflated relationship due to common method variance. For example, the correlations between the self-system processes and help seeking may be inflated because they share the commonality of student perspective. However, because both student and teacher reports were used, some of this bias may have been ameliorated. The use of additional methods to obtain information about students' and teachers' feelings and behaviors may aid researchers in partialling out true effects from those obtained due to common method variance.

Student records provide a useful objective measure of actual student achievement. The use of grades gives some indication of the possible link between coping and tangible scholastic outcomes. Yet, one weakness of this study is the lack of achievement data for roughly one third of the sample. Complete achievement data would have improved the possibility of finding significant relationships between coping and grades. 
The self-report data from this study would have been complimented by observational assessments, which provide an objective measure of how students and teachers behave. The use of observation, in conjunction with self-reports, would provide more information about frequency, type, and source of help seeking in the classroom. Also, additional insight may be gained about children's engagement in the classroom and how it is related to coping. Finally, observations could yield some much needed understanding of the interpersonal interactions that occur leading up to an instance of coping. There may be certain patterns that precipitate a child choosing to conceal rather than seek help. It is important to note however that in a study with an interest in intrapsychic processes, observations can only be a complementary method. The self-system processes, and indeed, concealment, are not accessible via direct observation.

The use of other methods, such as open-ended interviews, may have provided additional insight into the intrapsychic processes of interest in this study. In particular, because this was a relatively high functioning sample that displayed high stability between measurement points in their self-reports, the nuances of changes in selfperceptions may be quite subtle. General measures of self-report may be insufficient to capture some of these more subtle processes, while in-depth interviews may allow for more elaboration and description of internal motivations and perceptions. Assessing Development

This research was a significant improvement over purely single-time point cross-sectional designs (as are the norm in help seeking literature). The inclusion of 
two time points and four age groups allowed for an assessment of how children change over the course of a school year, as well as how these changes may differ depending on age. Yet, still more and better longitudinal research is necessary to uncover not only age differences in help seeking, but also the developmental shifts underlying those differences.

This study did not completely capture the variability that may occur both within a school year and between grades. This may be due to the limited age range $\left(3^{\text {rd }}-6^{\text {th }}\right.$ grade) of the sample as well as the time scale used for data collection. There is evidence to suggest that many students cease to ask for help during the high school years (Good et al., 1987). It may be that the students in the present study were in a relatively stable and secure school situation. If the study would have included a broader range of age, developmental shifts and age differences may have been detected.

Likewise, the initial assessment period of students and teachers was roughly six weeks into the school year. It is quite possible that relationships and patterns of behaviors are worked out in the first few weeks of school and the remainder of the year is spent solidifying the relationship. The present findings suggest that many constructs were in fact highly stable over the school year. In order to truly understand the feedback processes that contribute to the formation of the teacher-student relationship, assessments at multiple time points within the first few weeks of school, as well as a measure of teacher preconceptions of students, may be necessary. 
Help Seeking 96

\section{Generalizability Limitations}

The final study limitation is associated with the generalizability of these findings. As previously mentioned, the mean scores on the scales indicate that the sample used in this study was fairly high functioning. The constructs were quite stable across the school year, tending to improve slightly in the spring. In order to detect change effects statistically, variability is a necessary component. Simply put, something needs to change before evidence can be found to predict why changes might occur.

If a similar study were conducted with a less homogenous sample, more or different effects would be likely. For example, these participants were primarily white and living in working to middle class families. A sample with more ethnic or economic diversity may reveal how motivational processes could be affected by differences in individual and contextual factors. Recent research has shown that members of different ethnic groups may have varying school experiences that lead to differences in adjustment (Kuperminc, Blatt, Shahar, Henrich, \& Leadbeater, 2004). Likewise, attachment research has shown that economic hardship places children at greater risk for developing maladaptive relationships and behaviors across home and school contexts (Easterbrooks, Davidson, \& Chazan, 1993). The findings of the present study may not apply to these populations.

\section{Implications of the Results}

Findings from this study have implications for the conceptualization of classroom help seeking and help avoidance. There are also implications for the 
personal and contextual predictors and outcomes associated with classroom coping. Finally, this study leads to some interesting suggestions about the developmental processes that shape coping.

\section{The Conceptualization of Help Seeking}

Previous research had focused almost entirely on help seeking as skill acquired on the way to achieving self-regulated learning. Associated with this conceptualization was a search for individual-level, cognitive predictors of how and when students sought help. A common finding was that although many students had sufficient cognitive abilities to assess when help was needed and what kind of help to ask for, they still failed to effectively ask for help when they ran into trouble.

This study proposed that help seeking could be reconceptualized as a way of coping and framed within the self-system model of motivational development to broaden the self-regulatory view of help seeking to one with a more social orientation. The motivational pathways associated with help seeking as a way of coping were tested and this study found that social factors, such as teacher support, could promote or inhibit children's help seeking through the development of internal motivational resources. These findings provide a strong argument that the use of help seeking, as one way children cope with academic challenges, depends not only on knowledge about how to execute it, but on the social and motivational resources of the child. The Opposite of Help Seeking

Early help seeking research omitted any discussion of the possible antithesis of help seeking. Even recently, some of the most dynamic research investigating why 
students avoid asking for help, refers to help avoidance as "instances when a student needs help but does not ask for it" (Ryan \& Pintrich, 1997, p. 329). The literature has implicitly suggested that help avoidance is the bi-polar opposite or merely the absence of help seeking. Little, if any, research focused on how help seeking and help avoidance could be structurally related (cf. Butler, 1998) or on unique individual and contextual antecedents and consequences associated with help avoidance. Moreover, little is known about different forms of help avoidance, theoretically potentially ranging from passive not asking to active concealment.

When this study conceptualized students' responses to classroom challenges as coping, the opposite of help seeking became a very real and unique construct that could be investigated. Within the self-system model of motivational development, one way help could be avoided is through the motivated action of active concealment that help is needed. The results of the structural equation modeling in this study indicated that concealment is not the bipolar opposite of help seeking, but rather an independent, yet associated construct. In the same vein, while help seeking is associated with positive academic outcomes, like engagement, concealment is associated with negative outcomes, like disaffection.

Concealment was predicted by students' self-system resources, suggesting that it is a motivated response to academic failure. This implies that when students feel incompetent, coerced, or disconnected in school, they tend to cope with problems not only by not asking for help, but by hiding that they need help. The findings of this study also imply that when students hide that they need help, over time teachers 
respond by withdrawing their support. This pattern of behavior could lead to increasingly maladaptive responses to academic threats. Children appear to engage in a self-fulfilling prophecy so that their own behaviors may exacerbate the withdrawal of support, leading to diminished opportunities to bolster their self-system processes.

This study suggests that concealment may be just one way of coping with academic problems that could be interpreted as avoidance of help. There may be different or better measures of or operationalizations of help avoidance than were used in this study. Ryan and Pintrich (1997) developed a measure to assess avoidance of help seeking which included items like, "I don't ask questions in math class, even when I don't understand the lesson." This language suggests a passive behavior rather than an active, motivated response like concealment.

More research is needed to identify and understand the possible dimensions of help avoidance and the associated motivational processes of each. Are there ways of avoidance that are associated with better outcomes than others? How do children learn how to conceal? Could a way of avoiding help ever serve an adaptive purpose for a student? One could imagine a situation in which a student may protect his self-concept and maintain an achievement status quo by deciding not to ask an unsupportive teacher for help (which may nevertheless result in a loss of personal resources for use in future situations). Perhaps these three ways of coping; help seeking, passive avoidance, and concealment may lie along a help seeking continuum, with different functions and outcomes associated with each. At the very least, this research implies that not enough is known about what it means to "not ask for help". 


\section{Self-System Predictors of Help Seeking and Help Avoidance}

Help seeking research has consistently demonstrated that perceptions of competence and autonomy (as operationalized by goal orientation) feed into various aspects of the help seeking process (Nelson-Le Gall et al., 1989; Newman, 1990; Ryan $\&$ Pintrich, 1997). The present research is consistent with these findings. Children who perceive themselves to be effective in their schoolwork tend to ask for help more often while those who feel incompetent are more likely to conceal when help is needed.

Likewise, this research suggests that students whose reasons for participation in school are linked to external or internal pressures tend to respond by hiding their need for help, while those who have an internalized enjoyment in schoolwork tend to seek out help from their teachers.

A third self-system process, relatedness, although theorized to be an important predictor of help seeking, had not been directly examined (Newman, 2000). The finding that a sense of relatedness predicts help seeking, even above the powerful effects of perceived competence and autonomy, is a significant contribution to the field. Relatedness, the roots of which may lie in attachment, has been associated with better school adjustment and academic outcomes (Furrer \& Skinner, 2003; Kuperminc et al., 2004). Since relatedness predicts help seeking, this implies that schools, teachers, and parents can help children achieve better outcomes if they not only support perceived competence and promote a mastery goal orientation, but also help children feel comfortable and able to go to their social partners when they are having difficulties. 
An equally novel finding, that all three self-system processes predict concealment, also has broad implications. Ryan and her colleagues (Ryan \& Pintrich, 1997; Ryan et al., 1998) have provided evidence that low perceived cognitive competence and negative attitudes about help seeking are associated with intentions to avoid help. Negative attitudes associated with help seeking were hypothesized to stem from perceived exposure of incompetence and threats to self-worth. The current research offers potential expansions of this hypothesis. When children feel as if they are not liked by their teacher or that they do not belong, those feelings of threat may be amplified. Likewise, if students have low perceived relatedness, they may not feel as if they have anyone they can go to for help. Their reservoir of possible responses to threat is more limited and less flexible than students who feel as if they have multiple available sources for help.

This study did find that perceived relatedness does not predict changes in concealment over time, even when the two were correlated at concurrent time points. It is unclear why this might be the case and there is no corresponding research in the help seeking literature to offer enlightenment. The correlation between concealment in the fall and concealment in the spring was very strong $(r=.66)$, which suggests that students who started out the year using concealment to cope tended to retain that behavior. This may represent an established style of coping that does not change much. If so, it may be important for teachers to begin to work on relatedness early in the school year to keep students from adopting concealment as a preferred coping 
strategy. More research is needed in this area to understand the complexities of this relationship as it develops.

The mediated models in this study demonstrate that teacher support acts on help seeking and concealment by increasing or decreasing students' perceptions of relatedness, competence, and autonomy. This implies that children are sensitive to changes in their social context and that contexts that are supportive of children's relatedness can contribute to the frequency and type of help seeking executed in the classroom. These results also demonstrate that all three self-systems are important to children's coping and that school environments should support the development of all three motivational processes, not just competence and autonomy. This includes support for the development and maintenance of classroom relationships. Children's social and emotional selves are important in school and more attention should be given to how to support the development of strong personal resources.

\section{Other Motivational Outcomes}

The findings from this study support the hypothesis that help seeking is a way for students to remain active participants in the school environment in the face of obstacles and challenges. Help seeking is not necessarily an end in itself, but can also be an avenue to increased classroom engagement. This link was previously unexplored in the help seeking literature. The current results imply that help seeking and help avoidance may have different effects on engagement.

The act of seeking help predicts changes in behavioral engagement over the school year, but not emotional engagement. The action of raising one's hand or 
requesting help requires interaction with the classroom environment. It is possible that the emotional engagement of these students is already at a high point at the beginning of the school year, so very little change could occur. Or, it may be that by thinking about the problems they are having, students already feel committed to their work and the act of seeking help does not generate an increase in feelings of involvement. Or perhaps re-engagement when help is needed can be emotionally challenging for children. Clearly, this study cannot answer the question about why help seeking did not predict changes in emotional engagement. Additional research may shed some light on these questions.

On the other hand, when students conceal that they need help, a toll is taken on both their behavioral and emotional engagement. One hypothesis is that, obviously, hiding something seems to require active behavioral disengagement. It is not surprising that over time, students report interacting less in class. On the emotional side, students may feel increasingly alienated by their inability to get help. Eventually, students may become apathetic and become emotionally disaffected from class work.

\section{Social Context}

Although recent research has begun to address the role of environmental influences on help seeking (Ryan et al., 1998; Turner et al., 2002), overall, very little is known about the role of social contexts in help seeking behavior (Newman, 1991). It was understandable, given the search for cognitive correlates within the selfregulation paradigm, that the role of social partners would be minimized. However, a reconceptualization of help seeking placed within the self-system model of 
motivational development, explicitly requires an examination of the role of social interactions in coping (Skinner \& Wellborn, 1994). In this study, the only social context investigated was teacher support as reported by the teacher. Findings are twofold: first, social relationships play an integral part in help seeking and concealment; and second, a feedback loop exists from coping to contextual support.

Clear links were concurrently found between coping and teacher supports. Additionally, teacher support in the classroom can lead to changes in help seeking over time. This finding, in conjunction with recent developments demonstrating that when teachers perceive their role to be emotionally supportive, the negative impacts of poor self-efficacy on help seeking are ameliorated (Ryan et al., 1998), suggest that social support matters over the short and long term, in how students cope with their academic problems. The results from the mediated models suggest that teacher support has an indirect effect on coping by supporting or inhibiting the development of students' self-system processes. In this study teacher support was found to have little direct effect on coping. Yet, if anything, this provides an even stronger rationale for the importance of training teachers to be perceptive and supportive of student needs; when teachers provide support, they are creating lasting changes in the underlying motivation of students, not merely eliciting a momentary reaction from a student. This study also investigated reciprocal effects of coping on teacher support. Previously, this feedback loop had only been studied in relation to coping and parental support (Skinner \& Edge, 1998) and student engagement and teacher support (Skinner \& Belmont, 1993). The current self-regulatory model of help seeking is fairly 
unidirectional. Teachers may provide support for relationships or communicate classroom goals, but there is no mention of the responses elicited by students' help seeking attempts. Despite high stability across the school year and different reporters (teachers and students), clearly help seeking and concealment predict changes in how teachers support students. When students seek help, teachers respond by increasing their levels of support, particularly through involvement and autonomy support. When students hide their need, teachers withdraw their involvement, decrease structure, and become more coercive.

Considering that teacher support is vital to the development of intrapsychic resources and in turn, future coping, this reciprocal relationship could create an escalating positive feedback loop. The implication is that teachers naturally respond more positively over the school year to students they perceive to be more capable and have more positive interactions with (see also Nelson-Le Gall \& Scott-Jones, 1985). However, teachers have been shown to withdraw support when students display boredom or anxiety in the classroom (Furrer, Marchand, \& Skinner, 2003). Emotions, especially negative emotions, can signal underlying motivational deficits. Perhaps these same emotional cues, which signal disaffection, can help teachers diagnose students who are likely to conceal their scholastic problems. This suggests an intervention in which teachers must make a conscious effort to diagnose when help is necessary and to engage students who do not seek them out. 


\section{Development}

Most help seeking research utilizing a cross-sectional design has found age differences in the frequency and type of help seeking. However, the present study uncovered no significant age differences in the effects of the self-systems or teacher support on coping. This study presented underlying motivational resources as one possible developing process that could account for age differences in help seeking and concealment. It was hypothesized that different self-systems may be more salient in coping at different ages. Data from this study did not support this hypothesis. On the contrary, the mean levels of self-system processes were fairly stable across grades and within the school year. Perhaps the most telling change was a decrease during the transition to middle school in coping, the self-systems, and teacher support. It is possible that the self-system model does not vary with age and that the self-systems processes are equally important to coping behavior at every age.

Thus far, when research has found age differences, there has been little accompanying empirical investigation about what is developing and creating these differences. Eccles (1999) points to changes in cognitive competencies, perspective taking, and social comparison as major developmental shifts during middle childhood. Any of these processes could possibly shape the development of coping. Theoretical work is needed to specify how these developmental shifts might influence willingness to seek help or a desire to conceal. It would be useful if future research would directly examine the developmental shift thought to be responsible (when it comes "on line") and see if a corresponding shift in help seeking and concealment can be detected. If 
educators and psychologists seek to develop age-appropriate interventions that optimize student experiences, help seeking researchers would be well served to get a handle on what is actually developing during middle childhood that impacts academic coping. Otherwise, interventions are likely to have temporary benefits that do not facilitate the development of independent, flexible problem-solvers.

\section{Future Directions}

The motivational model utilized in this study suggests a program of research to examine help seeking and concealment as motivated ways of coping. The limitations and implications of this study lead to recommendations for future research research regarding avoidance ways of coping, special populations, capturing developmental processes, additional social contexts, and the transition to middle school that might serve to broaden our understanding of children's academic coping.

\section{Avoidance}

Future research should focus on expanding knowledge about the etiology of help avoidance and whether it can serve an adaptive, or protective, function. At present, little is known about the contexts that could make concealing a need for help adaptive. There may be contexts or situations that do not just undermine help seeking, but actually promote concealment. For example, if the teacher makes a child feel stupid or inferior for not understanding class material, that child may respond with attempts to protect his self-esteem by not exposing his confusion. In this case, it may very well be more aversive for the child to put himself on the line and ask a question than to attempt to deal with challenges on his or her own. In the short term, more 
damage could be done via a negative response to a question than by not drawing attention to oneself or preventing any interaction.

In the same vein, future studies can focus on the basis for the seeming stability of avoidant behaviors. The current study indicated that there was little change in concealment over the course of the school year. If these findings are replicated, it may turn out that is difficult to predict changes in concealment because of its high stability. As a result, researchers interested in finding out the variables that influence changes in concealment may have a difficult time detecting antecedents of avoidance. Likewise, it may be difficult to track down the origins or roots of avoidance and the processes through which these became incorporated into a child's repertoire as a preferred way of coping. If these patterns are set at an early age, even very high levels of teacher support may not result in changes in concealment.

Clearly, this is an area that is ripe for elaboration. It is difficult to develop interventions to help children cope better without fully describing the range of behaviors that might be avoidant, the level of stability or change in avoidance, the contextual influences that shape help avoidance, and whether avoidance can ever serve a protective function.

\section{Diverse populations}

How might help seeking and concealment look in a more diverse population? A consistent theme throughout this discussion has been the homogeneity of this study's sample. It is unknown if and how these findings might pertain to other groups of children. Although Nelson-Le Gall and her colleagues $(1985,1986)$ conducted 
some descriptive help seeking research with black children, no studies have had a racially diverse sample with which to look for similarities and differences among groups in help seeking and avoidance. Future research should consider that children of different socioeconomic status or members of other ethnic or racial groups may have varying experiences within the school context or hold different cultural values that could affect their motivational resources and/or coping behaviors.

Research has shown that children living in low SES households and African American and Hispanic children are at high risk for under performing at school (Becker \& Luthar, 2002; Nelson, Knight, Kagan, \& Gumbiner, 1981; Norman, Ault, Charles, Bentz, \& Meskimen, 2001). In an effort to explain and address the gap in achievement between dominant and minority groups, researchers have examined a number of contextual and personal variables. This achievement gap has been associated with differences in home and school resources, the treatment of minority children as deviant, and teacher expectations (among other things) (Garcia Coll, Crnic, Lamberty, Wasik, Jenkins, Garcia, et al., 1996). It is possible that part of the achievement gap could be related to differences in children's coping. If so, educators could target interventions to help children develop positive ways of coping as one way to address the achievement gap.

Research is needed to determine how cultural values translate into coping behaviors. Perhaps in some cultures, it is not acceptable to ask an adult for help, while in others, seeking help is a highly valued way of coping. Children are socialized in cultural values, beliefs, and expectations, which may not be congruent with those of a 
school environment (Garcia Coll et al., 1996). When stressful situations happen at school, minority children must appraise the situation and cope accordingly depending on a different set of rules than they are accustomed to. This could lead to a restriction in coping options. The fit of the child's culture with the independent orientation of Western schools may be better or worse for some groups. For example, African American children may respond to stress in more active and assertive ways, whereas Mexican American children may respond in more passive ways (Munsch \& Wampler, 1993).

Research on teacher expectations has also shown that minority children may be the victims of lowered expectations (Baron, Tom, \& Cooper, 1985). Some teachers, whether consciously or not, tend to provide fewer challenges to minority students. At the same time, one could imagine that teachers may provide unsolicited help or spend less time in instructive aid to students they perceive as less able. The combination of expectations of failure coupled with insufficient help, could lead to an increase in concealment on the part of students. Classroom interactions that inhibit academic progress and are incongruent with a child's values could undermine the perceived competence, autonomy, and relatedness of students. If empirical evidence is found to support the idea that help seeking varies among different groups, steps could be taken to bolster the motivational resources of these students through the modification of contextual supports and greater sensitivity in school-family partnerships.

Additional research is also needed to clarify the role that SES plays in school coping behavior. Patterns of relatedness to parents are associated with feelings of 
relatedness in other relationships, such as with teachers (Lynch \& Ciccheti, 1991). The stress placed on families living in poverty (often associated with a single, working parent) may leave children with fewer people to go to during times of trouble. By the time children enter school, this pattern of not feeling as if others are available, coupled with the social stigma of poverty (manifested by free lunch, etc.), may inhibit the formation of positive school relationships. Research into how classroom size (often larger in poor neighborhoods), perceptions of social distance, and working models of interpersonal availability influence classroom relationships and in turn, coping, is necessary. Children living in poverty already enter school at a disadvantage. If their academic coping is also compromised and may be remedied through teacher support, steps should be taken to level the playing field.

The face of America's school children is changing and research needs to address the needs and experiences of all children. By the year 2020, one-half of American children between the ages of 5 and 14 will not be Caucasian (Cappell \& Lamar, 1999). Currently, $19 \%$ of children live below the poverty line and have greater nutritional challenges, less parental monitoring, live in more dangerous neighborhoods, and attend schools with fewer resources than wealthier children. Knowing that minority and poor children experience greater stress at school and achieve less should motivate educators and researchers to create environments where all children feel supported. Helping children cope more effectively with problems in school is a small, but important step. 


\section{Micro-Developmental Processes}

Another recommendation for future research is to design studies that examine more discrete time periods that provide windows into the formation of relationships between students and teachers. The correlations between the two time points for most constructs in this study were high, suggesting that a stable pattern was formed before the first measurement point. The first 6 weeks of school may be a crucial time during which teachers and students get to know each other and understand how the system works. Perhaps teachers find that their preconceptions of children are confirmed. Perhaps students have a single bad experience with the teacher that solidifies their expectations. It is important to understand the interactions that teach a child that it is safe to ask a question or it is better to conceal. Maybe the real developmental time of the formation of the classroom relationship is in minutes and days, not weeks. To truly understand the formation of these classroom perceptions, it is vital to conduct a more in-depth mapping of what leads the system to a stable state.

\section{Expanding the Social Context}

Many contexts exist for children's development, including, but not limited to immediate social partners, school, socio-economic status, familial culture, and public policy (Bronfennbrenner \& Morris, 1998). A developmental systems perspective would contend that coping is produced by the interactions among a child, family, peers, school, and community (Pianta \& Walsh, 1998). This suggests that it is important to understand the influence of other social partners, such as peers, on children's help seeking or concealment. This study only examined the teacher-student 
relationship, but a more in-depth description of classroom help seeking should include peers as targets of help. Peer reactions to help seeking may also inhibit or promote coping, as could the values of the child's immediate peer group.

Additional measures of the teacher context, such as teachers' perceptions of their roles (Ryan et al., 1998), should be included in future studies. Specifically, predictors of teacher behavior and support have not been sufficiently researched. This study suggested that student coping behavior is a factor that shapes teacher support. It is unknown what else leads a teacher to withdraw or provide support. Are there structural characteristics such as class size or desk location that make a difference? Or do personal characteristics of the teacher, such as personality or role perceptions, matter more? Maybe teacher preconceptions, as mentioned earlier, factor strongly into early supportive or non-supportive behaviors. Teachers are a constant and influential part of a child's life, particularly in middle childhood. Their role in children's coping should be better understood.

\section{Transition to Middle School}

Descriptive information from this study suggests that there is a general drop in help seeking and associated self-system resources and teacher support when students start middle school. Likewise, concealment increases slightly. Other research suggests that as students get older, attitudes associated with the perceived costs of help seeking, performance goals, and low achievement factor strongly into not seeking help (Newman, 1990; Newman \& Schwager, 1995). 
The transition to middle school, when accompanied by a change in the structure of classes, has been associated with increased psychological distress, decreased academic performance, and motivational decline (Eccles, 1999). Good et al. (1987) found that when students enter middle school, there is a brief increase in questioning for low achievers, but that most questions are procedural and factual. However, as students progress, low achievers tend to drop off in their questioning. These researchers suggested that low achievers may initially view a new school as a fresh start and be motivated to try to obtain information, yet the frequency of their questions may lead to negative teacher and peer feedback, resulting in a sharp decrease in help seeking. For early adolescents, in the face of teacher and peer rejection, concealment could be an adaptive behavior. For the most part, changes in help seeking have not been examined directly in relation to the school transition.

Additional research is needed to understand how contextual factors such as changes in class structure and multiple teachers influence help seeking. Eccles (1999) suggests that the transition to middle school results in a mismatch between students' motivational needs (for example, an increase in the value of autonomy) and their environment. The ability to remain engaged in school could be particularly crucial during transitions. It would be useful to know how academic coping in the form of help seeking or avoidance may support or inhibit the development of student motivational resources during this time of turbulence. Likewise, the utilization of alternative social partners, such as peers, to gain academic support may shift. These compensatory efforts have not yet been examined. Finally, the transition may widen 
the gap between teacher report of support and students' perceptions of support. This may be an area of particular sensitivity to adolescents' help seeking, particularly when considering how teachers may adjust their classroom provision of support to influence student motivational resources.

\section{Conclusion}

In conclusion, this study was conducted to extend the current view of help seeking as a strategy of self-regulated learning to one with a more social orientation. It focused on describing a possible "opposite" of help seeking, examining motivational outcomes of classroom coping, the motivational pathways associated with help seeking and help avoidance, the reciprocal relationships between coping and teacher support, and developmental processes underlying these ways of coping.

In general, this study provided support for a conceptualization of help seeking and help avoidance as unique, motivated ways of coping with academic troubles. For the first time, empirical evidence was found that links help seeking and concealment to classroom engagement. Likewise, the self-system of relatedness was included as an important predictor of coping, and it proved to have powerful effects beyond the two self-system processes (competence and autonomy) normally associated with help seeking.

The inclusion of an "objective" measure of classroom context, teacher support, provided evidence that student coping is affected by their environment. The selfsystem processes were suggested as a possible pathway through which teachers may influence coping. Further, the ways that children cope in the classroom can influence 
how teachers respond to them in future academic situations. Finally, although this study did not shed much light on the developmental processes associated with help seeking and avoidance, it did indicate that student self-system processes and teacher support are important predictors of coping all across middle childhood. 
Table 1
Definitions of Help Seeking

\begin{tabular}{|c|c|c|}
\hline Source & $\begin{array}{c}\text { Help Seeking } \\
\text { Conceptualization }\end{array}$ & Definition \\
\hline \multirow[t]{2}{*}{$\begin{array}{l}\text { Nelson-Le Gall } \\
\text { (1981) }\end{array}$} & Instrumental Help Seeking & $\begin{array}{l}\text { The activity of finding out about the environment } \\
\text { either through watching others, asking for } \\
\text { information, or engaging in information acquisition } \\
\text { with others. }\end{array}$ \\
\hline & Executive Help Seeking & $\begin{array}{l}\text { Those instances in which the child's intention is to } \\
\text { have someone else solve a problem or attain a goal } \\
\text { on his or her behalf. Types of help sought are not } \\
\text { needed to solve a problem. }\end{array}$ \\
\hline $\begin{array}{l}\text { Newman }(1991 \\
1994,1998)\end{array}$ & Adaptive Help Seeking & $\begin{array}{l}\text { Involves the student (1) being aware of task } \\
\text { difficulty (2) considering all available information } \\
\text { in deciding the necessity of the request, the content } \\
\text { or form of the request, the target of the request ( } 3 \text { ) } \\
\text { expressing the request for help in a way that is most } \\
\text { suitable to the particular circumstances (4) } \\
\text { processing the help that is received in such a way } \\
\text { that the probability of success in subsequent help } \\
\text { seeking attempts is optimized. }\end{array}$ \\
\hline \multirow[t]{3}{*}{ Nadler (1997) } & Autonomous Help Seeking & $\begin{array}{l}\text { Seeking others' assistance to enable one to solve a } \\
\text { problem on own. Predicated on motivation to solve } \\
\text { problem and belief one is able to do so. Help is } \\
\text { means to an end. }\end{array}$ \\
\hline & Dependent Help Seeking & Seeking help out of passivity and lack of self- \\
\hline & & efficacy, help is ends in itself. \\
\hline \multirow[t]{2}{*}{ Butler (1998) } & Autonomous Help Seeking & $\begin{array}{l}\text { Help seeking behavior initiated after pupil spends } \\
\text { time trying to solve problem along, is expressed in } \\
\text { requests for hints that clarify strategies and results } \\
\text { in improved capacity to solve subsequent problems } \\
\text { independently. }\end{array}$ \\
\hline & $\begin{array}{l}\text { Avoidant-covert Help } \\
\text { Seeking }\end{array}$ & Seeking covert help, like cheating. \\
\hline Arbreton (1998) & Excessive Help Seeking & $\begin{array}{l}\text { Seeking help prior to any initial independent } \\
\text { attempts at problem mastery. }\end{array}$ \\
\hline
\end{tabular}




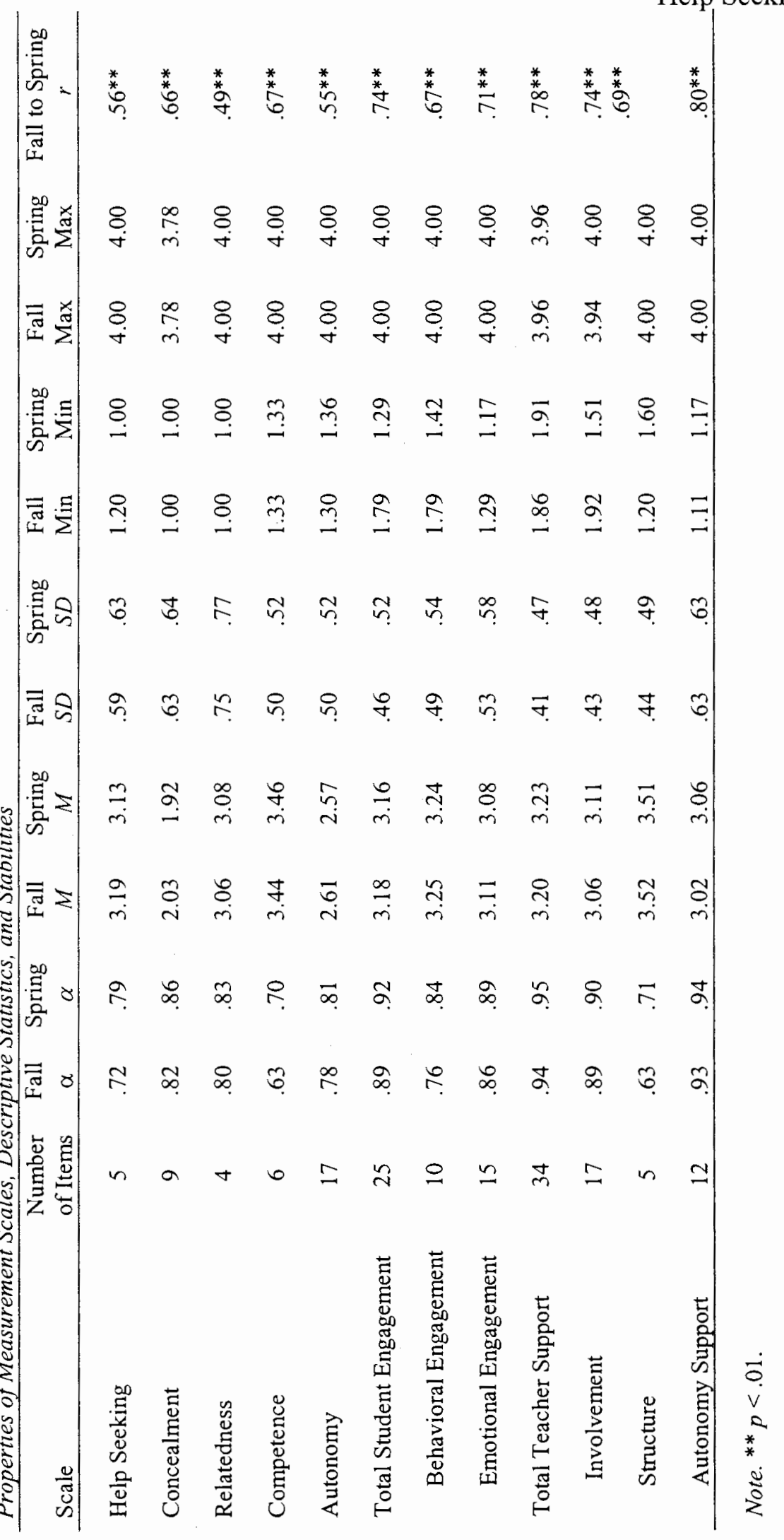


Help Seeking 119

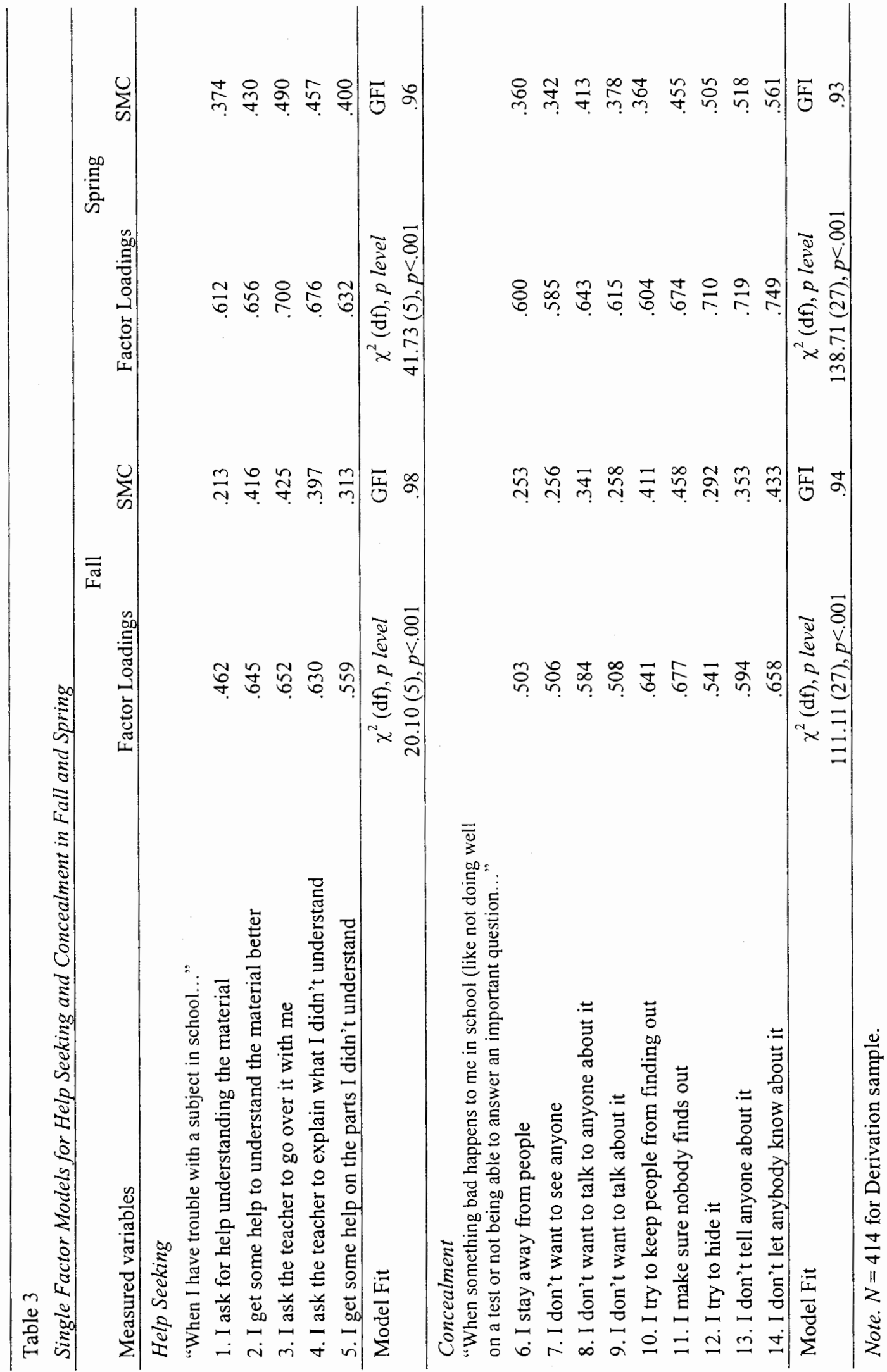




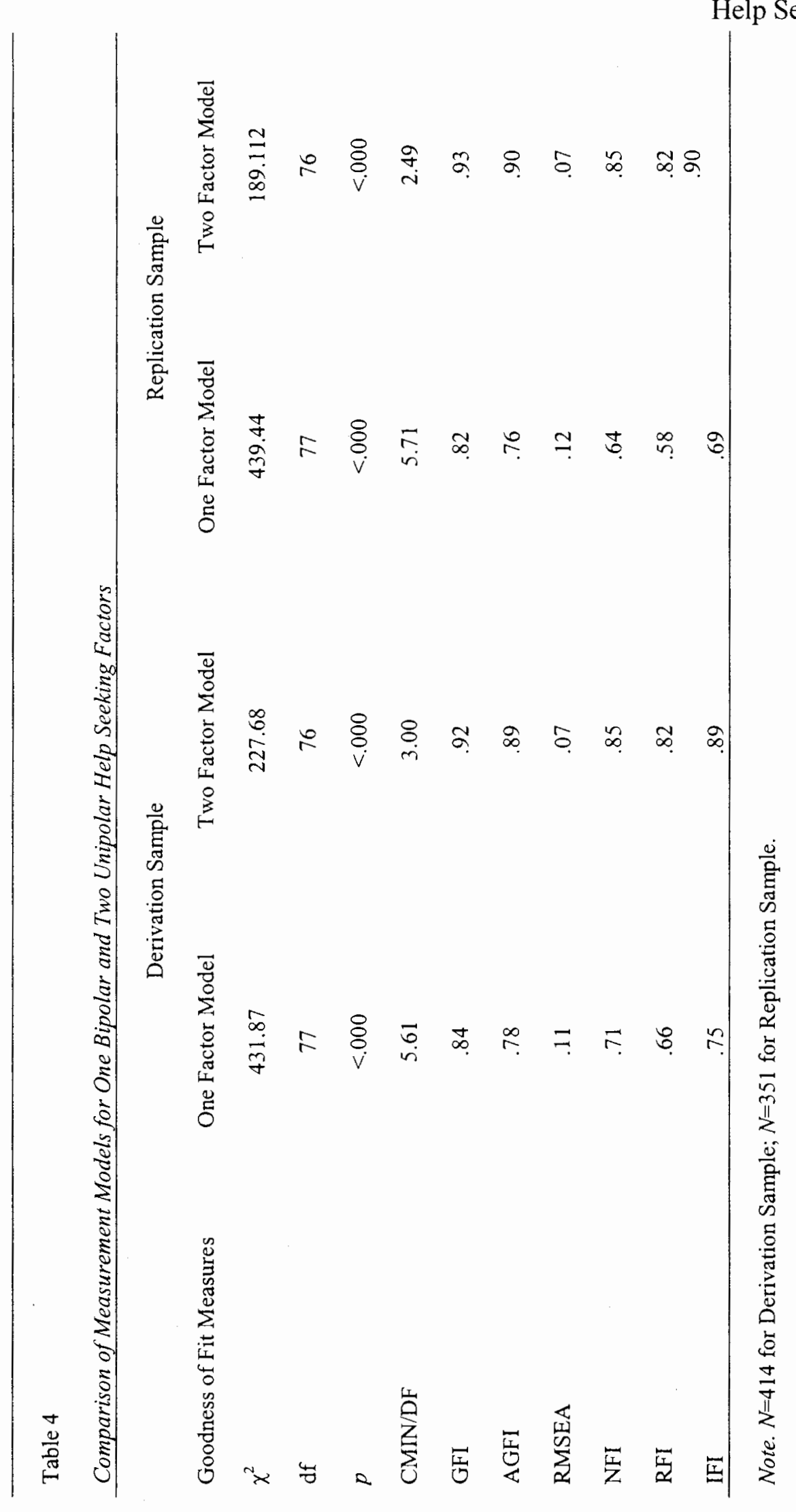




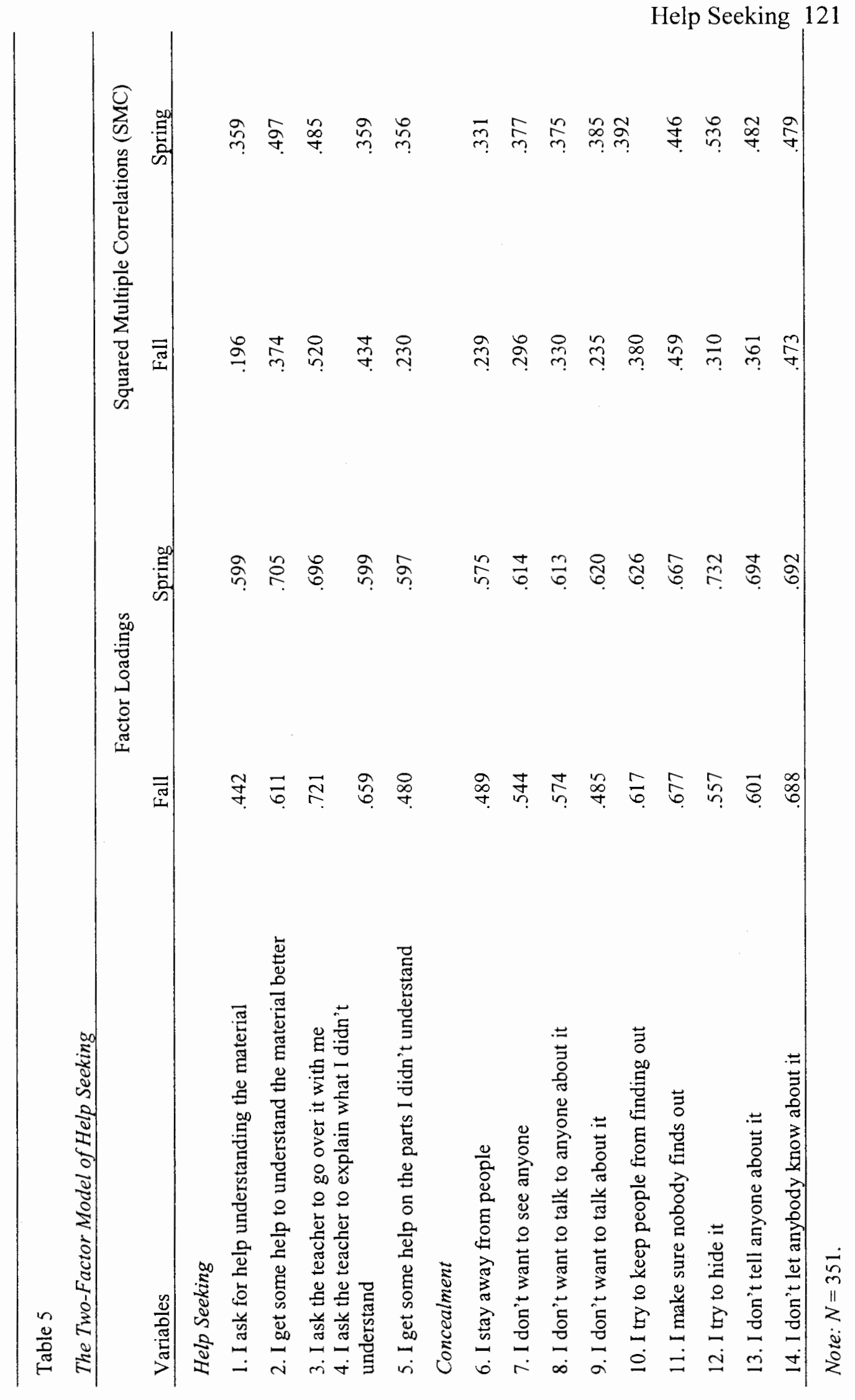


Help Seeking 122
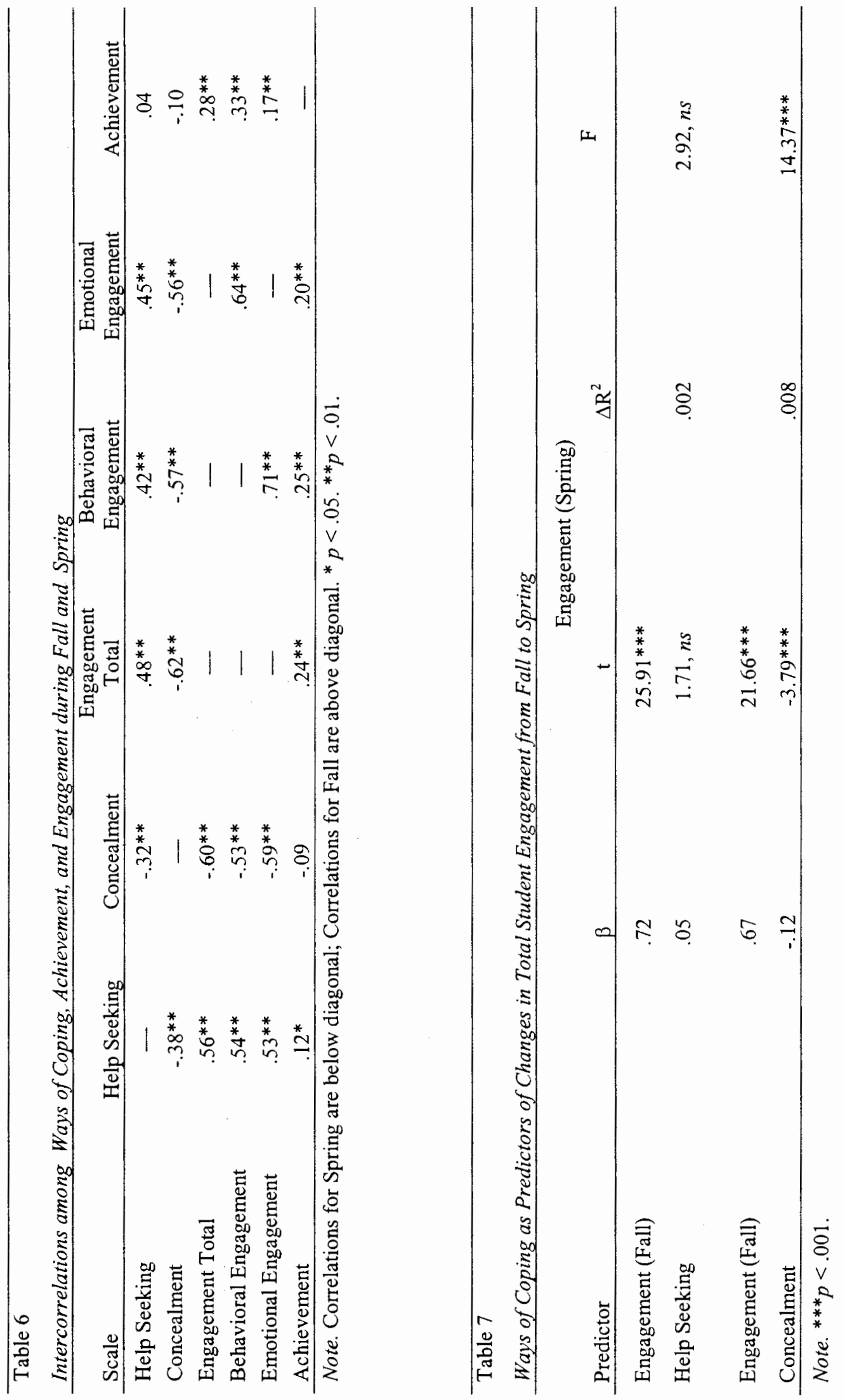
Help Seeking 123

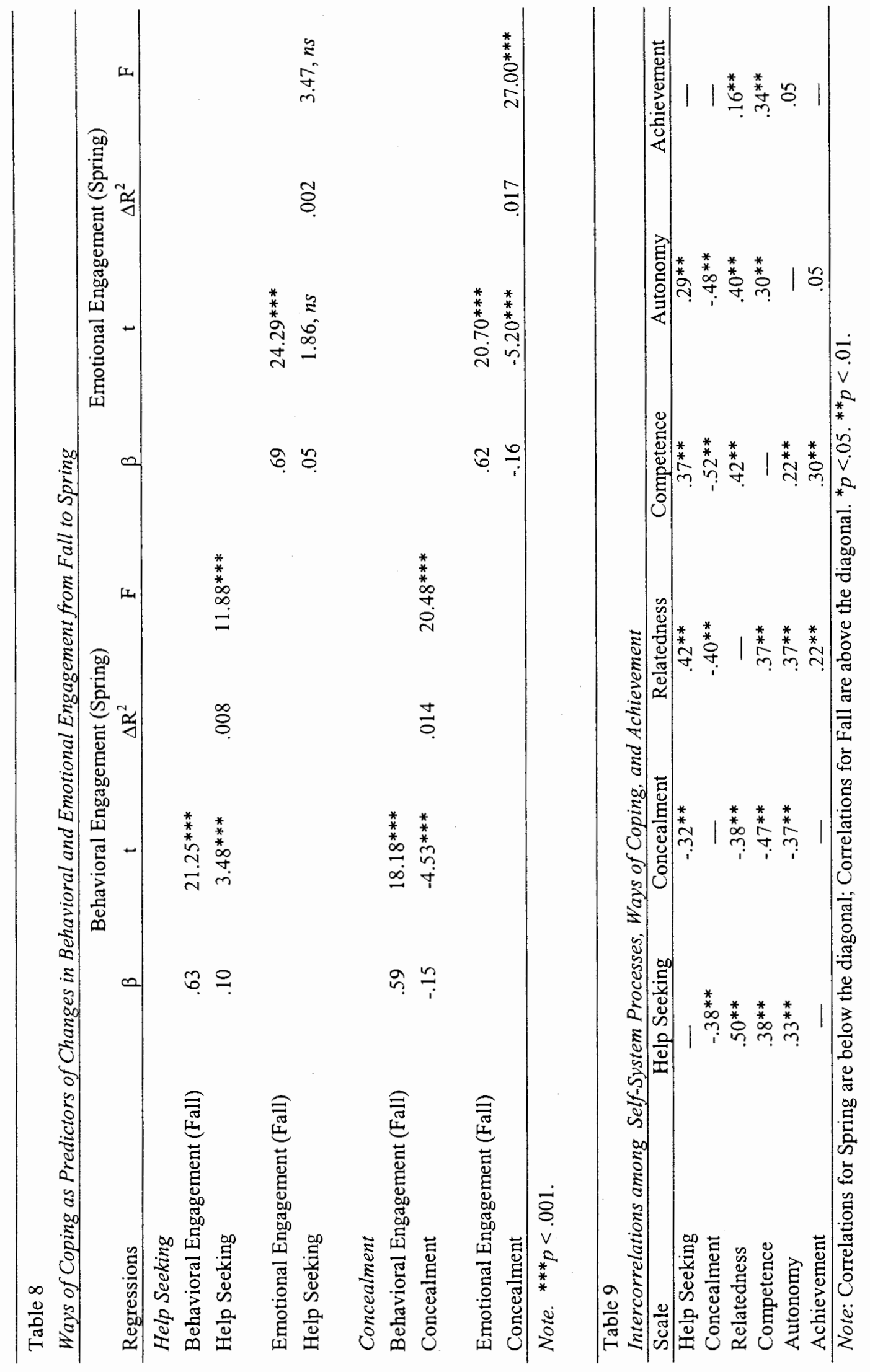


Help Seeking 124

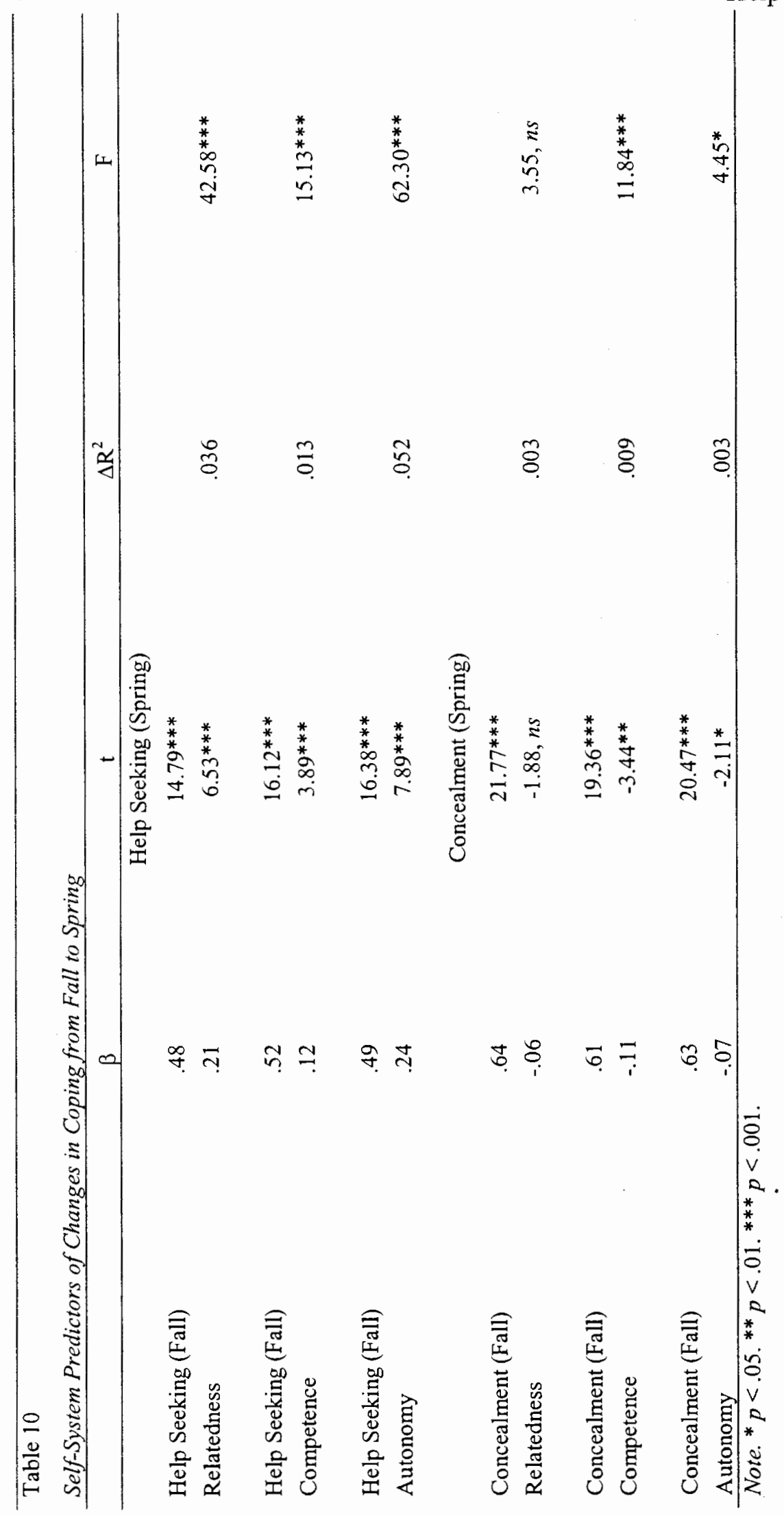



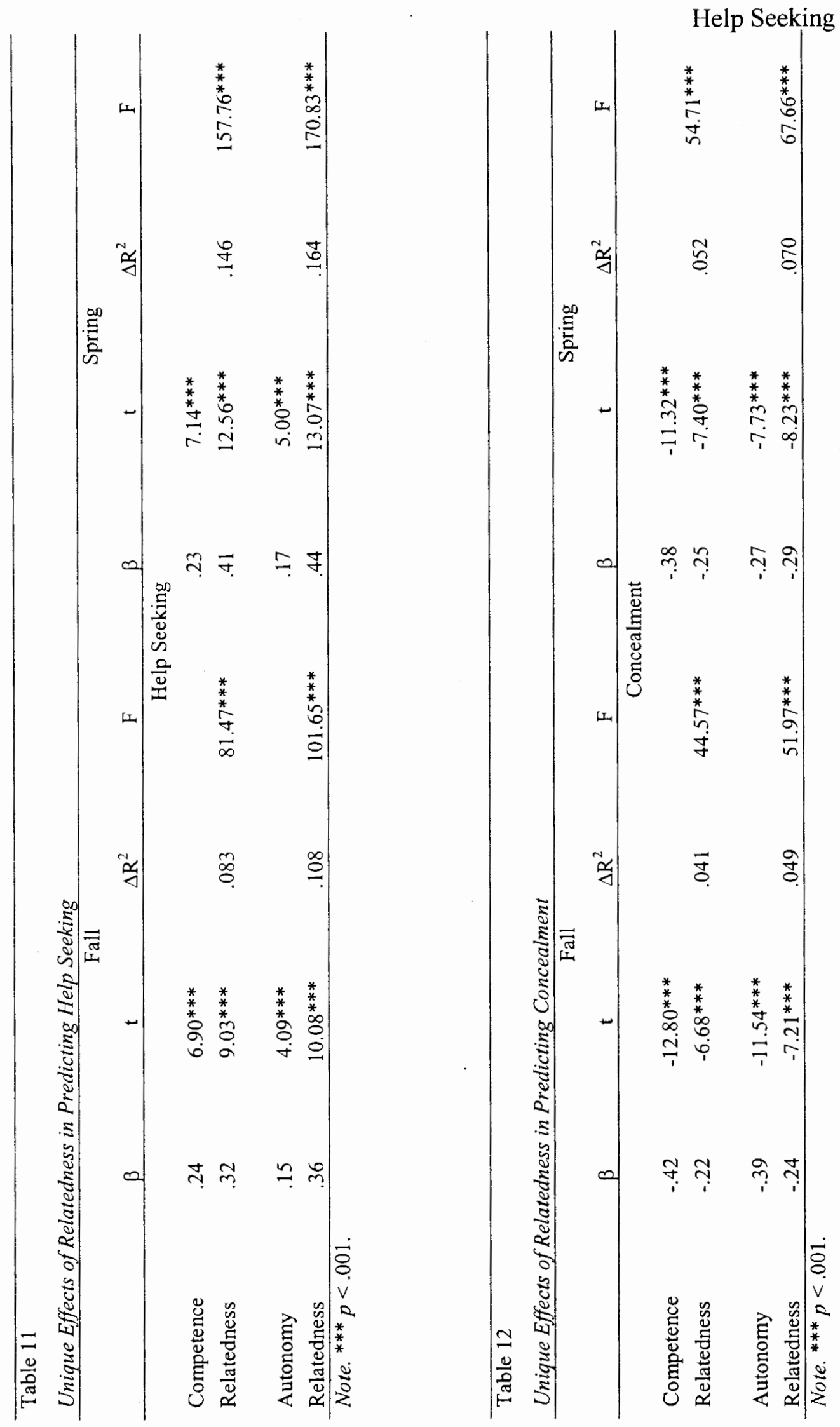


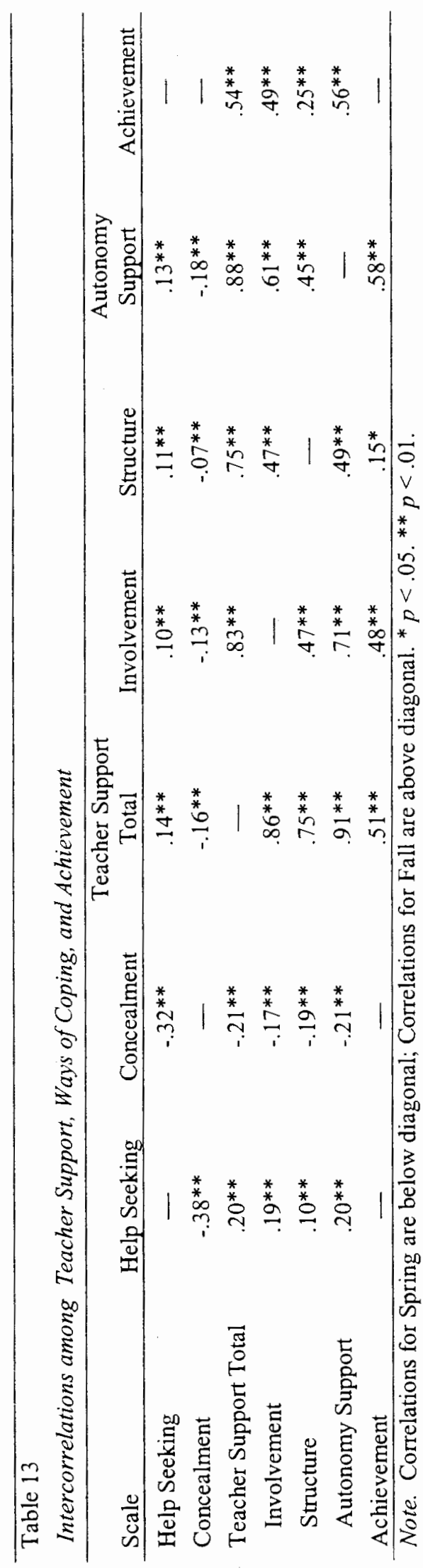

Help Seeking 126

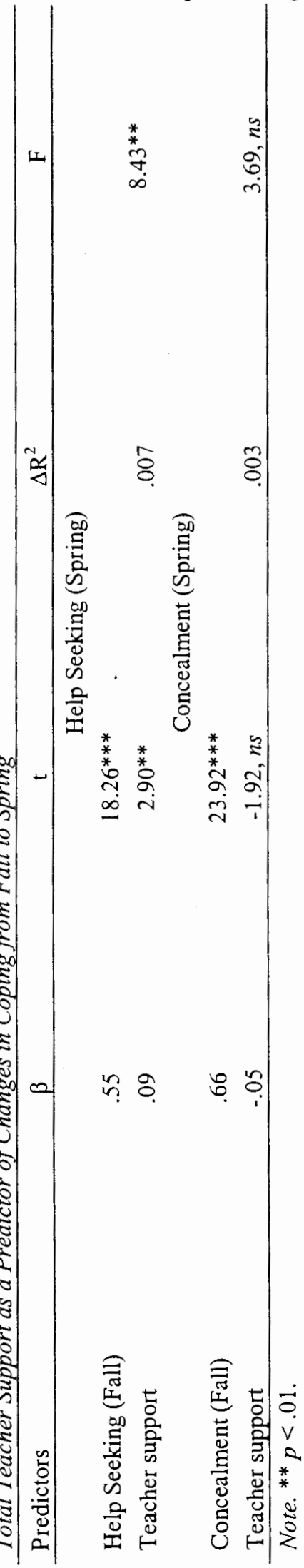




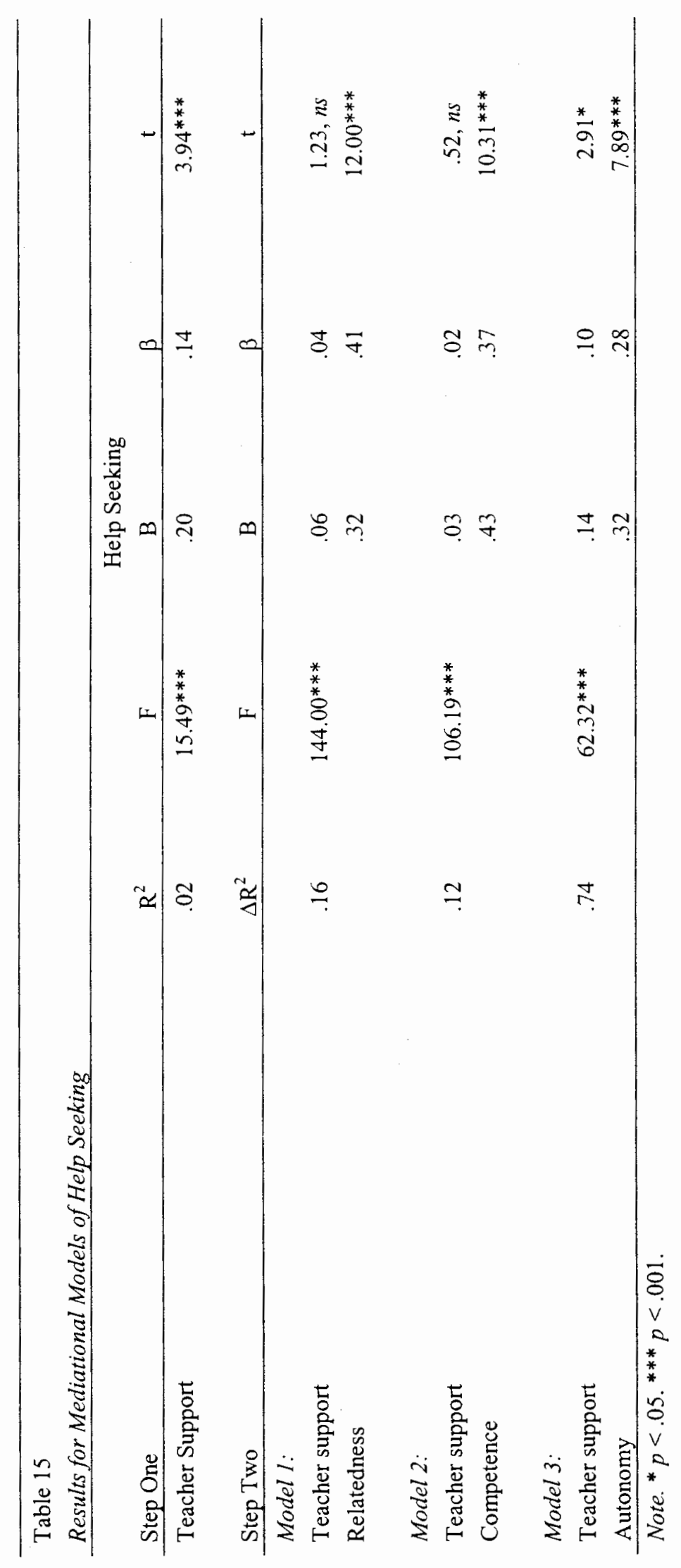

Help Seeking 127 


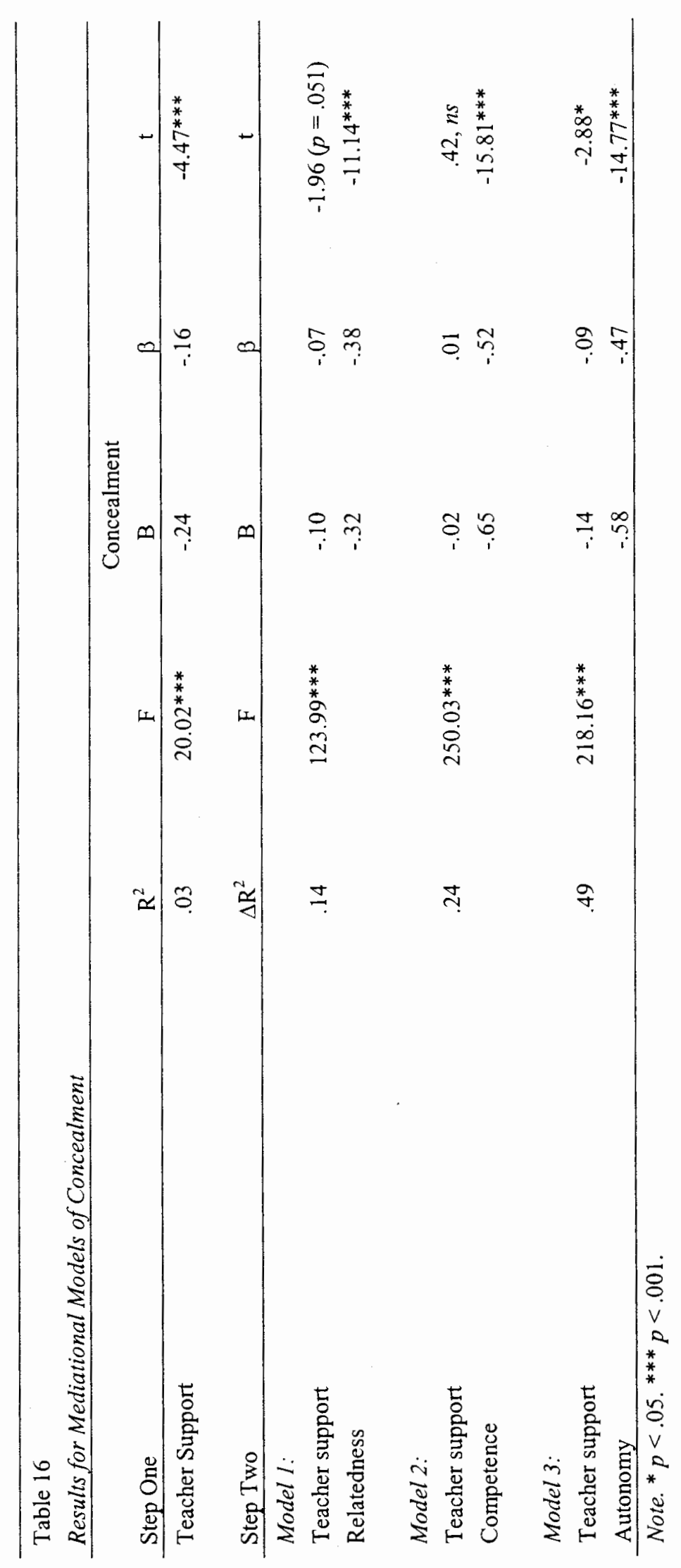

Help Seeking 128 
Help Seeking 129

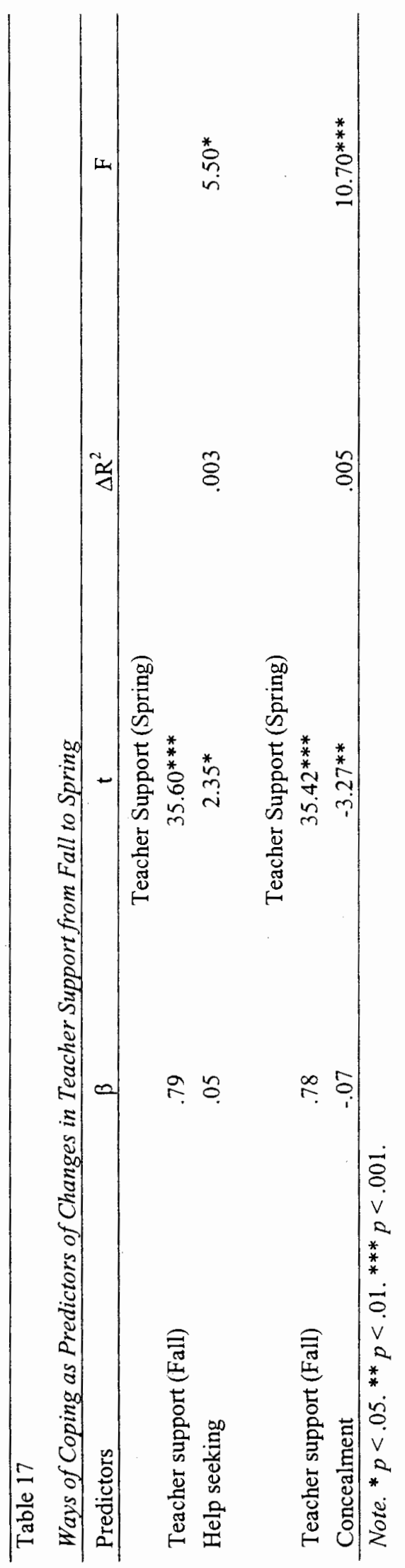




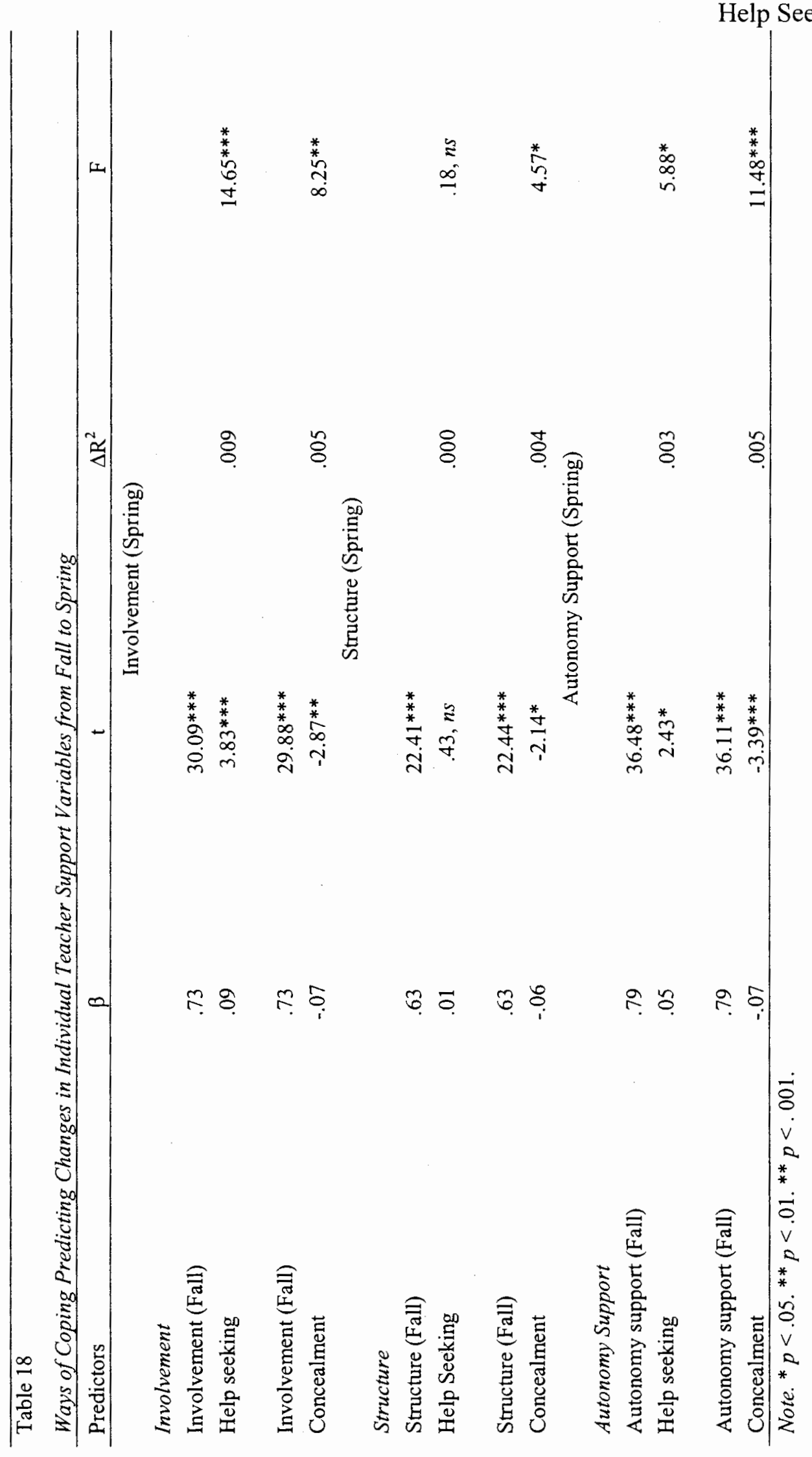




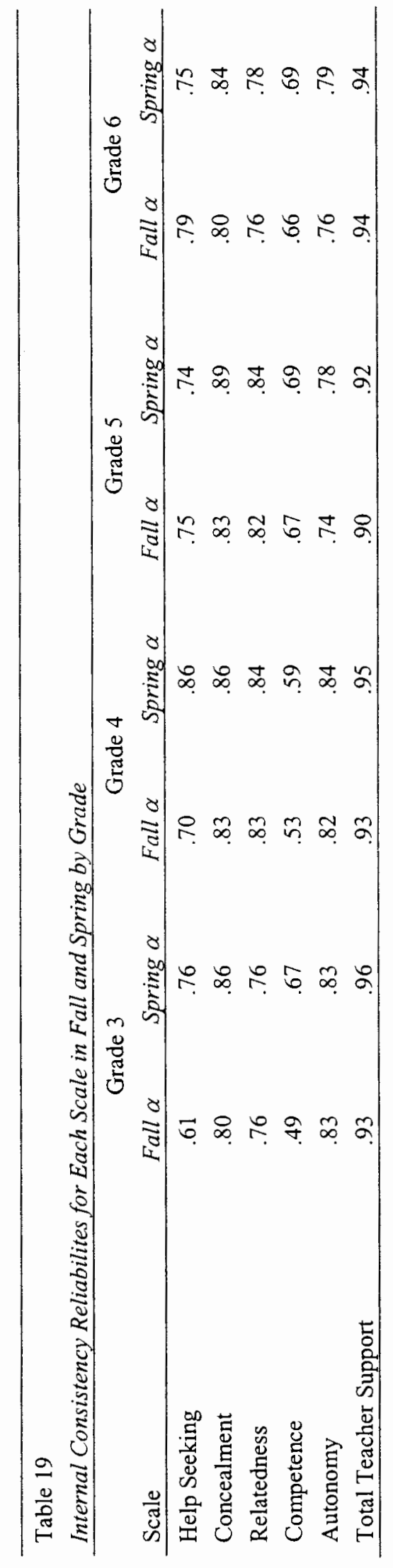

Help Seeking 131

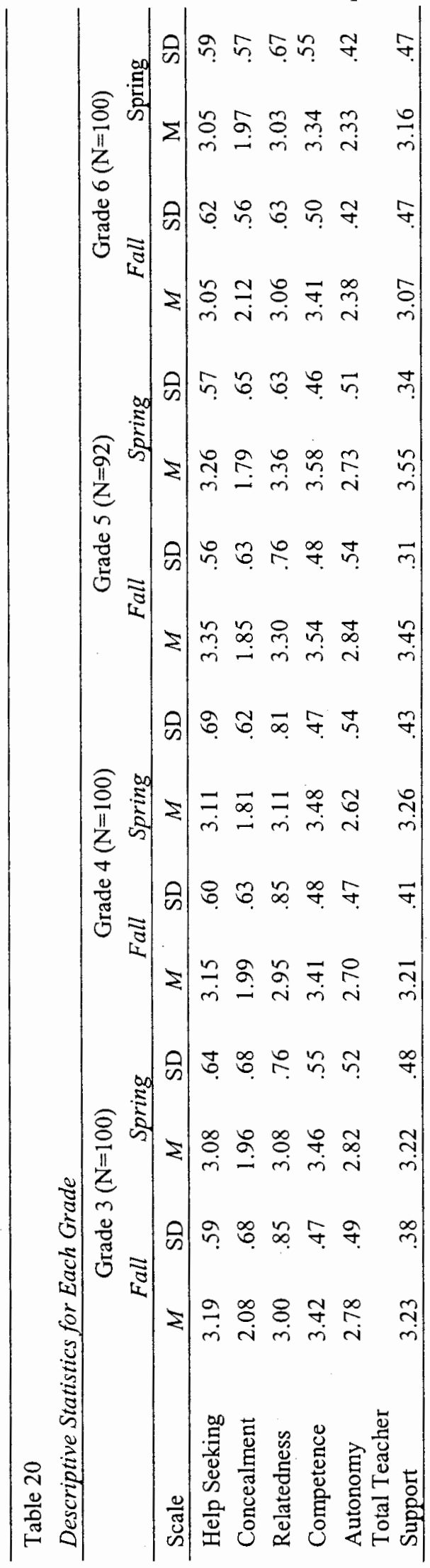




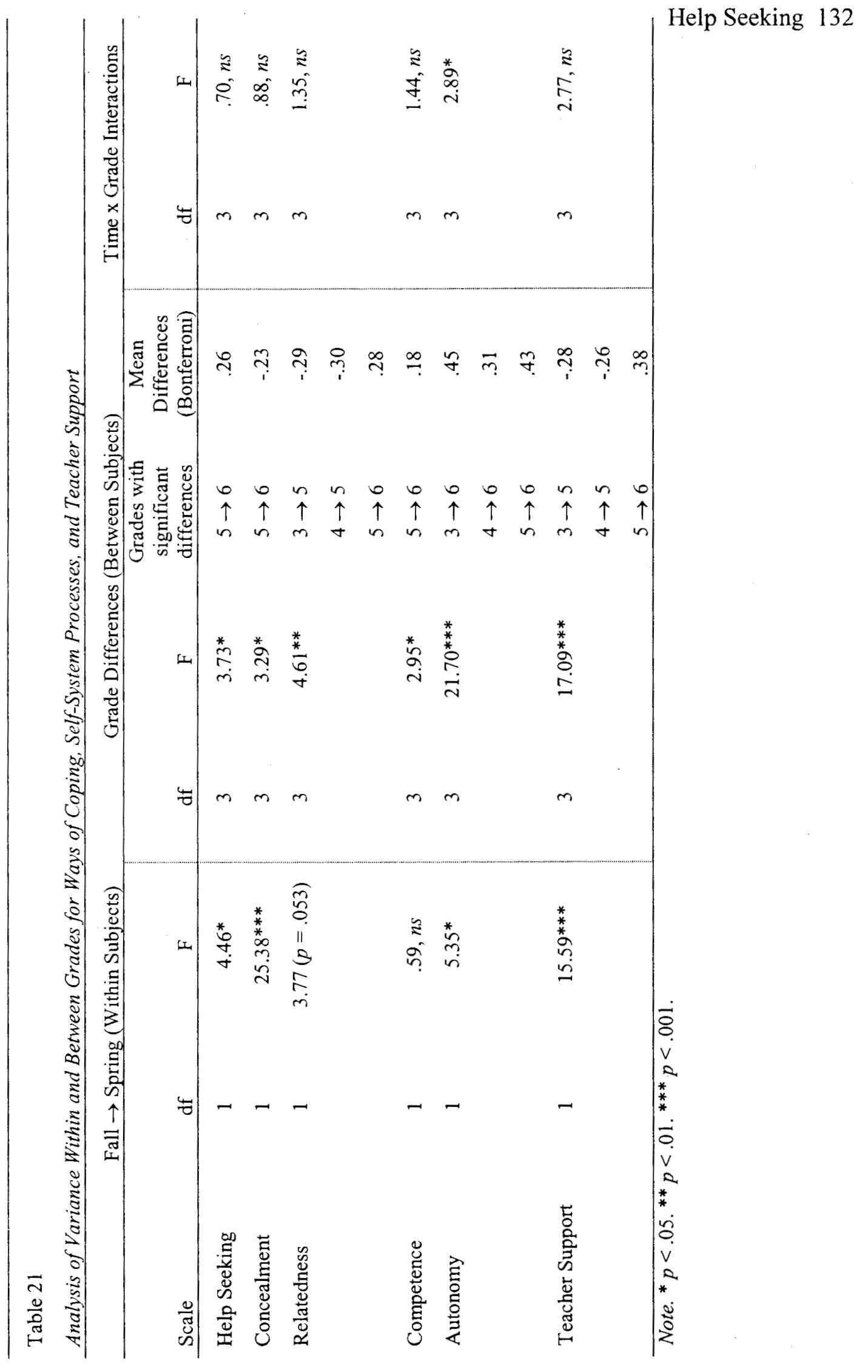



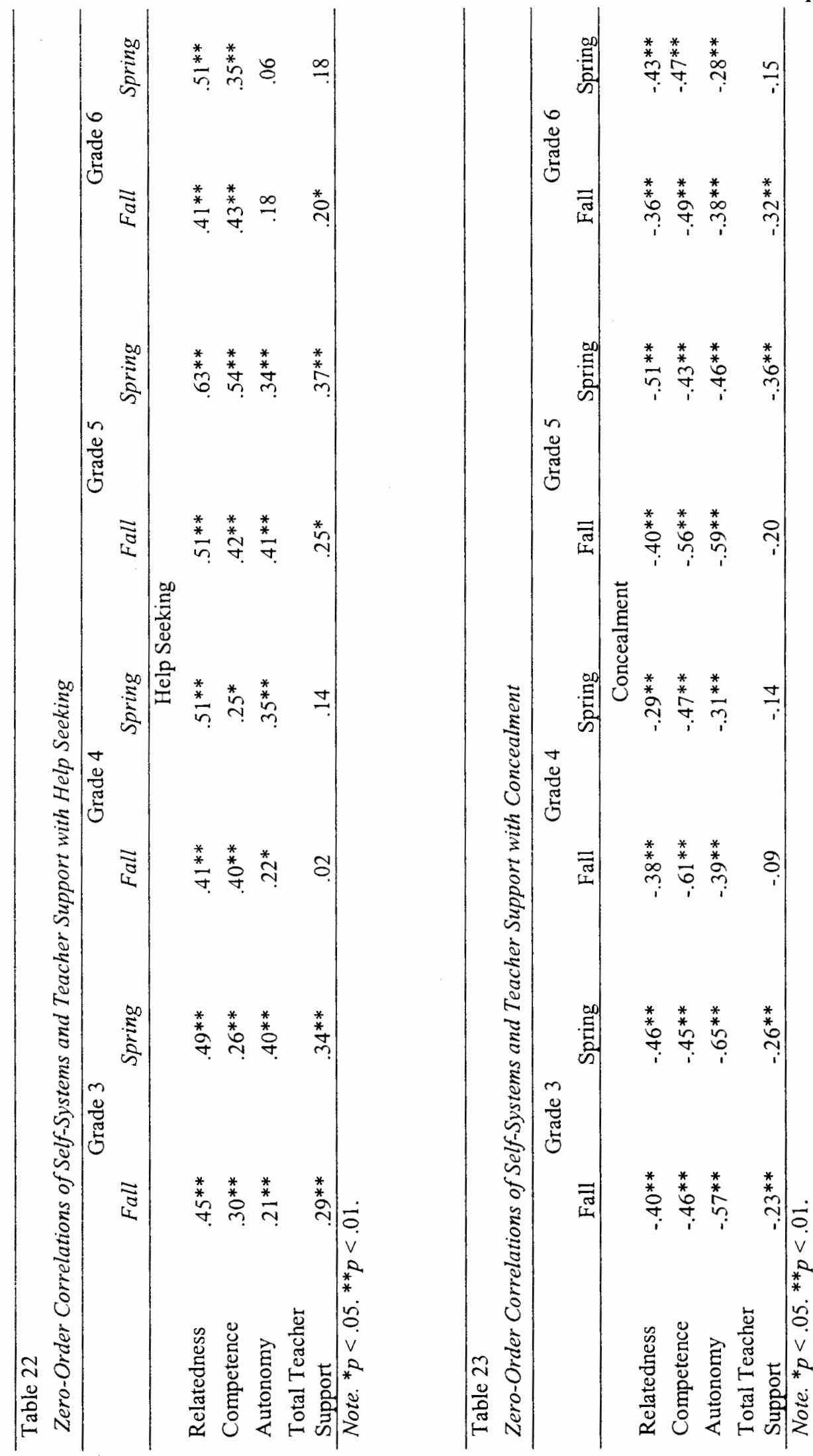


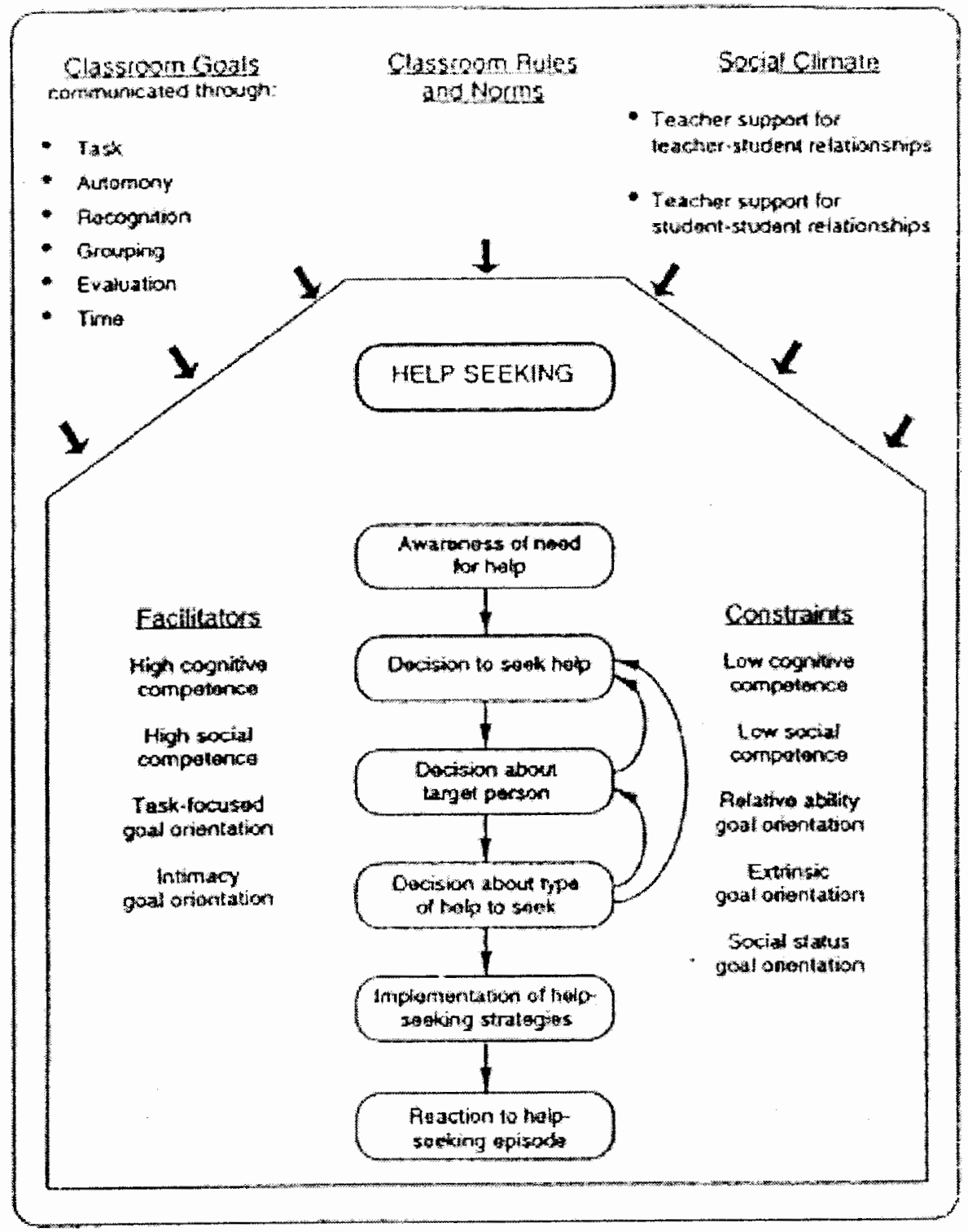

Figure 1. Help Seeking Model. 


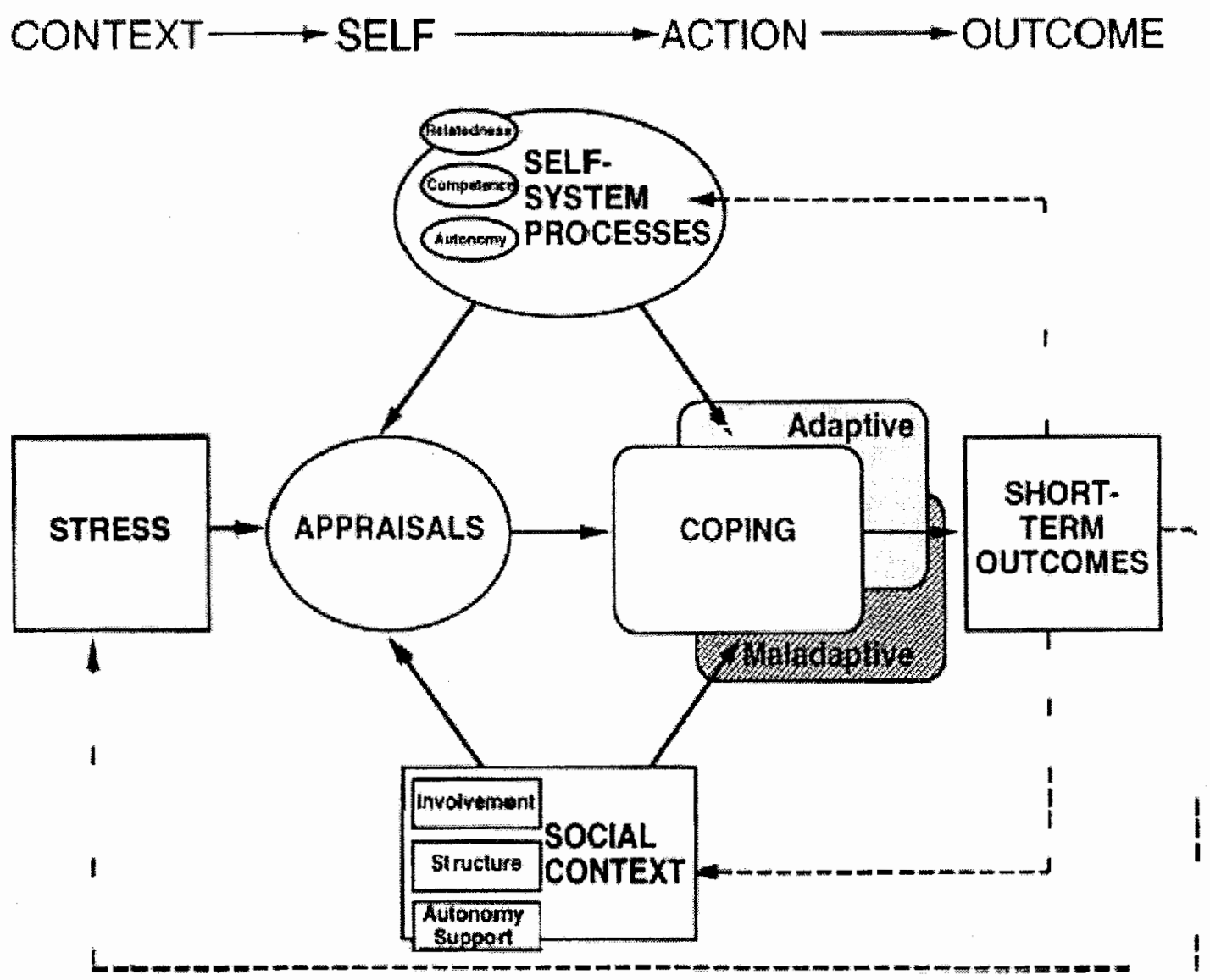

Figure 2. Self-System Model of Motivational Development. 
Help Seeking 136

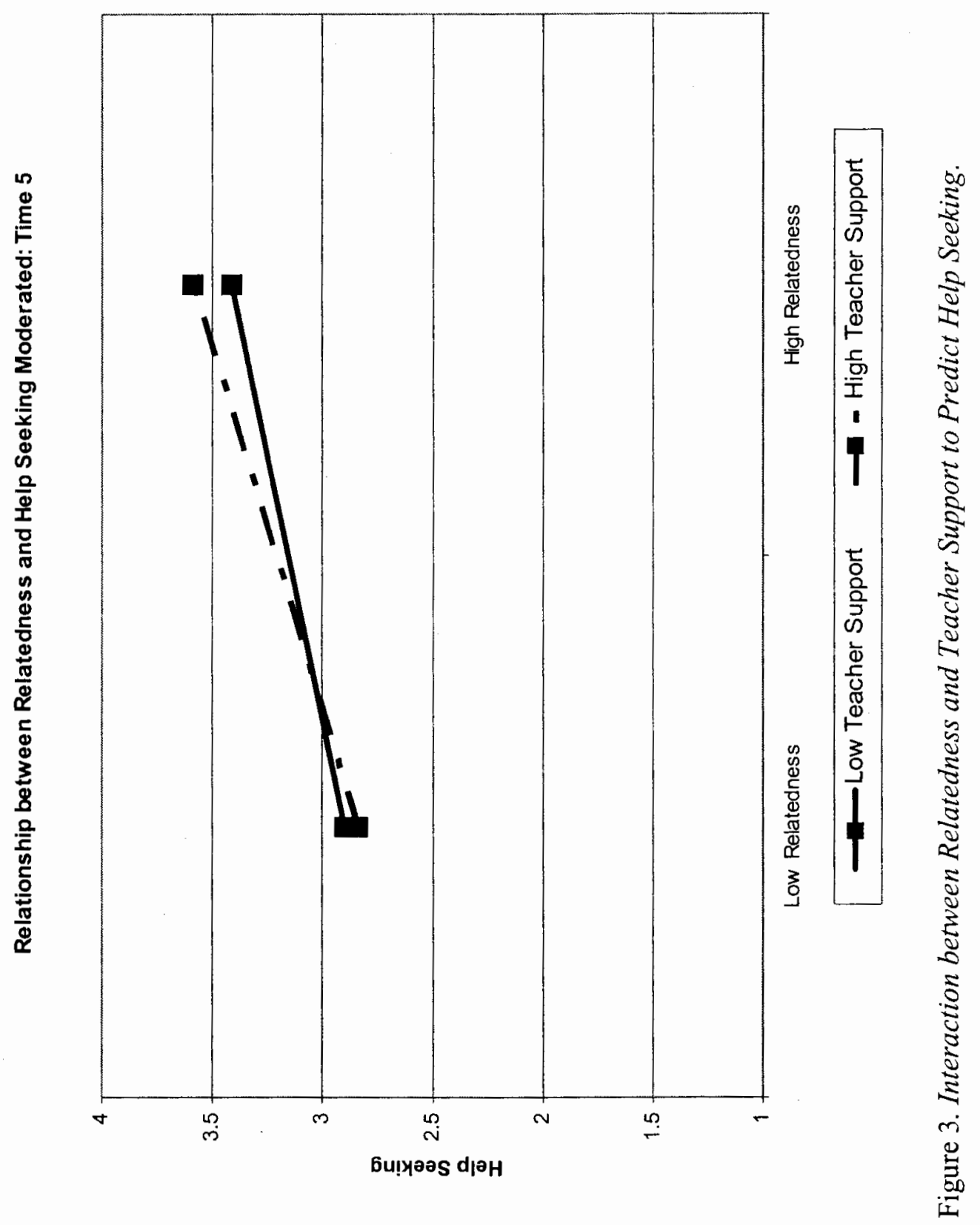


Help Seeking 137

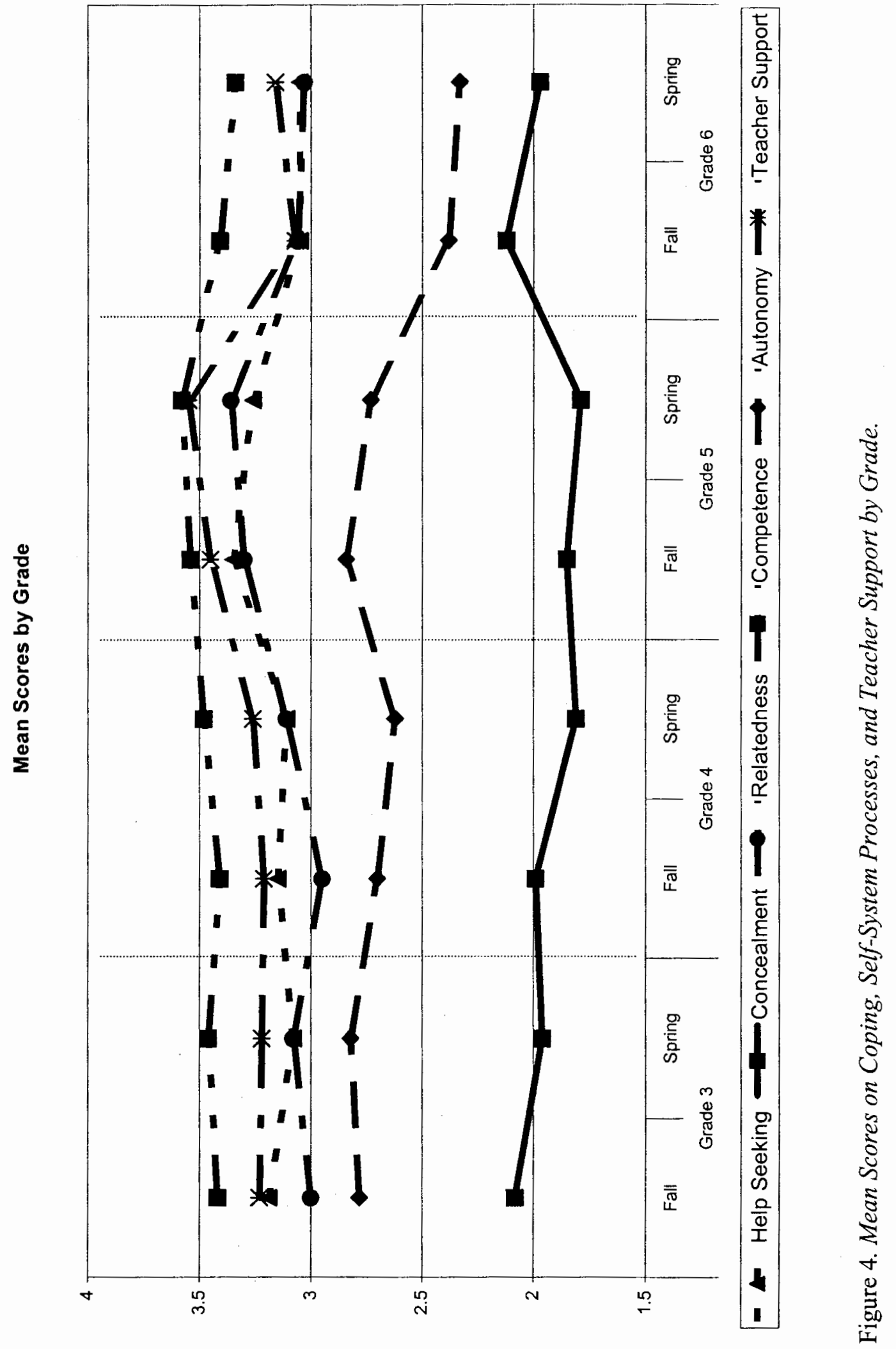


Help Seeking 138

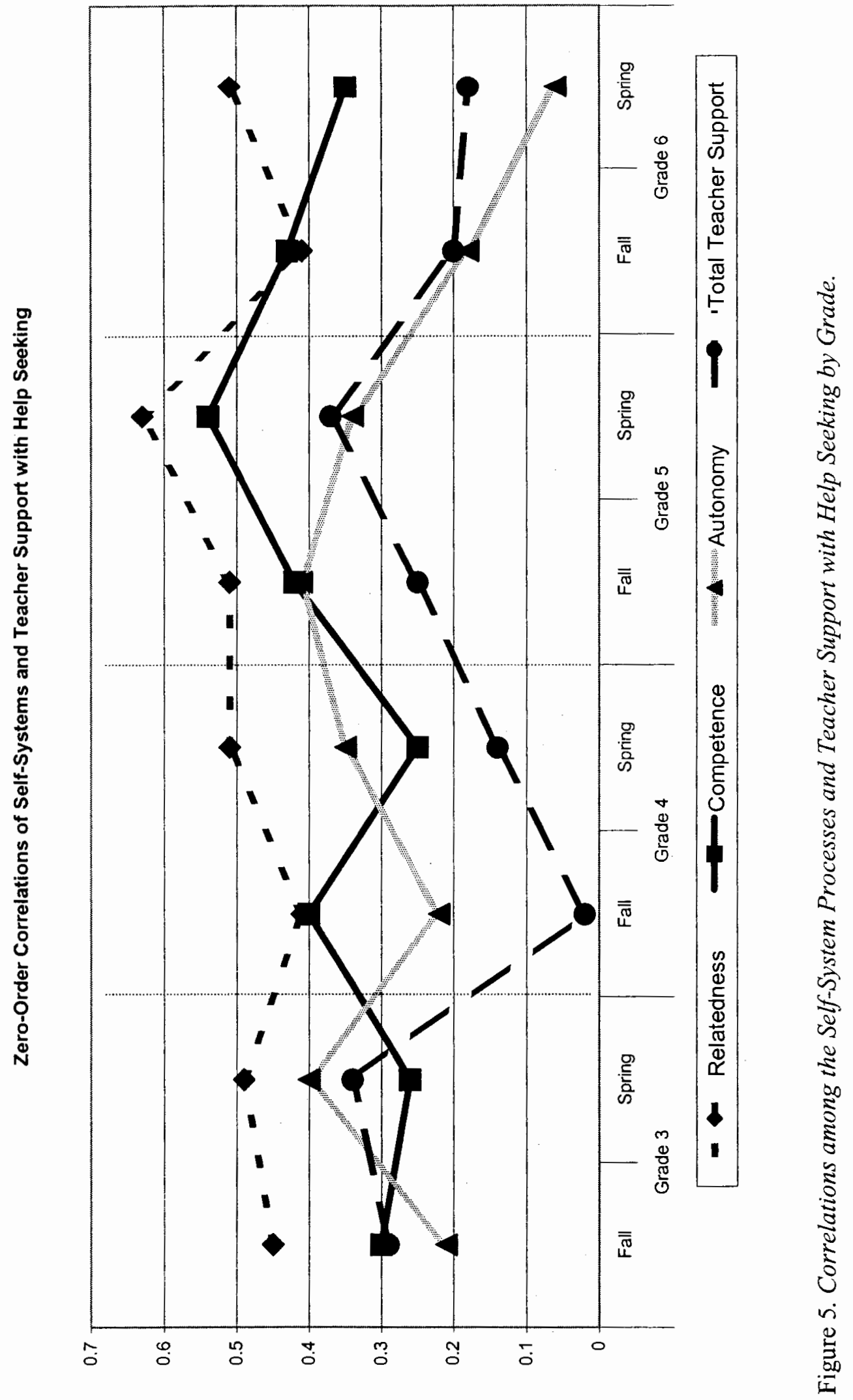


Help Seeking 139

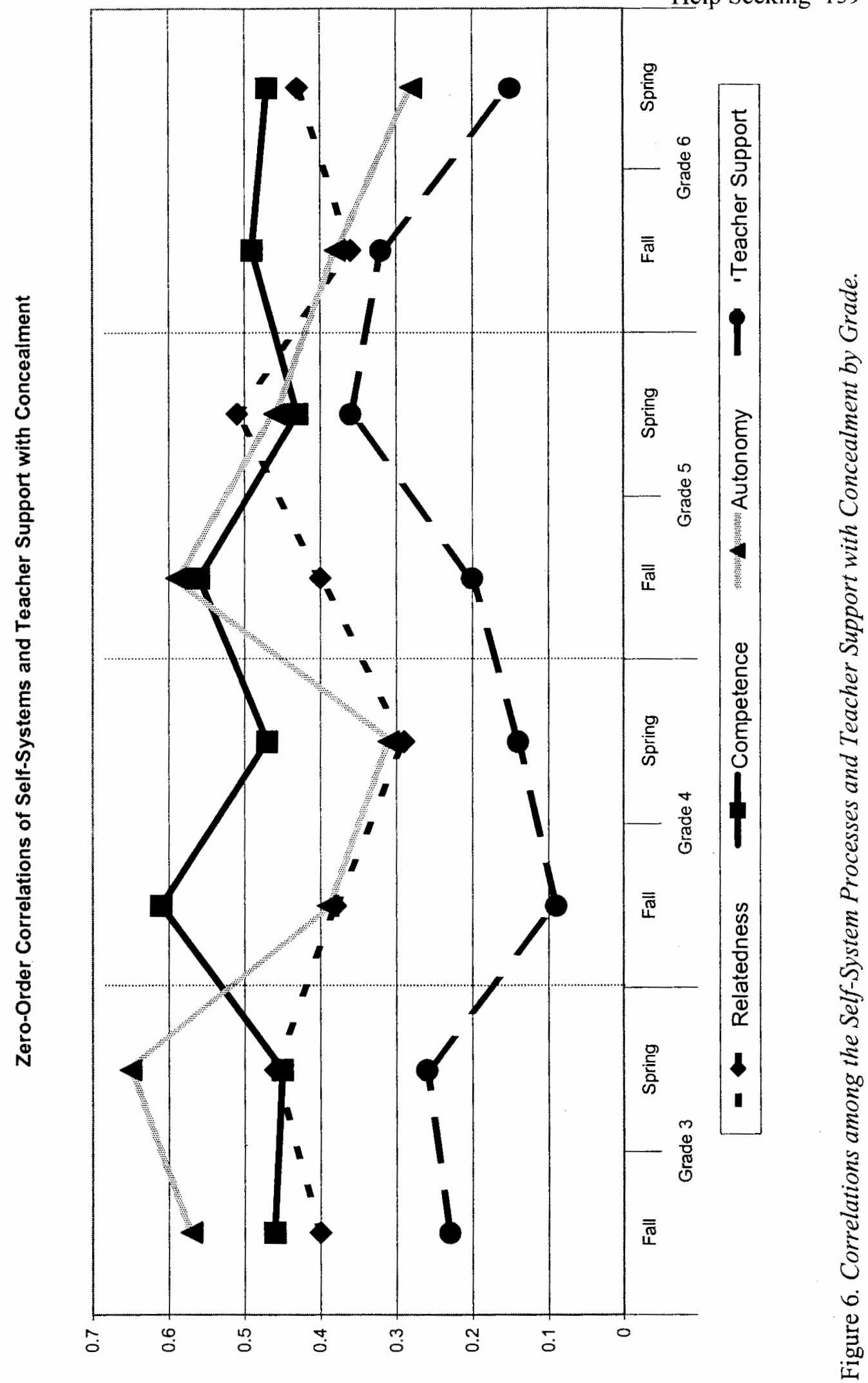




\section{REFERENCES}

Ames, C., \& Archer, J. (1988). Achievement goals in the classroom: Students' learning strategies and motivation processes. Journal of Educational Psychology, 80 (3), 262-297.

Arbreton, A. (1998). Student goal orientation and help-seeking strategy use. In S.A. Karabenick, (Ed), Strategic help seeking: Implications for learning and teaching (pp. 95-116). Mahwah, NJ: Lawrence Erlbaum Associates.

Baron, R. M., \& Kenny, D. A. (1986). The moderator-mediator variable distinction in social psychological research: Conceptual, strategic, and statistical considerations. Journal of Personality \& Social Psychology, 51(6), 1173-1182.

Baron, R.M., Tom, D.Y., \& Cooper, H.M. (1985). Social class, race, and teacher expectations. In J.Dusek, V. Hall, \& W. Meyer (Eds.), Teacher Expectancies (pp. 251-269). Hillsdale, NJ: Lawrence Erlbaum.

Becker, B. \& Luthar, S. (2002). Social-emotional factors affecting achievement outcomes among disadvantaged students: Closing the achievement gap. Educational Psychologist, 37(4), 197-214.

Bronfenbrenner, U., \& Morris, P.A. (1998). The ecology of developmental processs. In P.H. Mussen \& Wikessen (Eds.), Hankbook of Child Psychology (Vol. 1, pp. 993-1028). John Wiley \& Sons.

Butler, R. (1998). Determinants of help seeking: Relations between perceived reasons for classroom help-avoidance and help-seeking behaviors in an experimental context. Journal of Educational Psychology, 90 (4), 630-643. 
Bulter, R., \& Neuman, O. (1995). Effects of task and ego achievment goals on helpseeking behaviors and attitudes. Journal of Educational Psychology, 87 (2), 261-271.

Cappell, E. \& Lamar, M. (1999). America's schoolchildren: Past, present, and future. The Future of Children, 9 (2), 21-29.

Connell, J.P. (1990). Context, self, and action: A motivational analysis of self-system processes across the lifespan. In D. Cicchetti (Ed.), The self in transition: From infancy to childhood (pp. 61-97). Chicago: University of Chicago Press.

Connell, J.P, \& Wellborn, J.G. (1991). Competence, autonomy, and relatedness: A motivational analysis of self-system processes. In M.R. Gunnar, \& L.A. Sroufe (Eds.), Self processes in development: Minnesota symposium on child psychology (Vol. 23, pp. 43-77). Hillsdale, NJ: Erlbaum.

Deci, E.L. \& Ryan, R.M. (2000). The "what" and "why" of goal pursuits: Human needs and the self-determination of behavior. Psychological Inquiry, 11(4), $227-268$.

DeCooke, P.A., \& Nelson-Le Gall, S. (1989). The effects of familiarity on the success of children's help seeking. Journal of Applied Developmental Psychology, 10, 195-208.

Dillon, J.T. (1998). Questioning and teaching: A manual of practice. New York, NY: Teachers College Press.

Easterbrooks, M., Davidson, C., \& Chazan, R. (1993). Psychosocial risk, attachment, 
and behavior problems among school-aged children. Development \& Psychopathology, 5(3), 389-402.

Eccles, J. (1999). The development of children ages 6 to 14. The Future of Children, 9 (2), 30-44.

Fischer, P., \& Torney, J. (1976). Influences of children's stories on dependency, a sextyped behavior. Developmental Psychology, 12, 489-490.

Furrer, C., Marchand, G. \& Skinner, E. (2003). Are children's emotions in the classroom useful in diagnosing and treating motivational problems? Biennial Meeting for the Society for Research on Child Development; Tampa, FL.

Furrer, C., \& Skinner, E. (2003). Sense of relatedness as a factor in children's academic engagement and performance. Journal of Educational Psychology, $95(1), 148-162$.

Garcia Coll, C., Crnic, K., Lamberty, G., Waski, B., Jenkins, R., Garcia, H., et al. (1996). An integrative model for the study of developmental competencies in minority children. Child Development, 67, 1981-1914.

Good, T.L., Slavings, R.L., Harel, K., \& Emerson, H. (1987). Student passivity: A study of question asking in K-12 classrooms. Sociology of education, 60, 181199.

Granot, D., \& Mayseless, O. (2001). Attachment security and adjustment to school in middle childhood. International Journal of Behavioral Development, 25 (6), $530-541$.

Harter, S. (1981). A new self-report sclae of intrinsic versus extrinsic orientation in the 
Help Seeking 143

classroom: Motivational and informational components. Developmental Psychology, 17, 300-312.

Harter, S., \& Connell, J.P. (1984). A model of children's achievement and related selfperceptions of competence, control, and motivational orientation. In J. Nicholls (Ed.), Advances in motivation and achievement (Vol. 3, pp. 219-250).

Greenwich, CT: JAI Press.

Hu, L.T., \& Bentler, P. (1995). Evaluating model fit. In R. H. Hoyle (Ed.), Structural Equation Modeling. Concepts, Issues, and Applications (pp. 76-99). London: Sage.

Jennings, K.D. (1991). Early development of mastery motivation and its relation to the self-concept. The development of intentional action. Cognitive, motivational, and interactive processes, 22, 1-13.

Karabenick, S.A. (Ed.). (1998) Strategic help seeking: Implications for learning and teaching. Mahwah, NJ: Lawrence Erlbaum.

Karabenick, S.A., \& Knapp, J.R. (1991). Relationship of academic help seeking to the use of learning strategies and other instrumental achievement behavior in college students. Journal of Educational Psychology, 83 (2), 221-230.

Kesner, J.E. (2000). Teacher characteristics and the quality of child-teacher relationships. Journal of School Psychology, 38 (2), 133-150.

Kuperminc, G., Blatt, S., Shahar, G., Henrich, C., \& Leadbeater, B. (2004). Cultural Equivalence and Cultural Variance in Longitudinal Associations of Young Adolescent Self-Definition and Interpersonal Relatedness to Psychological and 
School Adjustment. Journal of Youth \& Adolescence, 33(1), 13-30.

Lynch, M. \& Cicchetti, D. (1991). Patterns of relatedness in maltreated and nonmaltreated children: Connections among multiple representational models. Development and Psychopathology, 3(2), 207-226.

Lynch, M., \& Cicchetti, D. (1997). Children's relationships with adults and peers: An examination of elementary and junior high school students. Journal of School Psychology, 35 (1), 81-100.

Maruyama, G.M. (1998). Basics of Structural Equation Modeling. Thousand Oaks, CA: Sage.

Munsch, J. \& Wampler, R. (1993). Ethnic differences in early adolescents' coping with school stress. American Journal of Orthopsychiatry, 63 (4), 633-646.

Nadler, A. (1983). Personal characteristics and help-seeking. In B.M. DePaulo, A. Nadler, \& J.D. Fisher (Eds.), New directions in helping: Help-seeking (Vol. 2, pp. 303-340). New York, NY: Academic Press.

Nadler, A. (1997). Personality and help seeking: Autonomous versus dependent seeking of help. In G.R. Pierce \& B.Lakey (Eds.), Sourcebook of social support and personality. The Plenum series in social/clinical psychology (pp. 379-407). New York, NY: Plenum Press.

Nelson, W., Knight, G., Kagan, S., \& Gumbiner, J. (1981). Locus of control, selfesteem, and field independence as predictors of school achievement among Anglo American and Mexican American children. Hispanic Journal of Behavioral Sciences, 2(4), 323-335. 
Nelson-Le Gall, S. (1981). Help-seeking: An understudied problem-solving skill in children. Developmental Review, 1, 224-226.

Nelson-Le Gall, S. (1985). Help seeking behavior in learning. In E.W. Gordon (Ed.), Review of Research in Education (Volume 12, pp. 55-90). Washington, D.C.: American Educational Research Association.

Nelson-Le Gall, S.A. (1987). Necessary and unnecessary help-seeking in children. Journal of Genetic Psychology, 148 (1), 53-62.

Nelson-Le Gall, S., (1990). Academic achievement orientation and help-seeking behavior in early adolescent girls. Journal of Early Adolescence, 10 (2), 176190.

Nelson-Le Gall, S., \& DeCooke, P.A. (1987). Same-sex and cross-sex help exchanges in the classroom. Journal of Educational Psychology, 79 (1), 67-71.

Nelson-Le Gall, S., DeCooke, P., \& Jones, E. (1989). Children's self-perceptions of competence and help-seeking. Journal of Genetic Psychology, 150 (4), 457 459.

Nelson-Le Gall, S., \& Glor-Scheib, S. (1985). Help Seeking in elementary classrooms: An observational study. Contemporary Educational Psychology, 10, 58-71. Nelson-Le Gall, S., \& Glor-Sheib, S. (1986). Academic help-seeking and peer relations in school. Contemporary Educational Psychology, 11, 187-193.

Nelson-Le Gall, S., \& Gumerman, R. (1984). Children's perceptions of helpers and helper motivation. Journal of Applied Developmental Psychology, 5, 1-12. Nelson-Le Gall, S., Gumerman, R.A., \& Scott-Jones, D. (1983). Instrumental help- 
seeking and everyday problem-solving: A developmental perspective. In B. DePaulo, A. Nadler, \& J. Fisher (Eds.), New directions in helping: Helpseeking (Vol. 2, pp. 265-284). New York, NY: Academic Press.

Nelson-Le Gall, S., \& Jones, E. (1990). Cognitive-motivational influences on the taskrelated help-seeking behavior of black children. Child Development, 61, 581589.

Nelson-Le Gall, S., Kratzer, L., Jones, E., \& DeCooke, P. (1990). Children's selfassessment of performance and task-related help seeking. Journal of Experimental Child Psychology, 49, 245-263.

Nelson-Le Gall, S., \& Scott-Jones, D. (1985). Teachers' and young childrens' perceptions of appropriate work strategies. Child Study Journal, 15 (1), 29-42.

Newman, R.S. (1990). Children's help-seeking in the classroom: The role of motivational factors and attitudes. Journal of Educational Psychology, 82 (1), $71-80$.

Newman, R.S. (1991). Goals and self-regulated learning: What motivates children to seek academic help? In P.R. Pintrich \& M.L. Maehr (Eds.), Advances in motivation and achievement: Goals and self-regulatory processes (Vol. 7, pp. 151-183). Greenwich, CT:

Newman, R.S. (1993). Student perceptions of the teacher and classmates in relation to reported help seeking in math class. Elementary School Journal, 94, 3-17

Newman, R.S. (1994). Adaptive help seeking: A strategy of self-regulated learning. In D.H. Schunk \& B.J. Zimmerman (Eds.), Self-regulation of learning and 
performance: Issues and educational applications (pp. 283-301). Hillsdale, NJ: Lawrence Erlbaum Associates.

Newman, R.S. (1998a). Students' help seeking during problem solving: Influences of personal and contextual achievement goals. Journal of Educational Psychology, $90(4), 644-658$.

Newman, R.S. (1998b). Adaptive help seeking: A role of social interaction in selfRegulated learning. In S.A. Karabenick (Ed), Strategic help seeking: Implications for learning and teaching (pp. 13-37). Mahwah, NJ: Lawrence Erlbaum Associates.

Newman, R.S. (2000). Social influences on the development of children's adaptive help seeking: The role of parents, teachers, and peers. Developmental Review, $20(3), 350-404$.

Newman, R.S. (2002). What do I need to do to succeed...When I don't understand what I'm doing!?: Developmental influences on students' adaptive help seeking. In A. Wigfield \& J.S. Eccles (Eds.), Development of achievement motivation (pp. 285-306). San Diego, CA: Academic Press.

Newman, R.S., \& Goldin, L. (1990). Children's reluctance to seek help with schoolwork. Journal of Educational Psychology, 82 (1), 92-100.

Newman, R.S., \& Schwager, M.T. (1995). Student's help seeking during problem solving: Effects of grade, goal, and prior achievement. American Educational Research Journal, 32 (2), 352-376.

Norman, O., Ault, C., Charles, R., Bentz, B. \& Meskimen, L. (2001). The Black- 
White "achievement gap" as a perennial challenge of urban science education: A sociocultural and historical overview with implications for research and practice. Journal of Research in Science Teaching, 38(10), 1101-1114.

Patrick, B.C., Skinner, E.A., \& Connell, J.P. (1993). What motivates children's behavior and emotions? The joint effects of perceived control and autonomy in the academic domain. Journal of Personality and Social Psychology, 65 (4), $781-791$.

Pianta, R.C. \& Walsh, D.J. (1998). Applying the construct of resilience in schools: Cautions from a developmental systems perspective. School Psychology Review, 27 (3), 407-417.

Pintrich, P.R., \& Schunk, D.H. (1996). Motivation in education: Theory, research, and applications. Englewood Cliffs, NJ: Merrill Prentice-Hall.

Pintrich, P.R., \& Zusho, A. (2002). The development of academic self-regulation: The role of cognitive and motivational factors. In A. Wigfield \& J.S. Eccles (Eds.), Development of achievement motivation (pp. 249-283). San Diego, CA: Academic Press.

Puustinen, M. (1998). Help-seeking behavior in a problem-solving situation: Development of self-regulation. European Journal of Psychology of Education, 13 (2), 271-282.

Ryan, A.M., Gheen, M.H., \& Midgley, C. (1998). Why do some students avoid asking for help? An examination of the interplay among students' academic efficacy, 
teachers' social-emotional role, and the classroom goal structure. Journal of Educational Psychology, 90 (3), 528-535.

Ryan, A.M., \& Pintrich, P.R. (1997). "Should I ask for help?" The role of motivation and attitudes in adolescents' help seeking in math class. Journal of Educational Psychology, 89 (2), 329-341.

Ryan, A.M., \& Pintrich, P.R. (1998). Achievement and social motivational influences on help seeking in the classroom. In S. Karabenick (Ed), Strategic help seeking: Implications forlearning and teaching (pp. 117-139). Mahwah, NJ: Lawrence Erlbaum Associates.

Ryan, R.M., \& Connell, J.P. (1989). Perceived locus of causality and internalization: Examining reasons for acting in two domains. Journal of Personality and Social Psychology, 57 (5), 749-761.

Ryan, R.M., \& Lynch, J.H. (1989). Emotional autonomy versus detachment: Revisting the vicissitudes of adolescence and young adulthood. Child Development, 60, 340-356.

Ryan, R., Stiller, J.D., \& Lynch, J.H. (1994). Representations of relationships to teachers, parents, and friends as predictors of academic motivation and selfesteem. Journal of Early Adolescence, 14(2), 226-249.

Schafer, J.L.\& Graham, J.W. (2002). Missing data: Our view of the state of the art. Psychological Methods, 7(2), 147-177.

Schunk, D.H., \& Ertmer, P.A. (2000). Self-regulation and academic learning: Self- 
efficacy enhancing interventions. In M. Boekaerts, P.R. Pintrich, \& M. Zeidner (Eds.), Handbook of self-regulation (pp. 631-649). San Diego: Academic Press.

Sears, R. (1972). Attachment, dependency, and frustration. In J.L. Gewirtz (Ed.), Attachment and Dependency. New York, NY: Halsted Press.

Skinner, E.A. (1999). Action regulation, coping, and development. In J.B.

Brandtstadter \& R.M. Lerner (Eds.), Action and self-development (pp. 465503). Thousand Oaks, CA: Sage.

Skinner, E.A., \& Belmont, M.J. (1993). Motivation in the classroom: Reciprocal effects of teacher behavior and student engagement across the school year. Journal of Educational Psychology, 85 (4), 571-581.

Skinner, E.A., Chapman, M., \& Baltes, P.B. (1988). Control, means-ends, and agency beliefs: A new conceptualization and its measurement during childhood. Journal of Personality and Social Psychology, 54, 117-133.

Skinner, E.A., \& Edge, K. (1998). Reflections on coping and development across the lifespan. International Journal of Behavioral Development, 22, 357-366.

Skinner, E.A., Wellborn, J.G., \& Connell, J.P. (1990). What it takes to do well in school and whether I've got it: A process model of perceived control and children's engagement and achievement in school. Journal of Educational Psychology, $82(1), 22-32$.

Skinner, E.A., \& Wellborn, J.G. (1994). Coping during childhood and adolescence: A 
motivational perspective. In D. Featherman, R. Lerner, \& M. Perlmutter (Eds.), Life-span development and behavior (Vol. 12, pp. 91-133). Hillsdale, NJ: Erlbaum.

Skinner, E.A., Zimmer-Gembeck, M.J., \& Connell, J.P. (1998). Individual differences and the development of perceived control. Monographs of the Society for Research in Child Development, 63 (nos. 2-3), whole no. 254.

Smith, E.R., Murphy, J., \& Coats, S. (1999). Attachment to groups: Theory and measurement. Journal of Personality and Social Psychology, 77 (1), 94-110.

Tabachnick, B. \& Fidell, L. (2001). Using Multivariate Statistics. Needham Heights, MA: Allyn and Bacon.

Turner, J.C., Midgley, C., Meyer, D.K., Gheen, M., Anderman, E.M., Kang, Y., et al. (2002). The classroom environment and students' reports of avoidance strategies in mathematics:A multimethod study. Journal of Educational Psychology, 94 (1), 88-106.

Van der Meij, H. (1988). Constraints on question asking in classrooms. Journal of Educational Psychology, 80 (3), 401-405. 
Appendix A: Descriptive Studies.

Help Seeking 152

\begin{tabular}{|c|c|c|c|}
\hline & 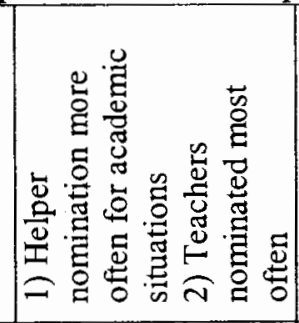 & 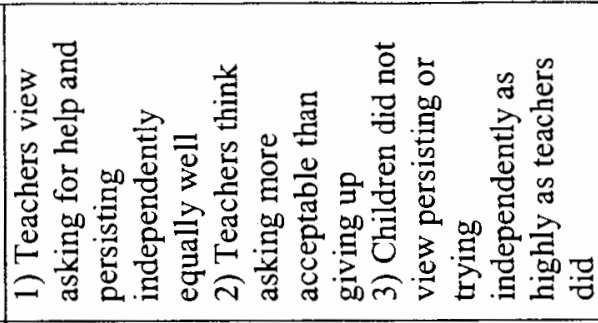 & 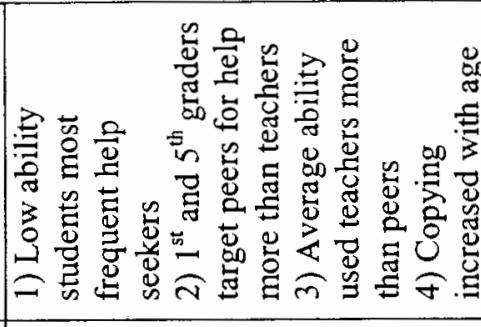 \\
\hline 造 & & & 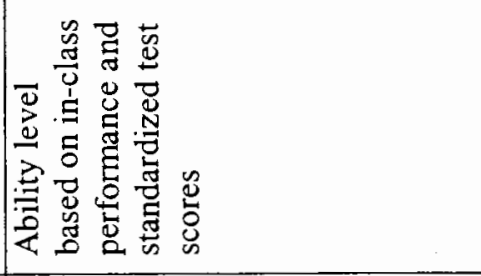 \\
\hline 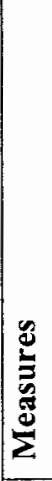 & 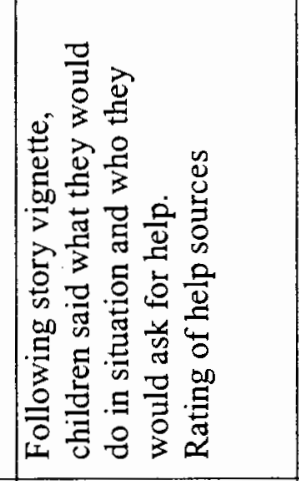 & 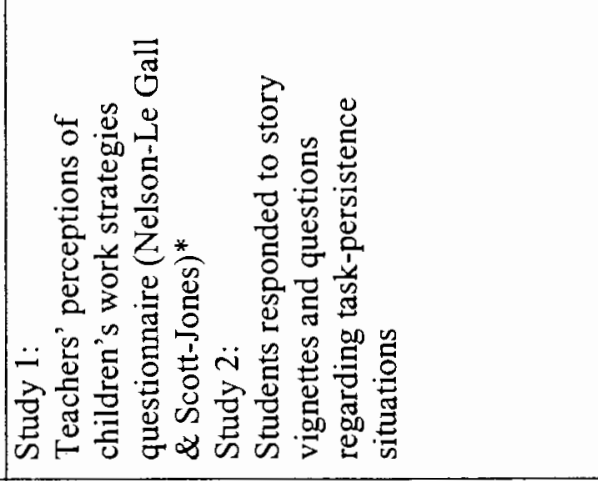 & 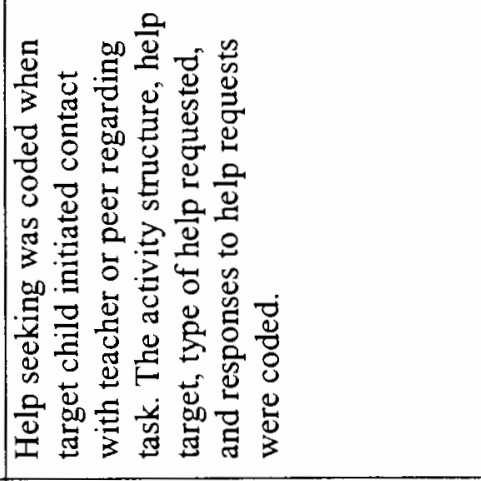 \\
\hline & 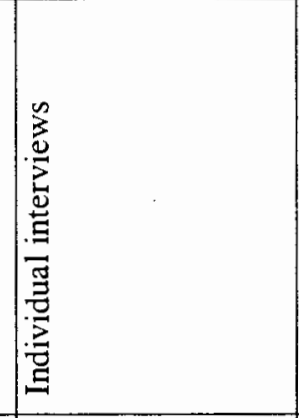 & 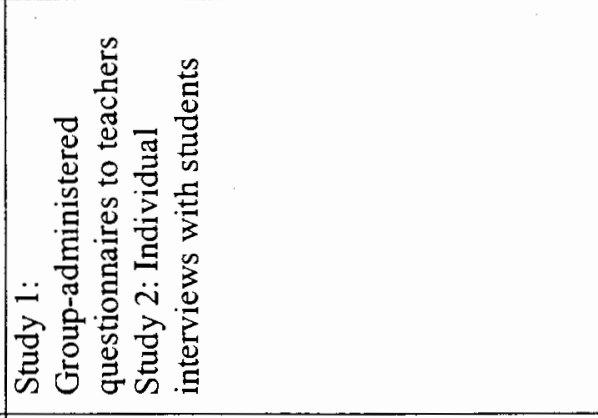 & 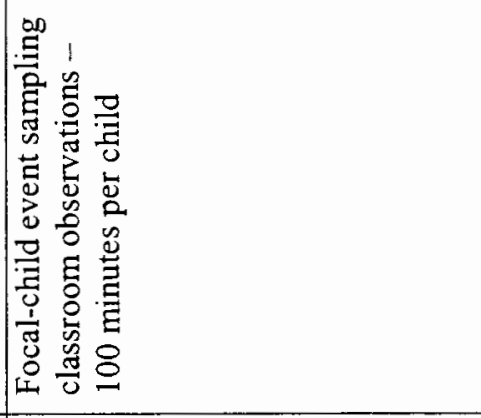 \\
\hline 总 & 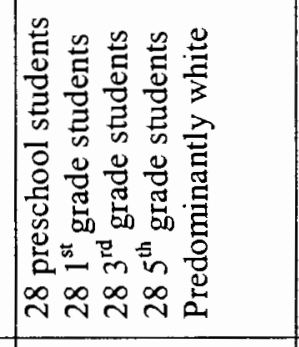 & 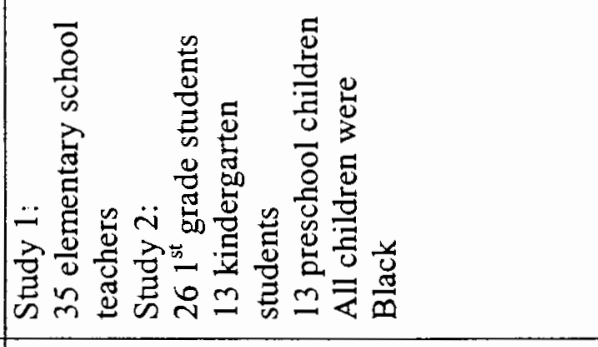 & 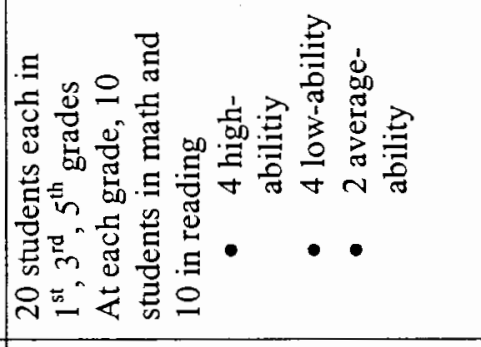 \\
\hline 党 & 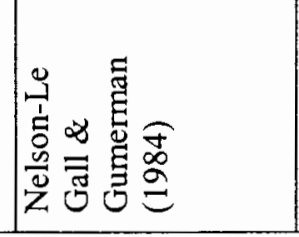 & 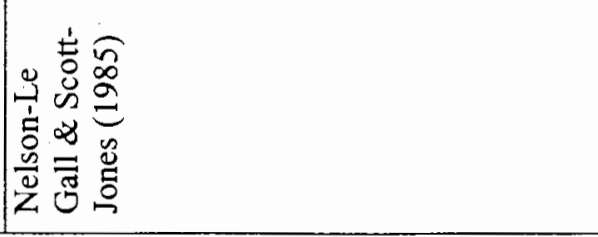 & 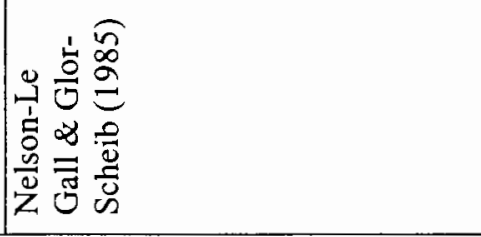 \\
\hline
\end{tabular}


Help Seeking 153

\begin{tabular}{|c|c|c|c|c|}
\hline 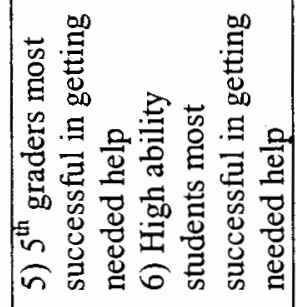 & 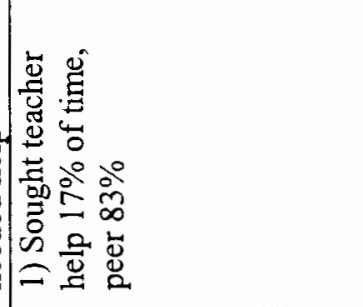 & 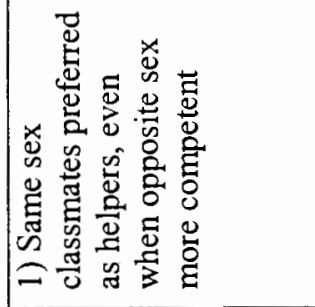 & 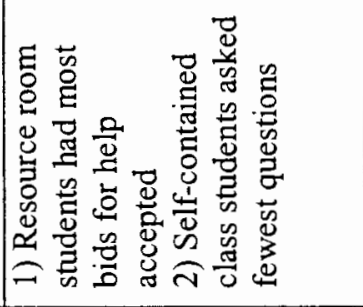 & 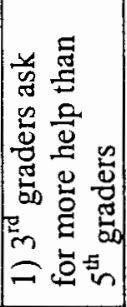 \\
\hline & 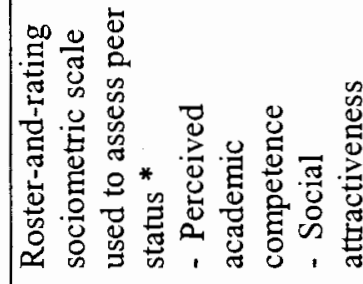 & 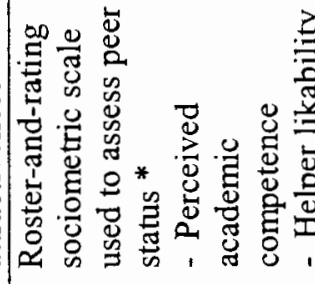 & 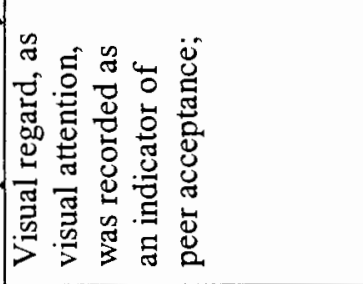 & 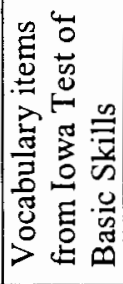 \\
\hline & 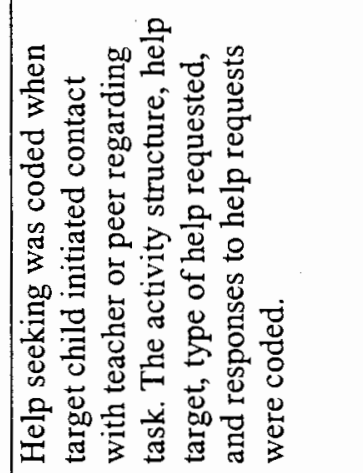 & 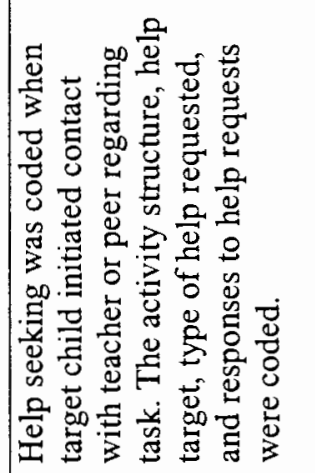 & 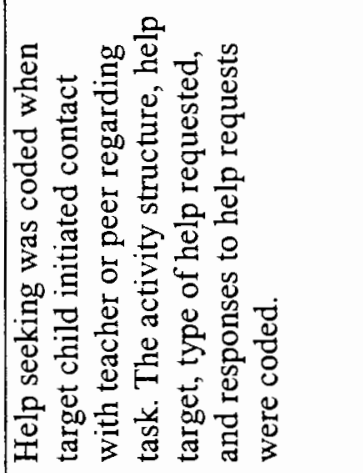 & 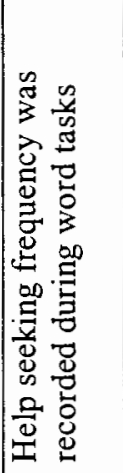 \\
\hline & 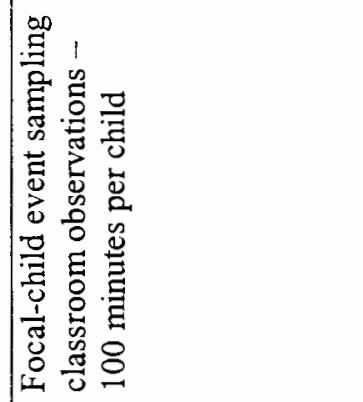 & 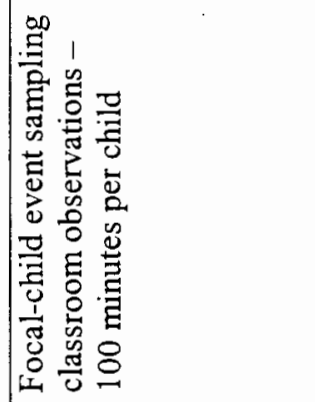 & 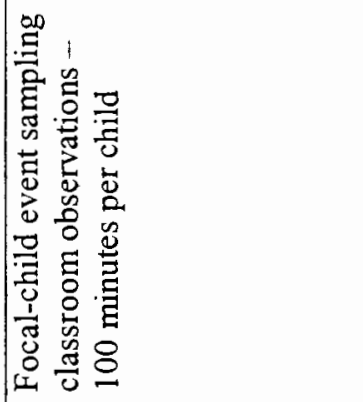 & 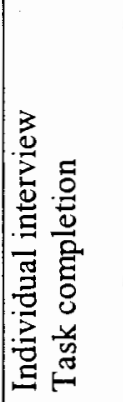 \\
\hline & 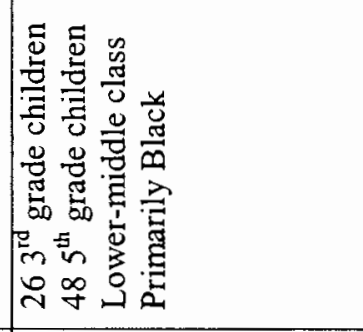 & 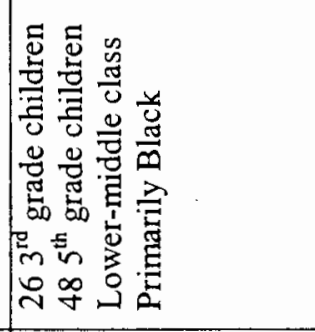 & 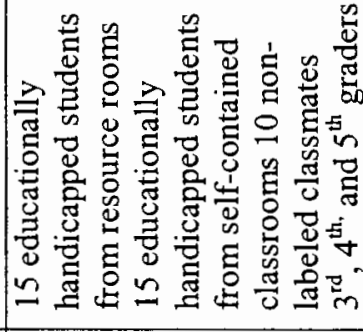 & 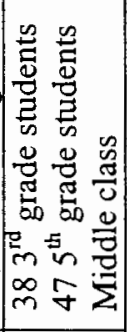 \\
\hline & 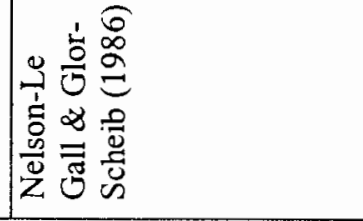 & 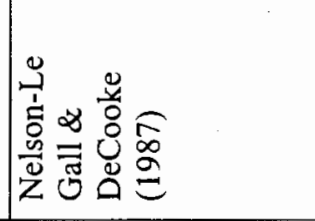 & 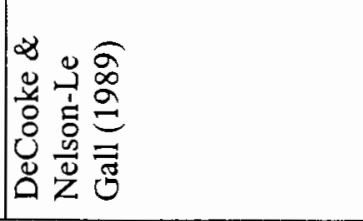 & 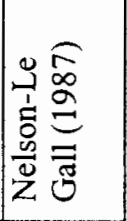 \\
\hline
\end{tabular}




\begin{tabular}{|c|c|}
\hline \multirow[t]{2}{*}{ 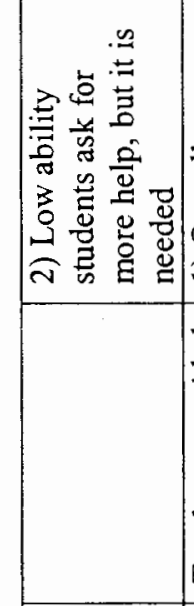 } & 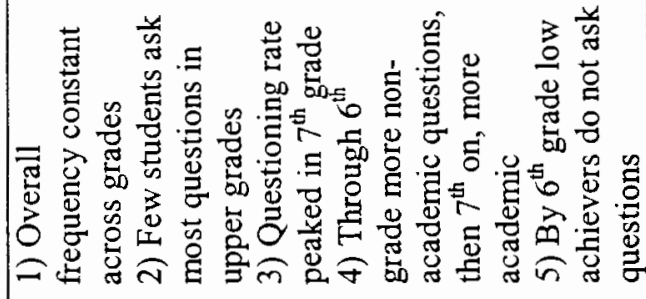 \\
\hline & 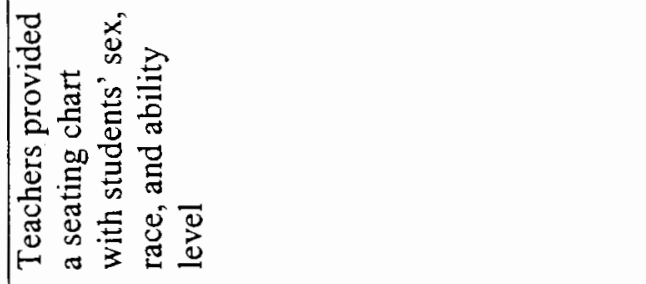 \\
\hline & 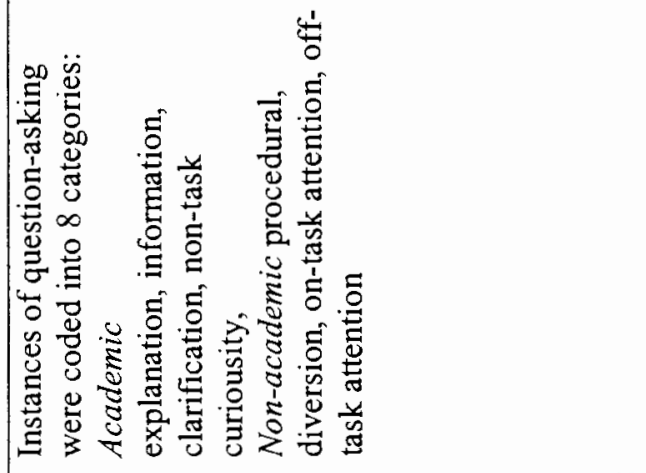 \\
\hline & 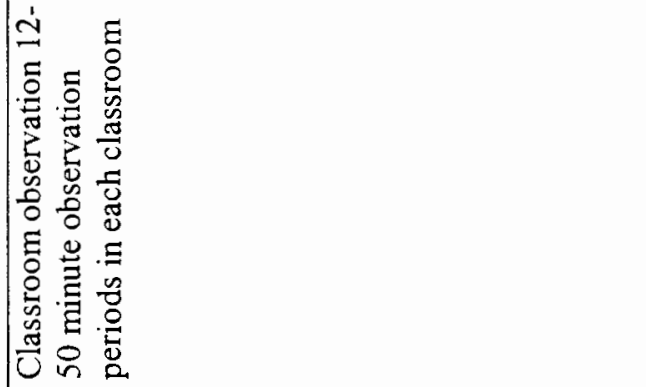 \\
\hline & 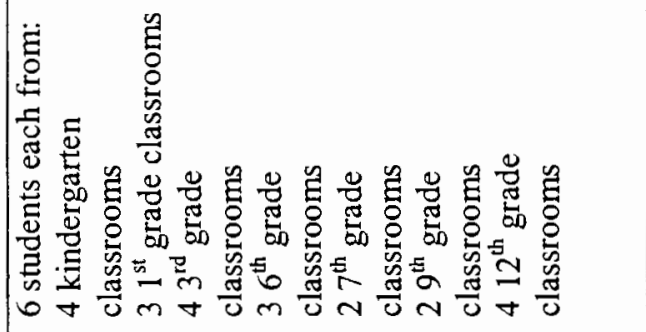 \\
\hline & 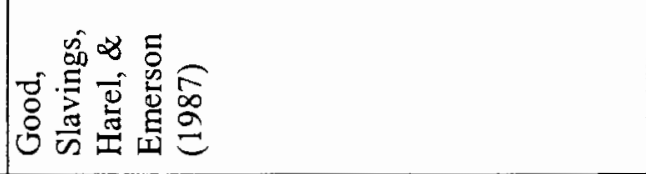 \\
\hline
\end{tabular}

Help Seeking 154 
Appendix B: Individual Differences, Help Avoidance. and Social Context Studies.

Help Seeking 155

\begin{tabular}{|c|c|c|c|c|c|}
\hline ن & & 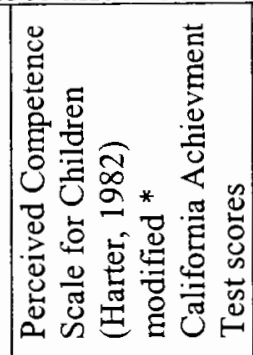 & 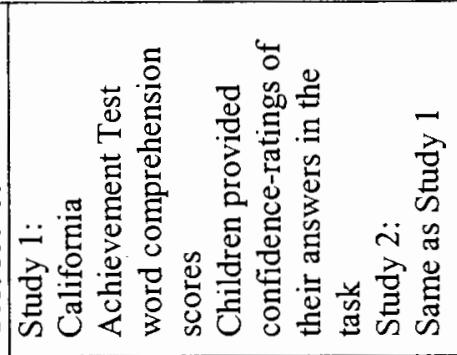 & 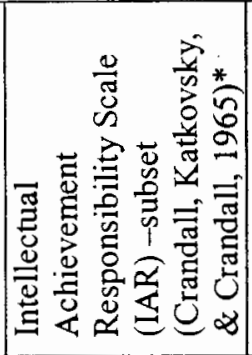 & 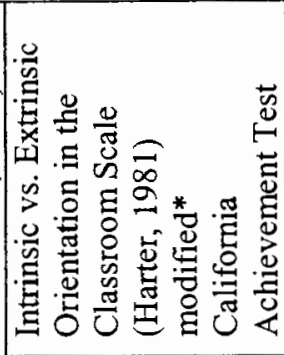 \\
\hline 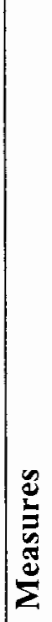 & & 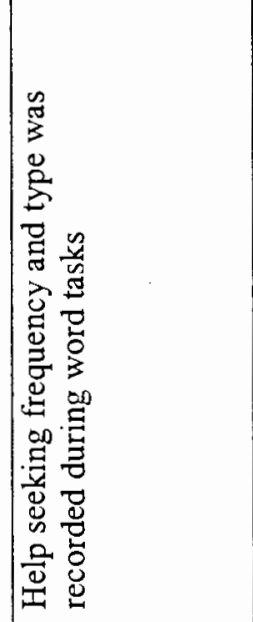 & 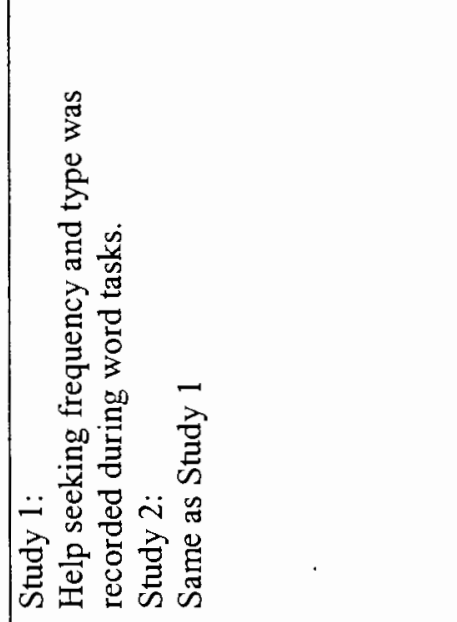 & 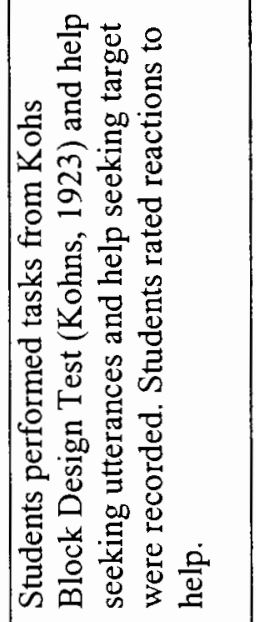 & 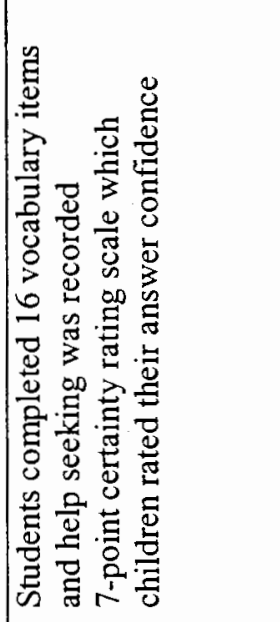 \\
\hline 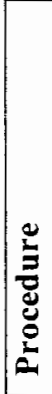 & & 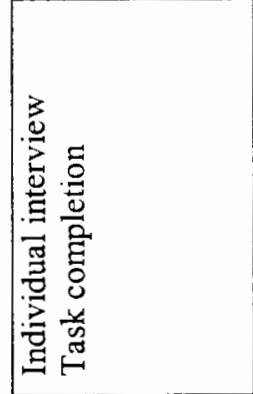 & 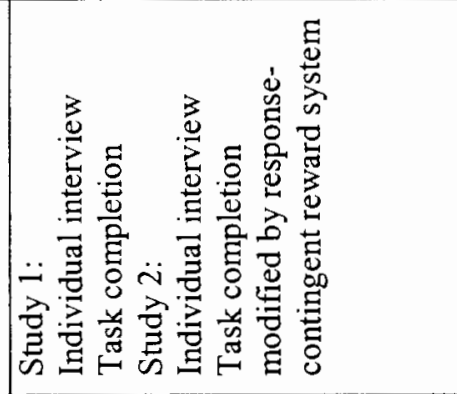 & 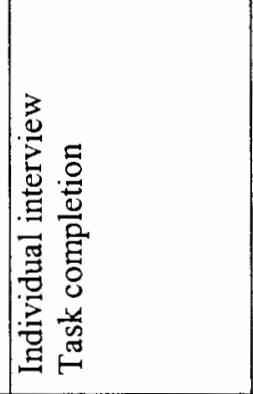 & 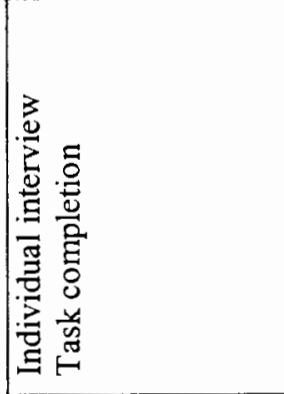 \\
\hline |ू. & 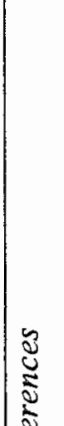 & 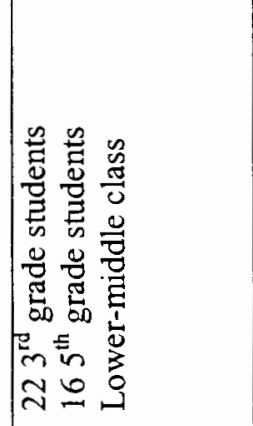 & 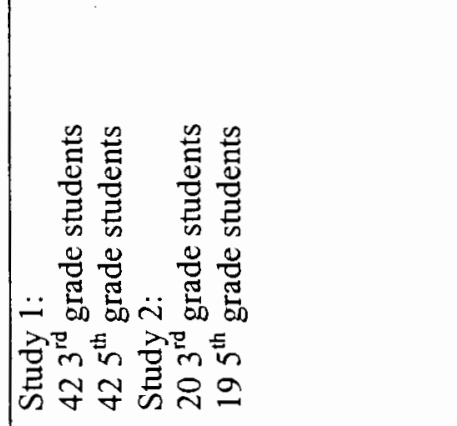 & 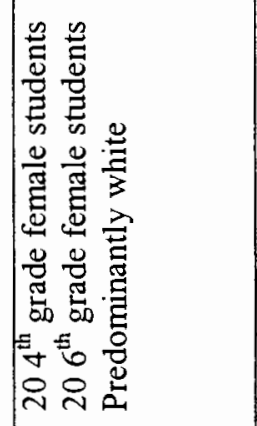 & 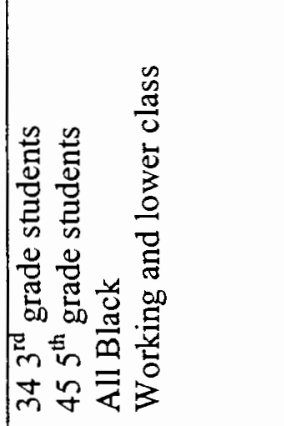 \\
\hline $\overrightarrow{\underline{B}}$ & 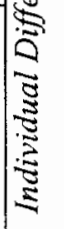 & 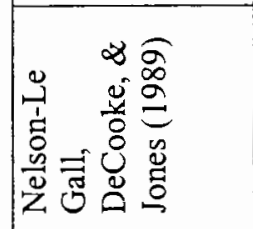 & 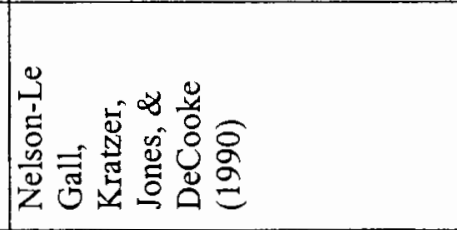 & 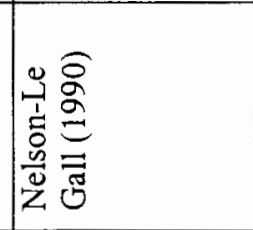 & 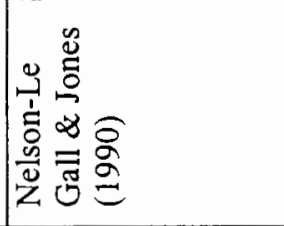 \\
\hline
\end{tabular}


Help Seeking 156

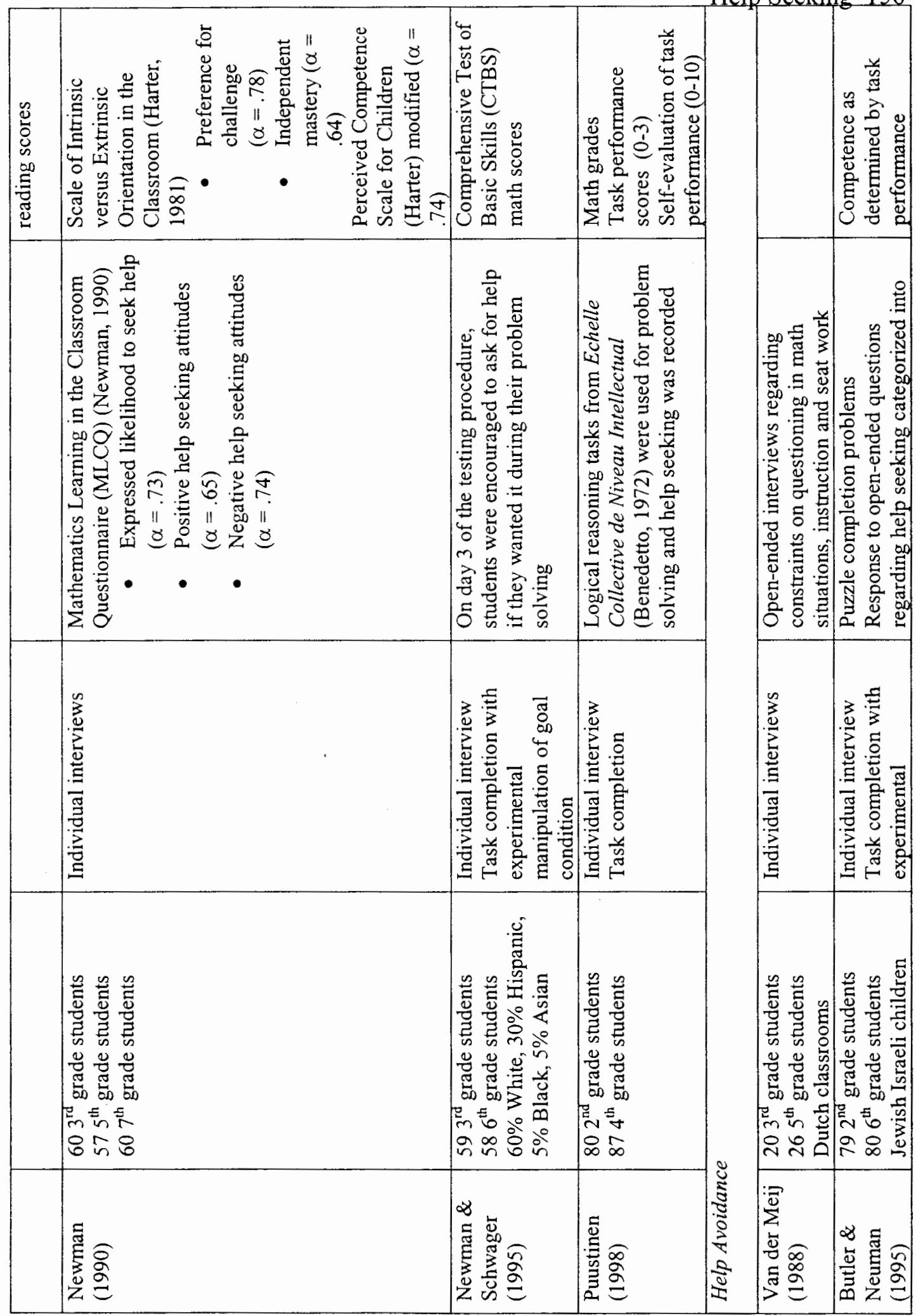


Help Seeking 157

\begin{tabular}{|c|c|c|}
\hline & 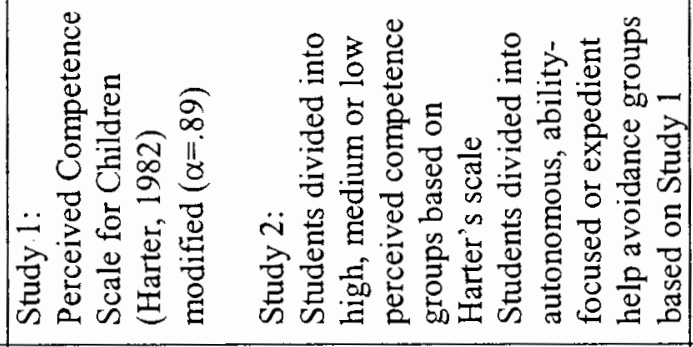 & 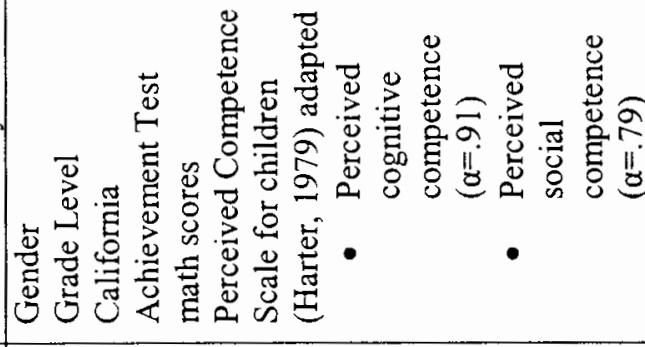 \\
\hline 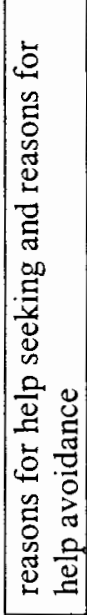 & 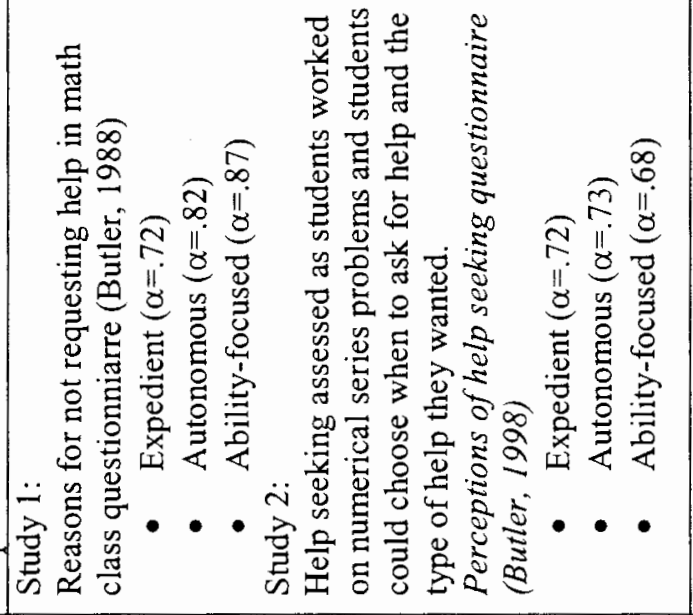 & 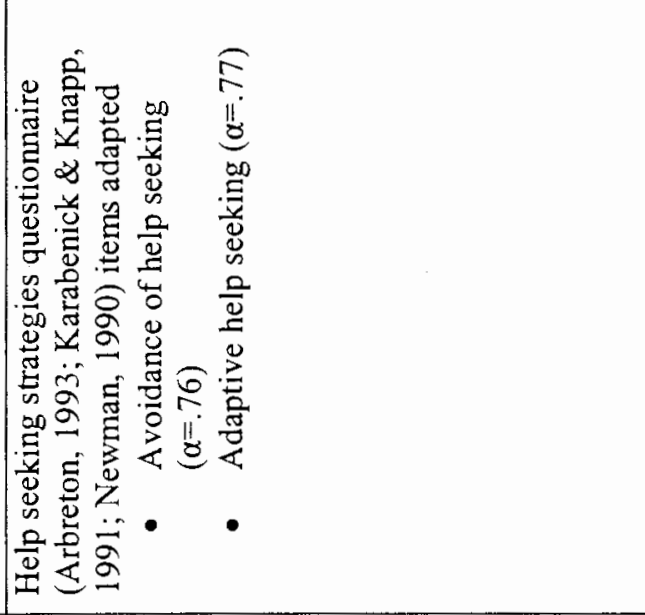 \\
\hline 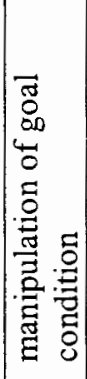 & 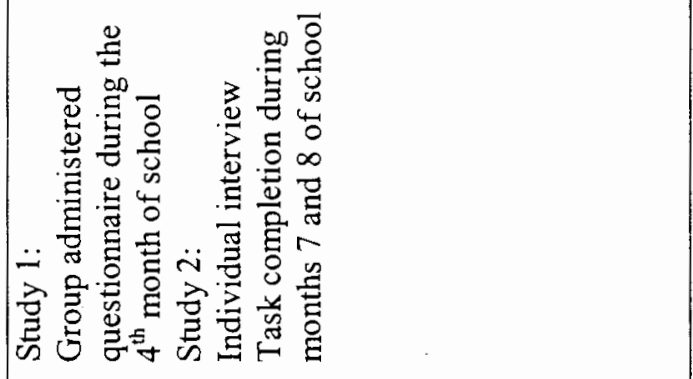 & 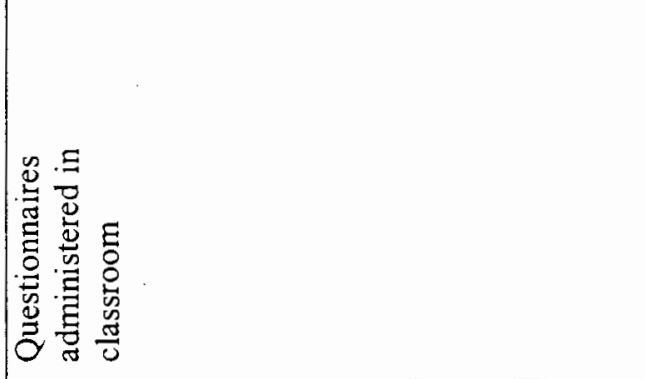 \\
\hline & 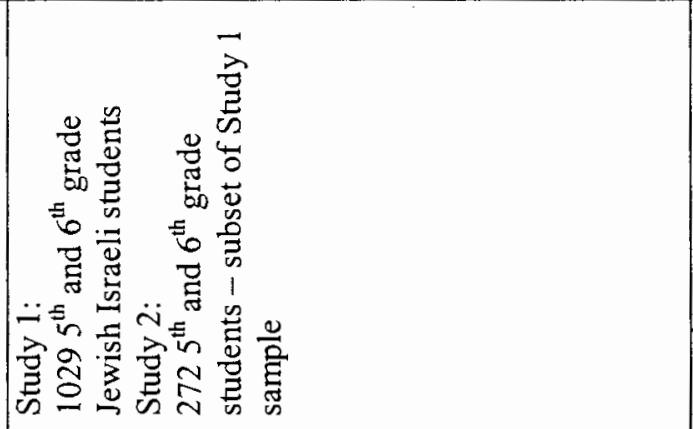 & 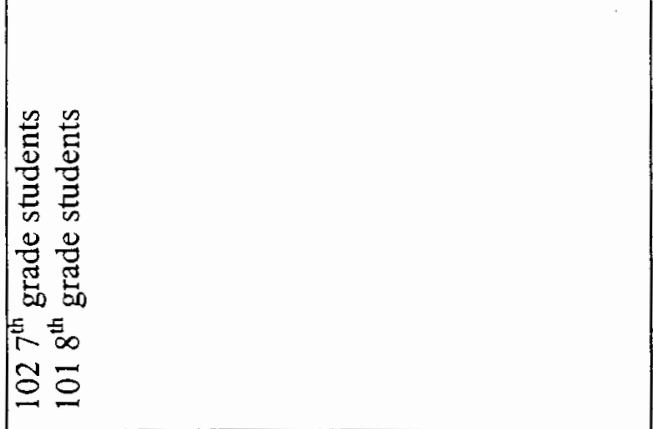 \\
\hline & 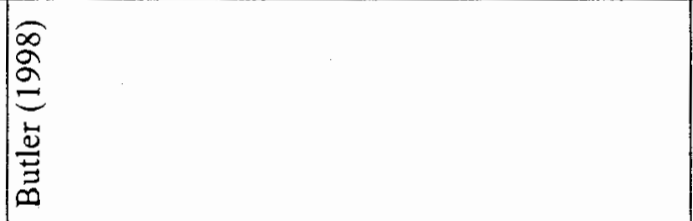 & 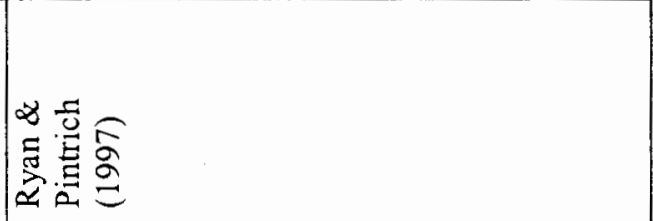 \\
\hline
\end{tabular}


Help Seeking 158

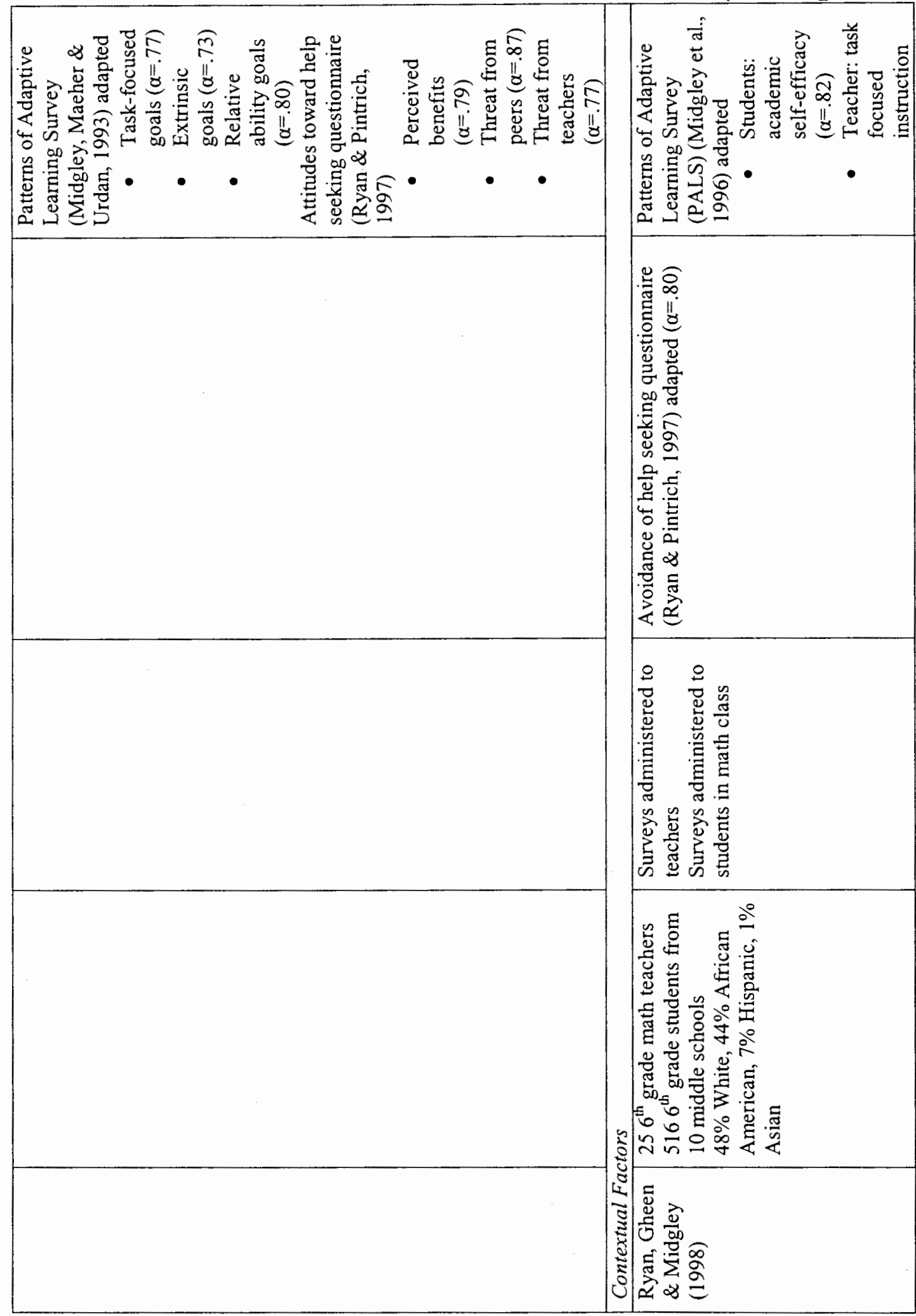


Help Seeking 159

\begin{tabular}{|c|c|c|}
\hline 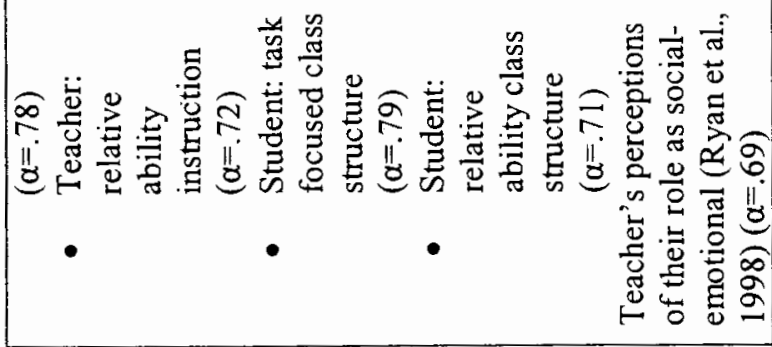 & 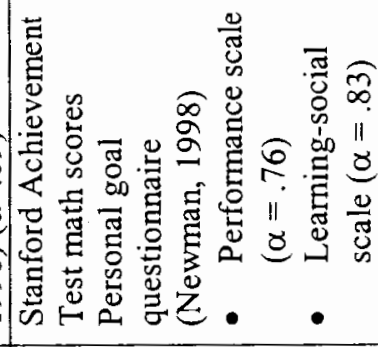 & 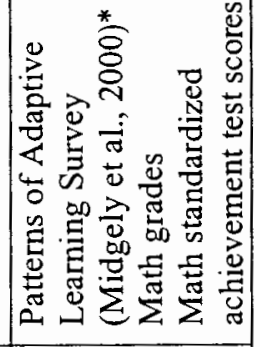 \\
\hline & 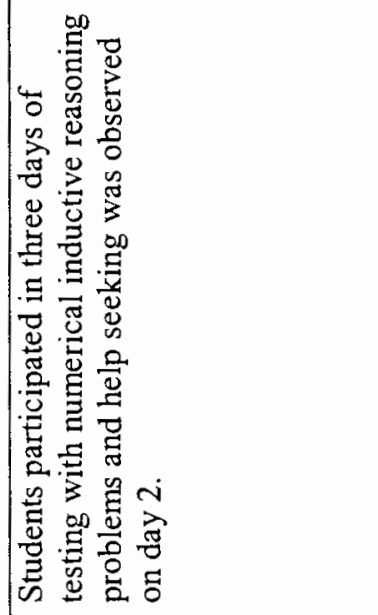 & 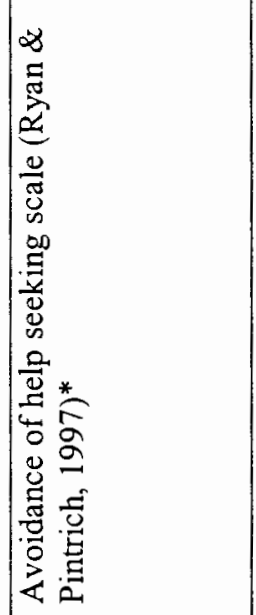 \\
\hline & 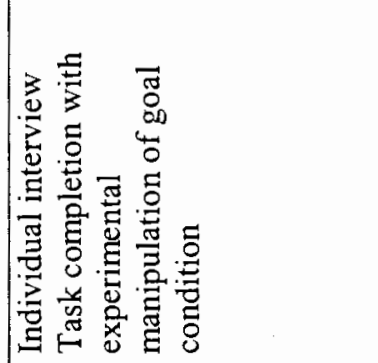 & 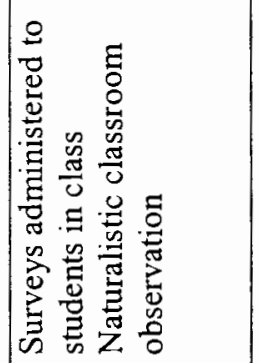 \\
\hline & 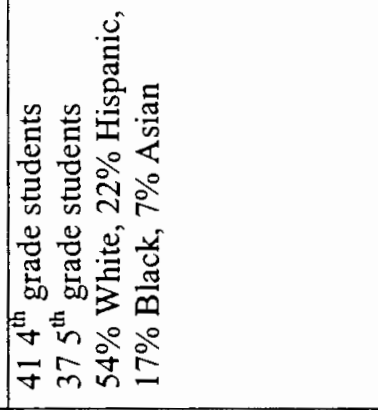 & 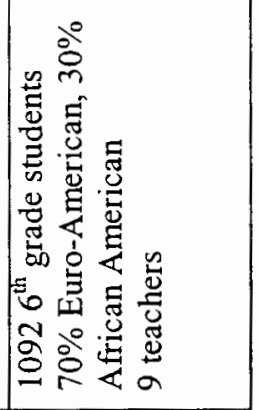 \\
\hline & 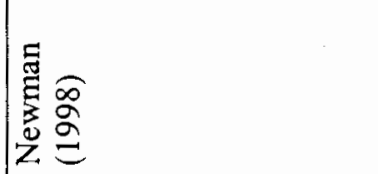 & 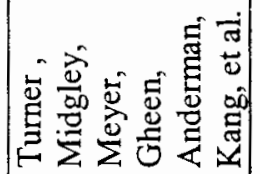 \\
\hline
\end{tabular}




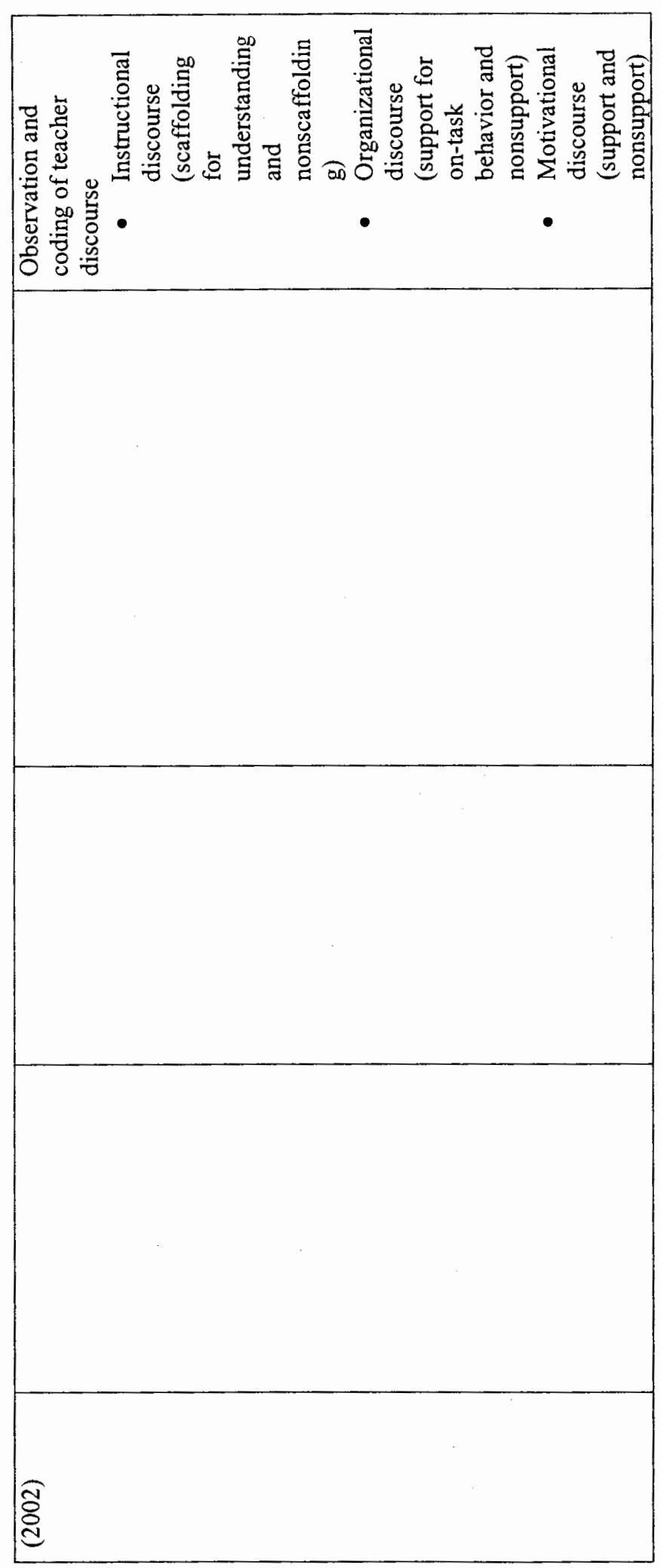

Help Seeking 160 


\section{Appendix C}

Index of Study Scales

\section{Student Report}

Help Seeking

When I have trouble with a subject in school.

1. I ask for some help with understanding the material. $(+)$

2. I get some help to understand the material better. $(+)$

3. I ask the teacher to go over it with me. $(+)$

4. I ask the teacher to explain what I didn't understand. $(+)$

5. I get some help on the parts I didn't understand. $(+)$

\section{Concealment}

When something bad happens to me in school (like not doing well on a test or not being able to answer an important question),

1. I try to keep people from finding out. (-)

2. I make sure nobody finds out. (-)

3. I try to hide it. (-)

4. I don't tell anyone about it. (-)

5. I don't let anybody know about it. (-)

6. I stay away from people. (-)

7. I don't want to see anyone. (-)

8. I don't want to talk to anyone about it. $(-)$

9. I don't want to talk about it. (-)

\section{Relatedness to Teachers}

When I'm with my teacher,

1. I feel accepted. $(+)$

2. I feel like someone special. $(+)$

3. I feel ignored. (-)

4. I feel unimportant. (-)

Perceived Control (Competence)

1. If I decide to learn something hard, I can. $(+)$

2. I can do well in school if I want to. $(+)$

3. I can get good grades if I want to. $(+)$

4. I can't get good grades no matter what I do. (-) 
5. I can't stop myself from doing poorly in school. (-)

6. I can't do well in school, even if I want to. (-)

\section{Academic Autonomy}

External Self-Regulation

1. Why do I do my homework?Because I'll get in trouble if I don't. (-)

2. Why do I do work on my classwork? So that the teacher won't yell at me. (-)

3. Why do I work on my classwork? Because that's the rule. (-)

4. Why do I work on my classwork? Because the teacher says we have to. $(-)$

Introjected Self-Regulation

1. Why do I do my homework? Because I'll feel bad about myself if I don't do it. (-)

2. Why do I work on my classwork? Because I'll be ashamed of myself if it doesn't get done. (-)

3. Why do I try to do well in school? Because I'll feel really bad about myself if I don't do well. (-)

4. Why do I try to do well in school? Because I feel guilty when I don't do as well as I should. (-)

Identified Self-Regulation

1. Why do I do my homework? Because I want to understand the subject. $(+)$

2. Why do I do my classwork? Because I want to learn new things. (+)

3. Why do I work on my classwork? Because I think classwork is important for my learning. $(+)$

4. Why do I try to do well in school? Because I enjoy doing schoolwork well. $(+)$

5. Why do I try to do well in school? Because doing well in school is important to me. $(+)$

Intrinsic Self-Regulation

1. Why do I do my homework? Because it's fun. $(+)$

2. Why do I do my homework? Because I enjoy doing my homework. (t)

3. Why do I work on my classwork? Because it's fun. $(+)$

4. Why do I work on my classwork? Because I enjoy doing my classwork. $(+)$ 


\section{Engagement}

Behavior

1. I participate when we discuss new material. $(+)$

2. I work hard when we start something new in class. $(+)$

3. The first time my teacher talks about a new topic, I listen very carefully. $(+)$

4. When we start something new, I practically fall asleep. (-)

5. My mind wanders when my teacher starts a new topic. (-)

6. I never seem to pay attention when we begin a new subject. (-)

7. I try very hard in school. $(+)$

8. I participate in class discussions. $(+)$

9. When I'm in class, I just act like I'm working. (-)

10. In class, I try to do just enough to get by. (-)

Emotion

When we start something new in school,

1. I feel interested. $(+)$

2. I feel worried. (-)

When my teacher first explains new material,

3. I feel relaxed. $(+)$

4. I feel bored. (-)

When I'm working on my classwork,

5. I feel relaxed. $(+)$

6. I feel involved. $(+)$

7. I feel nervous. (-)

8. I feel mad. (-)

When I'm doing work in class,

9. I feel worried. (-)

10. I feel bored. (-)

When I'm in class,

11. I feel good. $(+)$

12. I feel sad. (-)

When I'm in school,

13. I feel happy. $(+)$

14. I feel bad. (-)

15. I feel terrible. (-)

\section{Teacher Report Scales}

Warmth vs. Neglect (Involvement) 
Affection

1. This student is easy to like. (+)

2. I enjoy the time I spend with this student. $(+)$

3. This student is difficult to like. (-)

4. Teaching this student isn't very enjoyable for me. (-)

Attunement

1. I know a lot about what goes on for this student. $(+)$

2. I know this student well. $(+)$

3. I don't understand this student very well. (-)

4. I don't know very much about what goes on for this student outside of school. (-)

Dedication of Resources

1. I spend time with this student. $(+)$

2. I talk with this student. $(+)$

Dependability

1. When this student does not do as well as s/he can, I can make time to help him/her find ways to do better. $(+)$

2. This student can count on me to be there for him/her. $(+)$

3. Sometimes I feel like I can't be there for this student when s/he needs me. (-)

4. I can't always be available to this student. (-)

Structure vs. Chaos (Structure)

1. I try to be clear with this student about what I expect of him/her in class. $(+)$

2. I let this student get away with things I normally wouldn't allow. (-)

3. I find it hard to be consistent with this student. (-)

4. I change the rules about school work for this student. (-)

5. Sometimes I feel I don't make my expectations clear to this student. $(-)$

Autonomy Support vs. Coercion

Choice

1. I try to give this student a lot of choices about classroom assignments. $(+)$

2. My general approach with this student is to give him/her as few choices as possible. (-)

3. It's bettern not to give too many choices to this student. (-) 


\section{Control}

1. I have to lead this student through his/her schoolwork step by step. $(-)$

2. When it comes to assignements, I'm always having to tell this student what to do. (-)

3. I find myself telling this student every step to make when it comes to schoolwork. (-)

Respect

1. I let this student make a lot of his/her own decisions regarding schoolwork. $(+)$

2. I can't let this student do things his/her own way. (-)

3. I can't afford to let this student decide too many things about schoolwork for him/herself. (-)

Relevance

1. I explain to this student why we learn certain things in school. $(+)$

2. I encourage this student to think about how schoolwork can be useful to him/her. $(+)$

3. It is difficult to explain to this student why what we do in school is important. (-) 